Prepared in cooperation with Natural Communities Coalition

\title{
Modeling Resource Selection of Bobcats (Lynx rufus) and Vertebrate Species Distributions in Orange County, Southern California
}

With a section on

Modeling for Reptile, Amphibian, and Bird Distributions

Open-File Report 2018-1095 



\section{Modeling Resource Selection of Bobcats (Lynx rufus) and Vertebrate Species Distributions in Orange County, Southern California}

By Erin E. Boydston and Jeff A. Tracey

With a section on

Modeling for Reptile, Amphibian, and Bird Distributions

by Jeff A. Tracey, Kristine L. Preston, Carlton J. Rochester, Erin E. Boydston, and Robert N. Fisher

Prepared in cooperation with Natural Communities Coalition

Open-File Report 2018-1095

U.S. Department of the Interior

U.S. Geological Survey 


\section{U.S. Department of the Interior \\ RYAN K. ZINKE, Secretary}

\section{U.S. Geological Survey \\ James F. Reilly II, Director}

U.S. Geological Survey, Reston, Virginia: 2018

For more information on the USGS-the Federal source for science about the Earth, its natural and living resources, natural hazards, and the environment-visit https://www.usgs.gov/ or call 1-888-ASK-USGS (1-888-275-8747).

For an overview of USGS information products, including maps, imagery, and publications, visit https:/store.usgs.gov.

Any use of trade, firm, or product names is for descriptive purposes only and does not imply endorsement by the U.S. Government.

Although this information product, for the most part, is in the public domain, it also may contain copyrighted materials as noted in the text. Permission to reproduce copyrighted items must be secured from the copyright owner.

Suggested citation:

Boydston, E.E., and Tracey, J.A., 2018, Modeling resource selection of bobcats (Lynx rufus) and vertebrate species distributions in Orange County, southern California, with a section on Modeling for reptile, amphibian, and bird distributions by Tracey, J.A., Preston, K.L., Rochester, C.J., Boydston, E.E., and Fisher, R.N.: U.S. Geological Survey Open-File Report 2018-1095, 65 p., https://doi.org/10.3133/ofr20181095. 


\section{Contents}

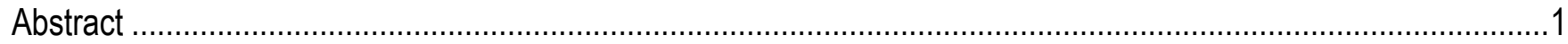

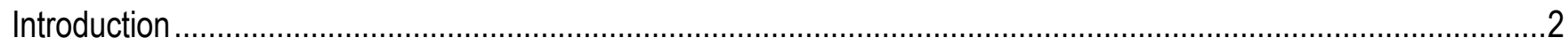

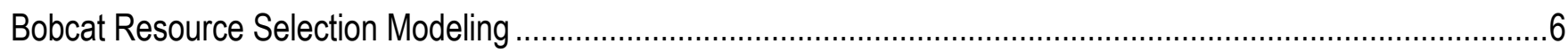

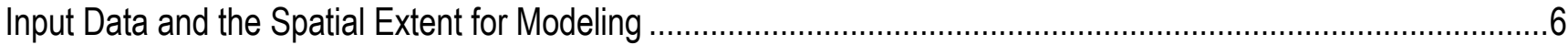

Characterizing the Landscape and Resources_Environmental Layers .........................................................

Topography, Climate, Primary Productivity, Roads, and Streams .............................................................

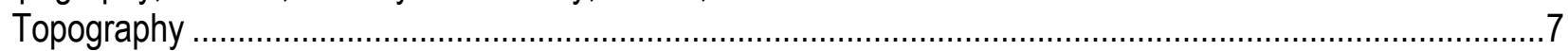

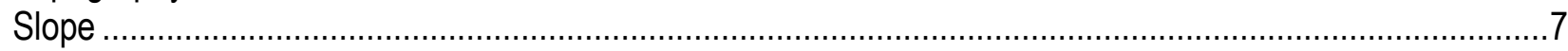

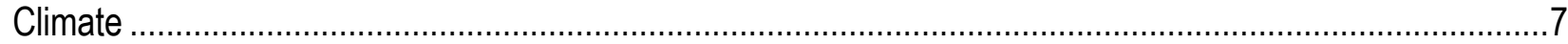

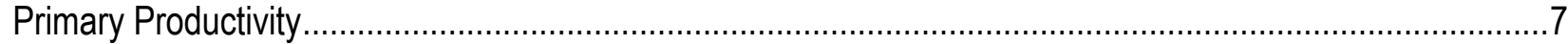

Linear Features_Roads and Streams ..................................................................................... 8

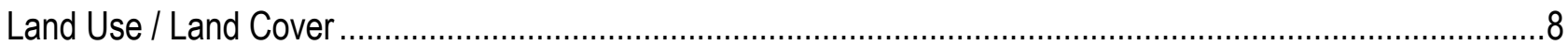

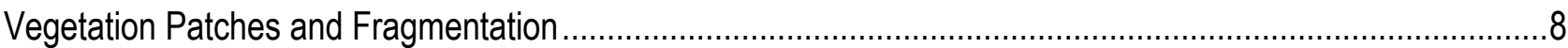

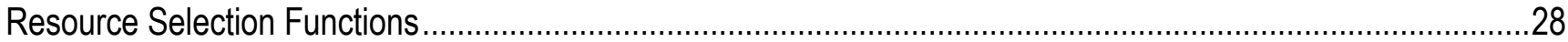

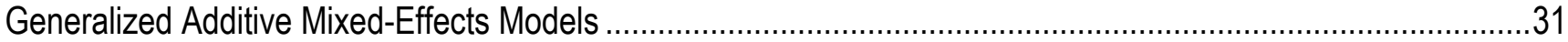

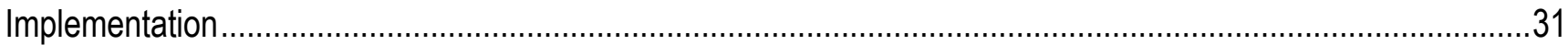

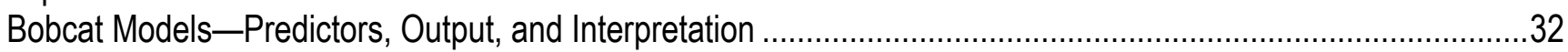

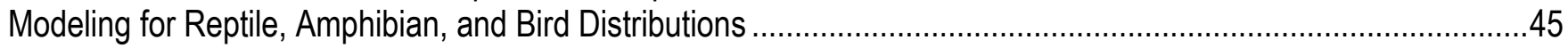

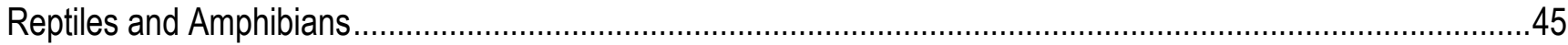

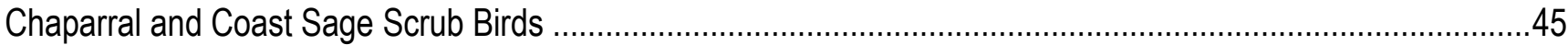

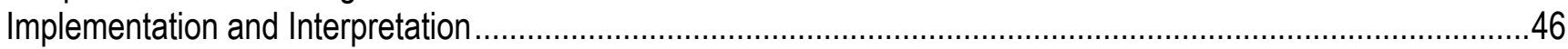

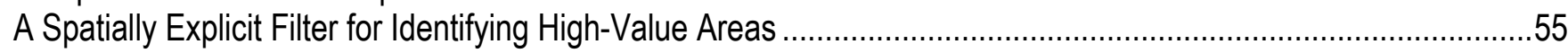

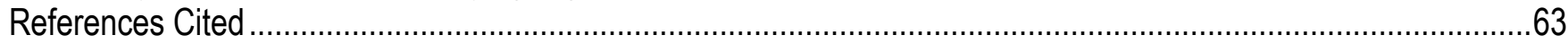

\section{Figures}

Figure 1. Image showing Global Positioning System locations for 30 collared male bobcats in and around Orange County Central and Coastal Natural Communities Conservation Plan reserve lands in Orange County, southern California.

Figure 2. Image showing Global Positioning System locations for 21 collared female bobcats in and around Orange County Central and Coastal Natural Communities Conservation Plan reserve lands in Orange County, southern California.....

Figure 3. Image showing shaded elevations based on Digital Elevation Model for the study area in Orange County, southern California

Figure 4. Image showing Topographic Position Index at 500-meter resolution, derived from Digital Elevation Model for the study area in Orange County, southern California.

Figure 5. Image showing Vector Ruggedness Measure based on a 500-meter analysis window depicting curvature, derived from Digital Elevation Model for the study area in Orange County, southern California .....

Figure 6. Image showing unevenness measure, an index based on the standard deviation of terrain curvature, derived from Digital Elevation Model for the study area in Orange County, southern California

Figure 7. Image showing Mean Annual Precipitation of about 263-619 millimeters for the study area in Orange County, southern California

Figure 8. Image showing Mean Minimum Temperature in January for the study area in Orange County, southern California. 
Figure 9. Image showing Mean Maximum Temperature in August for the study area in Orange County, southern California.

Figure 10. Image showing Normalized Difference Vegetation Index for the study area in Orange County, southern California.

Figure 11. Image showing Normalized Difference Water Index for the study area in Orange County, southern California.

Figure 12. Image showing distance to nearest road for the study area in Orange County, southern California..... 18 Figure 13. Image showing distance to nearest stream, creek, or creek bed, for the study area in Orange County, southern California

Figure 14. Image showing log of the distance to nearest stream for the study area in Orange County, southern California.

Figure 15. Image showing Land Cover Land Use classified from National Agriculture Imagery Program imagery for the study area in Orange County, southern California....

Figure 16. Image showing proportion urban within 125 meters of a pixel center, based on Land Cover Land Use, for the study area in Orange County, southern California.

Figure 17. Image showing Land Use Land Cover categories of barren and grass in Orange County, southern California

Figure 18. Image showing Land Use Land Cover categories of shrub and forest, called "VegCover" in the models, depicted for the study area in Orange County, southern California

Figure 19. Image showing Log Patch Area derived using FRAGSTATS applied to Land Use Land Cover, for the study area in Orange County, southern California. 26

Figure 20. Image showing Log Distance to Patch indicates distance to the nearest patch for all areas outside a large patch, for the study area in Orange County, southern California. 27

Figure 21. Schematic diagram showing levels of habitat selection

Figure 22. Image showing individual bobcat home range utilization distributions, estimated from Global Positioning System collar data for 51 bobcats tracked in Orange County, southern California, 2002-09. 30

Figure 23. Image showing mean of the best Resource Selection Function models for female bobcats based on home range compared to study area, in Orange County, southern California.....

Figure 24. Image showing standard deviation of the mean for the best female bobcat Resource Selection Function (RSF) models based on home range compared to study area, in Orange County, southern California.... 37 Figure 25. Image showing mean probability of use of the best Resource Selection Function models for female bobcats based on Global Positioning System locations compared to study area, in Orange County, southern California

Figure 26. Image showing standard deviation of the mean probability of use of the best Resource Selection Function models for female bobcats based on Global Positioning System locations compared to study area, in Orange County, southern California 39

Figure 27. Image showing mean probability of use of the best Resource Selection Function models for male bobcats based on home range compared to study area, in Orange County, southern California.

Figure 28. Image showing standard deviation of the mean probability of use for the best male bobcat Resource Selection Function models based on home range compared to study area, in Orange County, southern California.

Figure 29. Image showing mean probability of use of the best Resource Selection Function models for male bobcats based on Global Positioning System locations compared to study area, in Orange County, southern California

Figure 30. Image showing standard deviation (sd) of the mean probability of use of the best Resource Selection Function models for male bobcats based on Global Positioning System locations compared to study area, in Orange County, southern California 
Figure 31. Scatterplot of area under the curve values compared to the number of predictors for each of three model comparisons by sex....

Figure 32. Image showing average predicted species richness for five amphibian species, indicating that a maximum of 3-4 of these species were likely to co-occur in a few concentrated areas, Orange County, southern California.

Figure 33. Image showing average predicted species richness for 14 snake species, in Orange County, southern California.

Figure 34. Image showing average predicted species richness for 10 lizard species, in Orange County, southern California.

Figure 35. Image showing average predicted species richness for six bird species in chaparral and California coast sage scrub habitats, indicating that there were areas where all six species were likely to co-occur, Orange County, southern California

Figure 36. Image showing Combined Species Distribution Model for three target species in the Orange County Central and Coastal Natural Communities Conservation Plan/Habitat Conservation Plan, Orange County, southern California

Figure 37. Image showing Species Distribution Model for one identified species in the Orange County Central and Coastal Natural Communities Conservation Plan/Habitat Conservation Plan, Orange County, southern California.

Figure 38. Image showing Combined Species Distribution Model for four species of interest in the Orange County Central and Coastal Natural Communities Conservation Plan/Habitat Conservation Plan, Orange County, southern California

Figure 39. Diagram showing example of High-Value Area step-wise decision rule, with geographic information system layers for selected environmental variables passing through a virtual filter to yield an output layer indicating which areas met the step-wise criteria used for filtering

Figure 40. Image showing example output results of applying a step-wise decision rule (Decision Rule 01) to filter five input layers to depict a possible scenario for determining High-Value Areas in Orange County, southern California 57

Figure 41. Image showing Decision Rule 02 as a step-wise filter using abiotic factors.

Figure 42. Image showing Decision Rule 03 as one way of depicting threshold values for environmental characteristics relevant to bobcats, in Orange County, southern California

Figure 43. Image showing Decision Rule 05 as a step-wise filter using species distribution models as an example method for prioritizing levels of biodiversity, in Orange County, southern California

Figure 44. R code example for the function to assign High-Value Area levels, with raster inputs from the filter example

Figure 45. R code example for the function to get a vector of High-Value Area levels for each step in the filter process, with raster inputs from the detailed example

\section{Tables}

Table 1. Descriptive statistics from FRAGSTATS output of about 771 vegetated patches identified for the study area in Orange County, southern California. 25

Table 2. Terms used in the linear component of the alternative models in the second stage of model fitting......... 33 Table 3. Mean area under the curve, standard deviation, minimum, and maximum, grouped by comparison category.

Table 4. Species for which species distribution models were available; general taxonomic group; priority designation of target species, identified species, or species of interest in Orange County Central and Coastal Natural Communities Conservation Plan/Habitat Conservation Plan (NCCP/HCP); and common name for NCCP/HPC species, Orange County, southern California. 


\section{Conversion Factors}

U.S. customary units to International System of Units

\begin{tabular}{lcll}
\hline & Multiply & By & \multicolumn{1}{c}{ To obtain } \\
\hline & & Length & \\
\hline inch (in.) & 2.54 & centimeter (cm) \\
inch (in.) & 25.4 & millimeter (mm) \\
\hline
\end{tabular}

International System of Units to U.S. customary units

\begin{tabular}{lcll}
\hline & Multiply & \multicolumn{1}{c}{ By } & To obtain \\
\hline millimeter $(\mathrm{mm})$ & Length & & \\
meter $(\mathrm{m})$ & 0.03937 & inch (in.) \\
kilometer $(\mathrm{km})$ & 3.281 & foot $(\mathrm{ft})$ \\
\hline & 0.6214 & mile $(\mathrm{mi})$ \\
\hline square kilometer $\left(\mathrm{km}^{2}\right)$ & Area & \\
square kilometer $\left(\mathrm{km}^{2}\right)$ & 247.1 & acre \\
\hline
\end{tabular}

Temperature in degrees Celsius $\left({ }^{\circ} \mathrm{C}\right)$ may be converted to degrees Fahrenheit $\left({ }^{\circ} \mathrm{F}\right)$ as ${ }^{\circ} \mathrm{F}=\left(1.8 \times{ }^{\circ} \mathrm{C}\right)+32$.

\section{Datums}

Vertical coordinate information is referenced to the North American Vertical Datum of 1988 (NAVD 88).

Horizontal coordinate information is referenced to the North American Datum of 1983 (NAD 83).

Elevation, as used in this report, refers to distance above the vertical datum.

\section{Abbreviations}

$\begin{array}{ll}\text { AUC } & \text { area under the curve } \\ \text { CSS } & \text { California coast sage scrub } \\ \text { DEM } & \text { Digital Elevation Model } \\ \text { GAM } & \text { Generalized Additive Model } \\ \text { GAMM } & \text { Generalized Additive Mixed-effects Model } \\ \text { GIS } & \text { geographic information system } \\ \text { GPS } & \text { Global Positioning System } \\ \text { HSI } & \text { habitat similarity index } \\ \text { HVA } & \text { High-Value Area } \\ \text { LULC } & \text { land use land cover } \\ \text { NAIP } & \text { National Agriculture Imagery Program } \\ \text { NDVI } & \text { Normalized Difference Vegetation Index } \\ \text { NDWI } & \text { Normalized Difference Water Index } \\ \text { NCCP } & \text { Orange County Central and Coastal Natural Communities Conservation Plan } \\ \text { NCCP/HCP } & \text { Orange County Central and Coastal Natural Communities Conservation Plan/Habitat Conservation Plan } \\ \text { ROC } & \text { receiver operating characteristic } \\ \text { RF } & \text { Random Forest } \\ \text { RSF } & \text { Resource Selection Function } \\ \text { RU } & \text { Resource Unit } \\ \text { SDM } & \text { species distribution model } \\ \text { TPI } & \text { Topographic Position Index } \\ \text { VRM } & \text { Vector Ruggedness Measure }\end{array}$




\title{
Modeling Resource Selection of Bobcats (Lynx rufus) and Vertebrate Species Distributions in Orange County, Southern California
}

\author{
By Erin E. Boydston and Jeff A. Tracey
}

\begin{abstract}
For nature reserves in urban settings, wildlife and wildlife habitats may be affected by recreational activities and intensive, adjacent development. Sustaining biodiversity in such reserves is a challenge for land and natural resource managers, but identification of core areas and key resources for wildlife species may help in planning for current and emerging threats. To help identify core areas and resources, we conducted spatial analyses and predictive modeling of vertebrate distributions for a network of nature reserves in densely populated Orange County, California. We primarily focused on bobcats (Lynx rufus), a species with a strong association with natural habitat. Bobcat space use has been correlated with broad, simple land-use categories, but relatively little is known about the influence of greater landscape complexity on habitat suitability for bobcats. To examine habitat selection by bobcats, we developed spatial data layers representing environmental factors that might influence this species, and we used previously collected Global Positioning System tracking data for 30 male and 21 female bobcats to indicate bobcat response to complex landscape factors. We examined these inputs using Resource Selection Function (RSF) modeling and developed spatially explicit models of the probability of bobcat use (selection or avoidance) of landscape characteristics. RSF models highlighted the general importance of reserve habitat for bobcats, but suggested that female bobcats were more dependent that male bobcats on habitat within designated reserves. Male bobcats, which range more widely than female bobcats, were associated with undeveloped areas both within and outside reserves. Small areas were present outside reserves that seemed to provide additional suitable habitat or movement areas for bobcats, potentially through restoration, connectivity, or reduced edge effects.

Although bobcat RSFs suggested areas of high value to this species and potentially other species, taxa can differ greatly in their resource-selection and spatial requirements. Thus, for several species of reptiles, amphibians, and birds, we adapted species distribution models based on occurrence data to examine the response of other vertebrates to the landscape. To identify potential High-Value Areas (HVAs) for single or multiple species, we then developed a step-wise filtering process that can be applied to a series of spatial data layers. We provide examples of alternative decision models for HVAs that capture different elements of biodiversity and a range of management considerations. As landscape and management challenges change, these spatial layers and decision rules can be adjusted based on new information. Our approach thus establishes a general framework for identifying highvalue habitat that can be used for current management decisions and refined in the future, depending on management interests and goals and the availability of suitable quality data or adequate surrogate information.
\end{abstract}




\section{Introduction}

Sustaining biodiversity within nature reserves in Orange County, California, the most densely human-populated county in southern California (Cohen, 2015), is a challenge for land and resource managers. The goals of management plans for the region aim to balance public access to reserves with protection of wildlife and habitats that may be sensitive to recreational use, but planning is impeded by a lack of information. Furthermore, these reserves are in a region of intensive development and may be subject to edge and fragmentation effects. With millions of people living in the region, and increasing numbers of them seeking outdoor recreation opportunities, land managers and wildlife agencies are seeking answers to questions about effects on the ecological integrity of protected lands in Orange County from human activity. Methods to identify areas and resources of core importance to wildlife species are an important component of the planning. In this report, we sought to meet information needs about resource requirements of wildlife with spatial analyses and predictive modeling of vertebrate distributions in Orange County. In particular, we focused on protected areas covered by the Orange County Central and Coastal Natural Communities Conservation Plan/Habitat Conservation Plan (NCCP/HCP), where increased recreation and surrounding development are posing challenges to natural resource managers charged with meeting the goals of this plan.

To predict wildlife resource requirements for the area, we focused on a medium-sized obligate carnivore, the bobcat (Lynx rufus), as an umbrella species, and modeled resource selection functions for this species. Because the basic ecology of carnivores requires that they have large home ranges relative to their body size and live at low densities, these species can serve as valuable indicators of landscape connectivity, isolation, and reserve system success (Woodroffe and Ginsberg, 1998; Crooks, 2002; Hunter and others, 2003). Furthermore, conservation planning based on carnivore requirements may help protect species with less demanding needs (Lambeck 1997; Miller and others, 1998; Carroll and others, 1999).

Bobcats are an appropriate focal species for evaluating of connectivity of natural areas in southern California, given their strong association with natural habitat and sensitivity to habitat fragmentation, and because they can persist in more urban-associated areas with smaller habitat patches than mountain lions (Puma concolor; Crooks 2000, 2002; Tigas and others, 2002; Hunter and others, 2003; Riley and others, 2003; Ordeñana and others, 2010). Thus, bobcats can represent conservation opportunities across finer spatial scales and greater urbanization than mountain lions. Furthermore, they can do this at a scale relevant to local land and natural resource management. In the reserves covered by the NCCP/HCP, bobcats also appear to be present across the Orange County Central and Coastal Subregions (figs. 1 and 2), whereas mountain lions appear to be absent from the Coastal Subregion. 


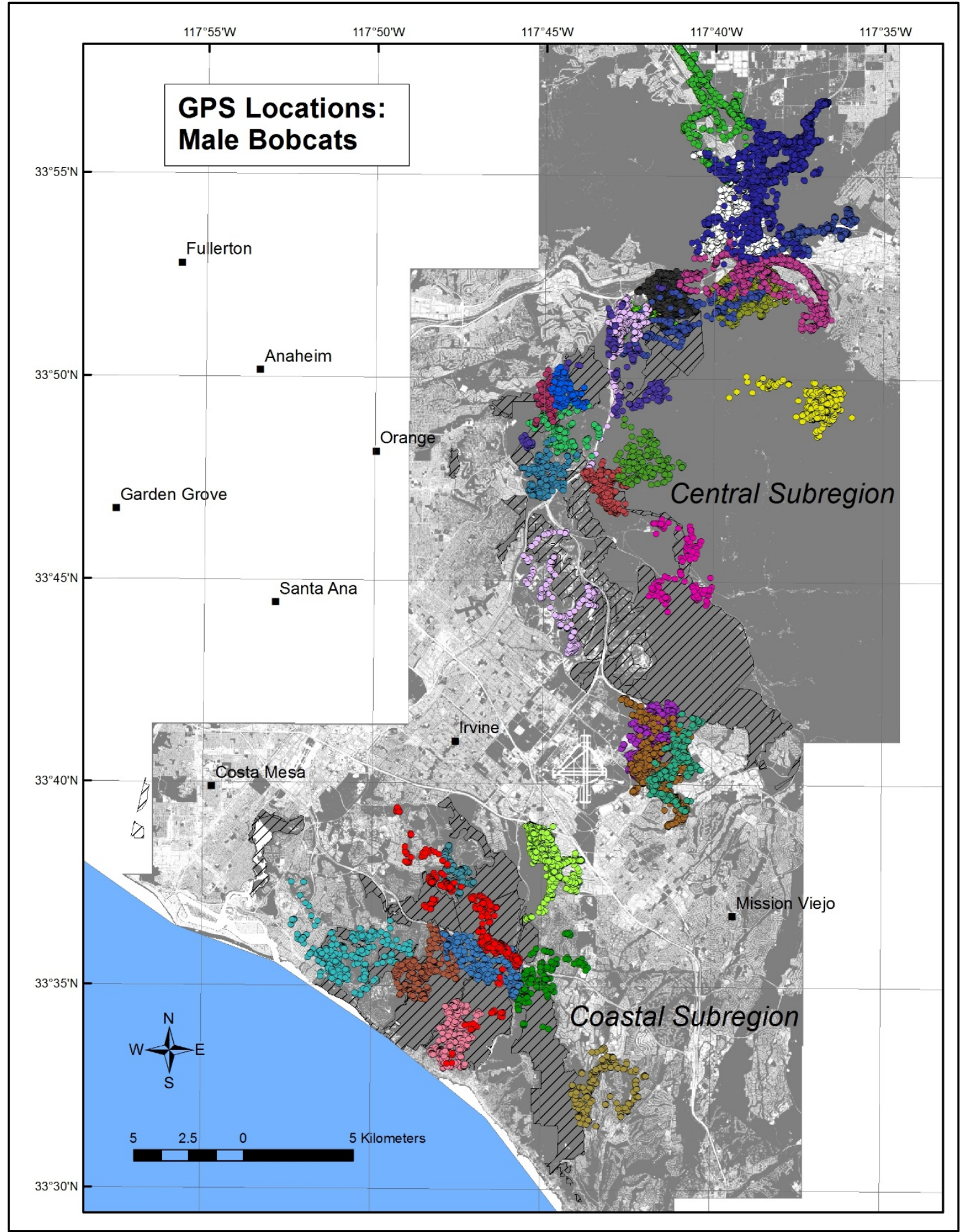

Figure 1. Image showing Global Positioning System (GPS) locations for 30 collared male bobcats in and around Orange County Central and Coastal Natural Communities Conservation Plan reserve lands (hatched areas) in Orange County, southern California. Different colors represent GPS data for different individuals. The grayscale layer represents urban land use (in white) for the study area and model prediction region. Larger cities are labeled (black squares). 


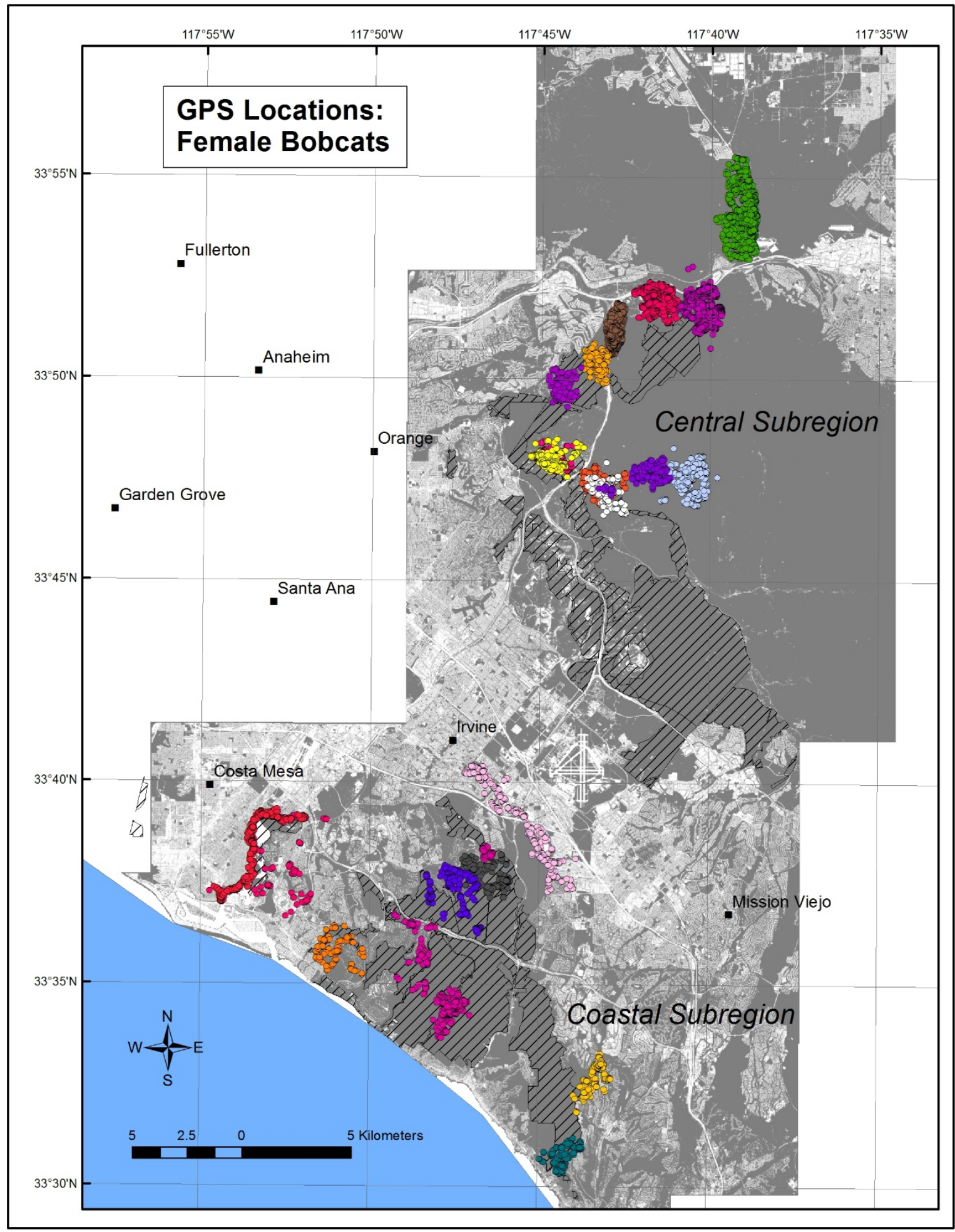

Figure 2. Image showing Global Positioning System (GPS) locations for 21 collared female bobcats in and around Orange County Central and Coastal Natural Communities Conservation Plan reserve lands (hatched areas) in Orange County, southern California. Different colors represent GPS data for different individuals. The grayscale layer represents urban land use (in white) for the study area and model prediction region. Larger cities are labeled (black squares). 
Although bobcats are good indicators of intact natural landscapes and high-quality habitat, they sometimes are reported in residential areas and even back yards, suggesting some adaptation to urban development. However, wildlife sightings are a biased sample of animal space use and activity patterns, representing the intersection of people and animals, and are influenced by the willingness of observers to report their sightings (Poessel and others, 2013). Bobcats generally avoid developed areas and roads (Riley and others, 2003; Poessel and others, 2014), their occurrence decreases with increasing proximity to urbanization (Ordeñana and others, 2010; Tracey and others, 2013), and they may move faster through developed areas than natural habitat (Nogeire and others, 2015). Bobcats living in developed areas appear to have the same food habits and other behaviors as conspecifics in more remote locations; they prey on wild animals, not pets or human-subsidized foods (Riley and others, 2010). To date, there has been little focus on habitat selection by bobcats or how bobcats may be affected by an increased numbers of people in and around natural areas. Bobcat movements have been correlated with coarsely defined land-use categories such as developed compared to undeveloped (for example, Riley and others, 2010), but understanding habitat suitability requires assessments incorporating greater landscape complexity.

We considered a broad range of biotic and abiotic factors, and developed layers of spatial data representing them, to examine habitat selection by bobcats. Environmental data layers and previously collected movement data from Global Positioning System (GPS)-collared bobcats were used as inputs in developing Resource Selection Function (RSF) models (Manly and others, 2002). These models were then used to estimate the probability of bobcat use, or selection, of biological and physical resources on the landscape in a spatially explicit framework. Habitat suitability for bobcats is an important component for identifying core areas of use, which served as a proxy for resources needed for bobcat survival and reproduction, such as functioning food webs, shelter, and interspecific interactions and avoidance of conspecifics.

Detailed movement data on individual animals were not available for taxa other than carnivores in this region, but we adapted species distribution models based on occurrence data for reptiles, amphibians, and birds, which included species from NCCP/HCP lists of priority vertebrates for conservation. Although the predictive ability of the models depends on the data inputs, estimates for other vertebrates can suggest where common and varying needs for species occur. Bobcat RSFs can indicate areas of high value to this species and potentially many other species; some taxa differ greatly in their resource selection, leading to different spatial requirements. The intersection of different taxa and the landscape characteristics that support them may indicate key areas or resources different from those represented by models of bobcat selection. To further examine the spatial intersection of biodiversity and landscape characteristics relative to designated protected areas, we developed a stepwise filter that can be applied to the many spatial layers we generated for the abiotic and biotic characteristics in a region encompassing the NCCP/HCP Coastal Reserve. 


\section{Bobcat Resource Selection Modeling}

\section{Input Data and the Spatial Extent for Modeling}

Bobcat movement data were collected using GPS collars fitted to free-ranging bobcats in southern California during 2002-09. A total of 30 male and 21 female bobcats were tracked (figs. 1 and 2-for details see Tracey and others, 2013; Poessel and others, 2014; Nogeire and others, 2015, Fountain-Jones and others, 2017). Tracking locations in Orange County included the North Irvine Ranch Open Space, December 2002-May $2004(n=16)$; the San Joaquin Hills from Newport Back Bay to Aliso and Woods Canyon Wilderness Park, May 2006-June 2007 ( $n=17)$; and north of the Orange County Great Park (the former Marine Corps Air Station El Toro), February-December 2007 $(n=4)$. Additional tracking locations outside Orange County included Chino Hills (San Bernardino County), Prado Basin (Riverside County), and the Santa Ana Mountains at State Routes 71 and 91 (Riverside County), December 2008-July 2009 ( $n=14)$. Most collars collected GPS data for 3-4 months with intermittent 15-min sampling periods, but four collars were set to collect data only for 1 week with continuous 15-min sampling to identify fine-scale temporal patterns of movement. Two of these four bobcats were then recaptured and received a 3-4 month collar, and data from the collars were combined for each individual.

To delineate the extent of the study area for modeling, we buffered the minimum bounding box of the NCCP/HCP by $2 \mathrm{~km}$ and extended this box to encompass bobcat GPS locations. We then intersected this bounding box with the perimeter of a composite 1-m resolution National Agriculture Imagery Program (NAIP) image. The inclusion of areas outside NCCP/HCP boundaries allowed us to examine bobcat resource selection across a greater range of environmental conditions than represented within the NCCP/HCP at the time of data collection. Furthermore, because functional connectivity is important for sustaining species with large area requirements, it was important to estimate resource selection across a continuous landscape surface.

\section{Characterizing the Landscape and Resources-Environmental Layers}

We focused on classic levels of habitat selection (Johnson, 1980) and applied recently developed statistical techniques for RSFs that could account for individual variability among bobcats and their generalized responses to multiple landscape characteristics. We identified environmental variables and landscape characteristics likely to be important resources to bobcats, and quantified the resources, their use by bobcats, and their availability to bobcats. Spatial data layers were converted to a standard raster format, with the landscape pixelated into a grid of the same extent and cell size for all variables. Each grid cell, or pixel, was considered a single Resource Unit (RU). We represented RUs as 28.11-m square cells, based on the resolution of a standard Digital Elevation Model (DEM). Where bobcat tracking data aligned with pixels for a particular landscape variable, the resource was considered "used" and the rest of the RUs, within a defined area, were considered available to the animal but not used.

We identified environmental variables and landscape characteristics likely to be important resources to bobcats, and then quantified the resources, their use by bobcats, and their availability to bobcats. Spatial data layers of these variables were converted from vector or raster to a standard raster format and resolution. The landscape was pixelated into a grid of small cells with the same grid extent and cell size used for all variables. 


\section{Topography, Climate, Primary Productivity, Roads, and Streams}

Potential environmental determinants of bobcat habitat suitability, selection, and movement were identified based on scientific literature, expert opinion, and previous U.S. Geological Survey research. We considered a broad range of environmental variables, anthropogenic features, biodiversity indicators, and other biotic factors, and identified suitable data for the study area. After finding data sources, we did additional modifications and derivations as needed to yield spatial data layers in raster format.

We created images for the potential environmental inputs, developing a standard image template to present each element as its own figure and product to help visualize spatial variation across the reserve in various factors that may influence ecological functioning of Orange County Central and Coastal Natural Communities Conservation Plan (NCCP) lands. Digital versions of these map layers can be assembled in different combinations or explored in detail. The main categories of environmental variables considered were topography, climate, primary productivity, certain linear features, land use land cover (LULC), and fragmentation metrics. Specific candidate variables are described in the subsections that follow.

Topography

Elevation (fig. 3)-DEM raster.

Slope

Topographic Position Index (TPI; fig. 4) - Derived from DEM raster using R code to evaluate whether the elevation of each pixel was higher or lower than the area within $500 \mathrm{~m}$ of it; thus, TPI shows the relative elevation of a point within a selected smoothing window, which we set to $500 \mathrm{~m}$.

Vector Ruggedness Measure (VRM; fig. 5) - Derived from DEM raster using R code and based on methods in Sappington and others (2007), who found that VRM was a means of assessing localized terrain variation that was less dependent on slope than on other existing measures and was a better predictor of bighorn sheep (Ovis canadensis nelsoni) occurrence.

Unevenness (also known as "fs8r_gencu" in Ironside, 2015; fig. 6) — This is the standard deviation of the total curvature and indicates the degree of localized undulation of the landscape. It was derived in ArcGIS ${ }^{\mathrm{TM}}$ from the DEM raster, following methods in Ironside (2015) and using an 8cell circular radius (that is, within a 224-m radius). Ironside (2015) reported that unevenness was a better predictor of mountain lion landscape use in the Southwestern United States than VRM (Sappington and others, 2007) or other terrain metrics; mountain lions appeared to prefer areas with uneven, irregular topography.

Climate

All climate data were from PRISM Climate Group (2016).

Mean Annual Precipitation (fig. 7).

Mean Minimum Temperature in January (fig.8).

Mean Maximum Temperature in August (fig. 9).

Primary Productivity

Normalized Difference Vegetation Index (NDVI; fig. 10)

Normalized Difference Water Index (NDWI; fig. 11) 
Linear Features-Roads and Streams

Roads (fig. 12)—From Enhanced National Highway System shape file, available at http://www.dot.ca.gov/hq/tsip/gis/datalibrary/.

Streams (figs. 13 and 14)—Streams for the region were a subset of the National Hydrography Data; only free-running, natural creeks were included here.

Recreation Trails - We did not create a raster version of recreation trails as a potential model input because we did not have trails data throughout the bobcat data region. However, geographic information system (GIS) layers for recreation trails can be overlaid with raster coverages and model results here.

\section{Land Use / Land Cover}

Existing land-cover datasets for the Orange County area were too coarse in resolution or did not distinguish landscape features in enough detail to perform meaningful habitat modeling. Our goal was to use 1-m NAIP imagery to generate land-cover categories that would capture vegetation structure and potential cover in enough detail to be meaningful in assessing bobcat responses to these landscape characteristics.

A draft land-cover classification (fig. 15) was created by performing a supervised classification on a segmented, false-color version of 2009 NAIP imagery in ArcGIS ${ }^{\mathrm{TM}}$ Desktop 10.2.2 and 10.3.1. Training polygons were digitized using the Image Classification toolbar and Training Sample Manager to create a representative set of land-cover category samples. Google Earth ${ }^{\mathrm{TM}}, 2005$ southern California Association of Governments land-use data, and Nogiere and others (2015) habitat rasters were used as a guide when identifying some land-cover types. A Support Vector Machine classifier file of spectral signatures was generated from the training polygons from which the cells of the entire study area could then be classified using the Classify Raster tool. Additional improvements were made to the output results using NDVI data to identify and correct class confusion between impervious features and reflective water, as well as manual clean-up throughout to change large shadow and barren ground errors. We refined the classes as follows: Draft classification results were formatted for habitat modeling tests by converting each category into individual binary rasters and resampling to $28 \times 28-\mathrm{m}$ proportion cover within each pixel.

Urban (fig. 16).

Grass (fig. 15) - Mostly landscaped areas such as lawns, golf courses, playing field, and some agriculture; a relatively small proportion of the total area.

Barren (fig. 17) — Grasslands and bare ground.

Shrub and forest (fig. 18) - A combination of California coast sage scrub (CSS), chaparral, and forest.

Using the rasters for proportion of cover for each category, we created an overall LULC raster by assigning the land-cover type represented by the higher proportion to each RU. We also created a version of the LULC raster where any RUs intersected by major roads were set to the urban land-cover class. For each raster corresponding to a proportion of cover for a land-cover category, we also calculated the distance to cells (RUs) with greater than $(>) 0.50$ proportion cover for that type and proportions of cover within 125-, 250-, 275-, and 500-m radii. 


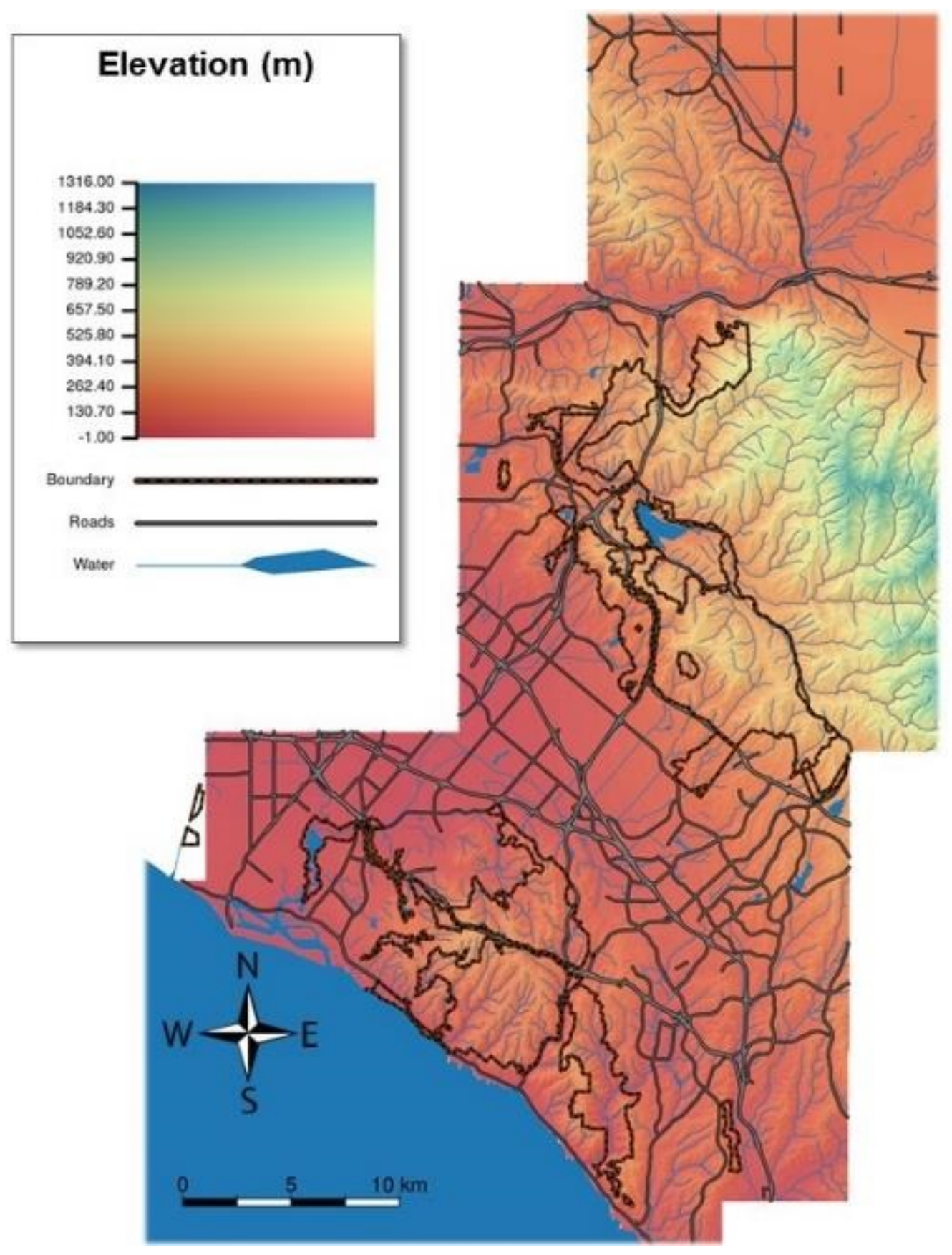

Figure 3. Image showing shaded elevations (in meters [m]) based on Digital Elevation Model for the study area in Orange County, southern California. Orange County Central and Coastal Natural Communities Conservation Plan/Habitat Conservation Plan boundaries and major roads are shown at 28-m resolution. 


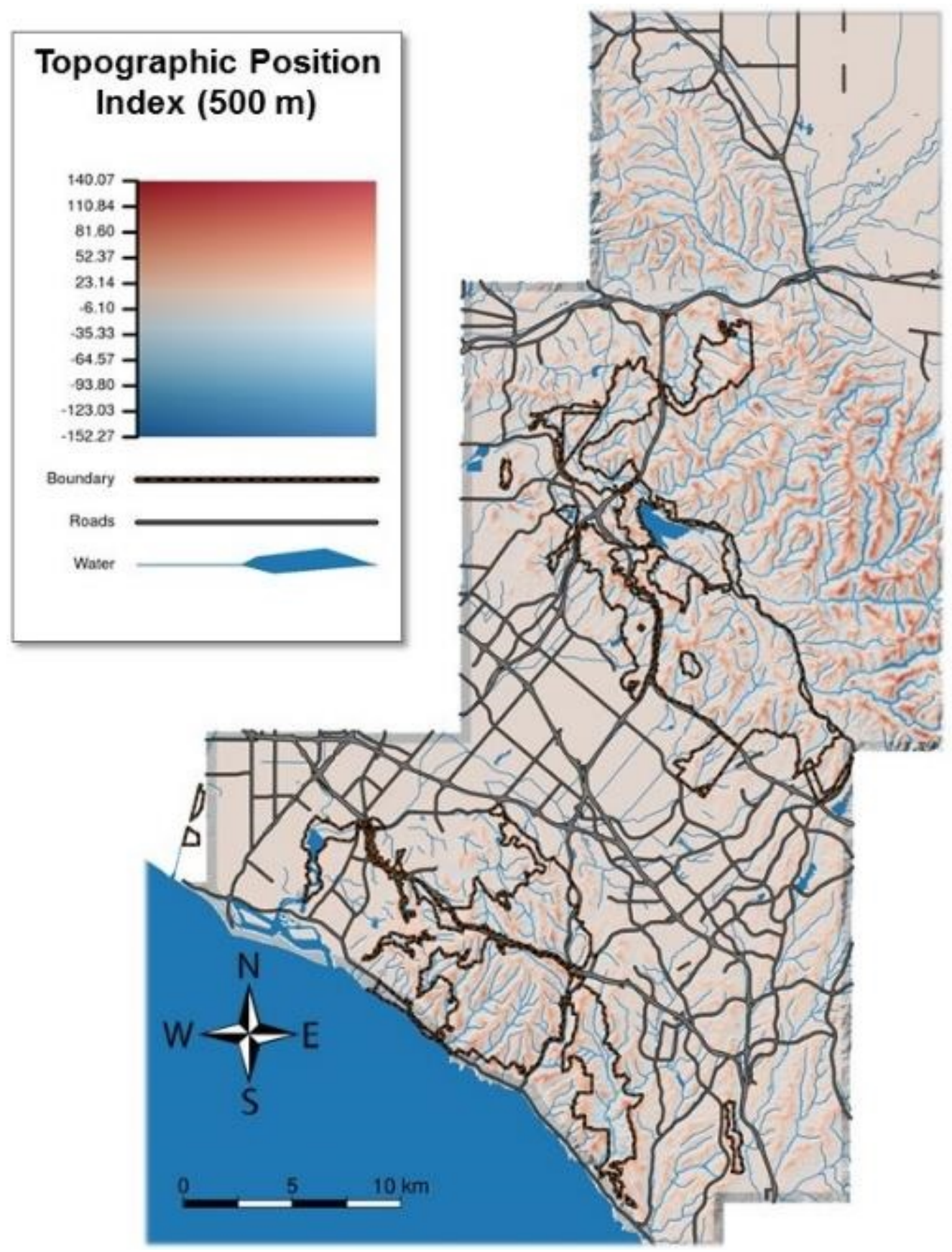

Figure 4. Image showing Topographic Position Index at 500-meter $(\mathrm{m})$ resolution, derived from Digital Elevation Model for the study area in Orange County, southern California. Orange County Central and Coastal Natural Communities Conservation Plan/Habitat Conservation Plan boundaries and major roads are shown at 28-m resolution. 


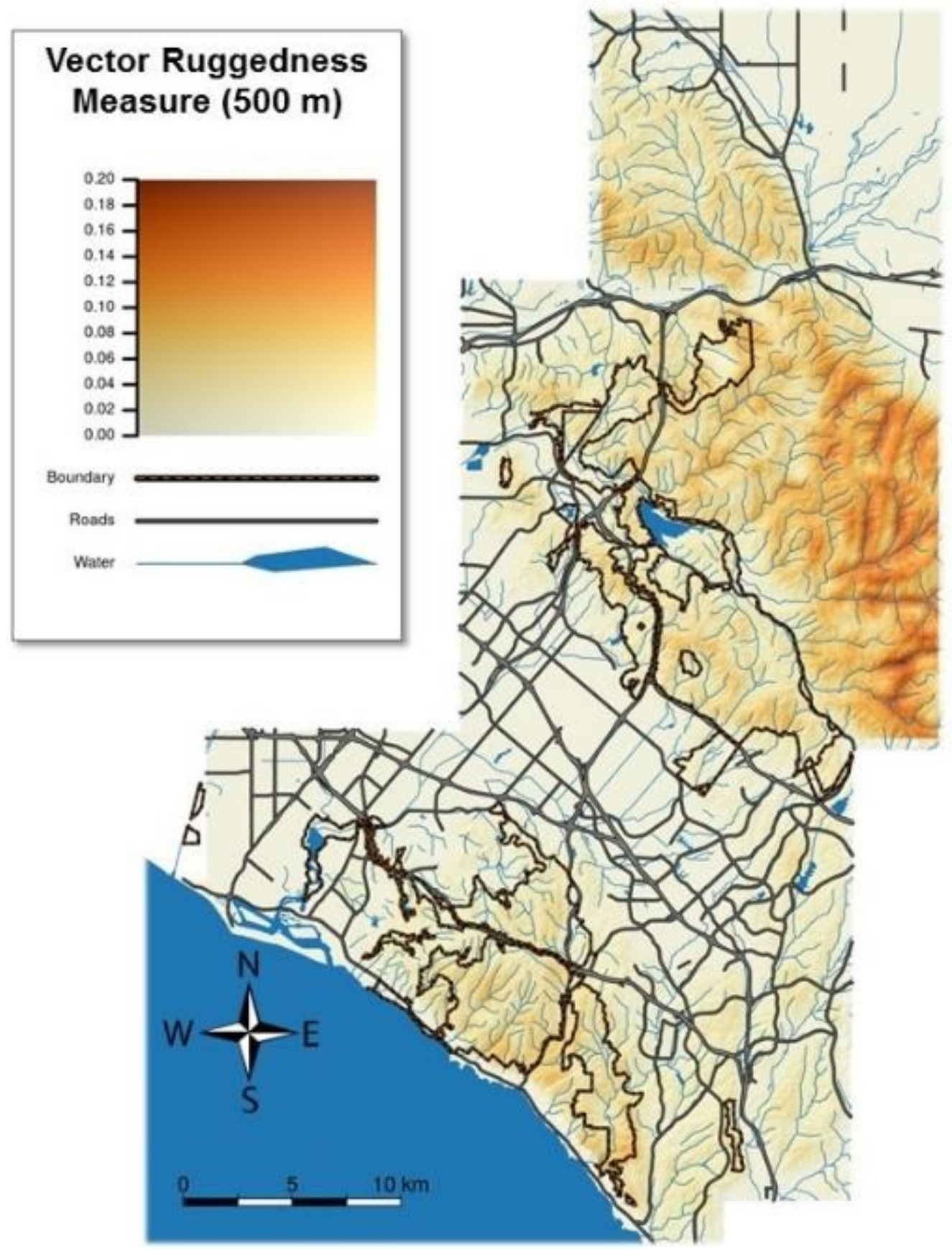

Figure 5. Image showing Vector Ruggedness Measure (Sappington and others, 2007) based on a 500-meter $(\mathrm{m})$ analysis window depicting curvature, derived from Digital Elevation Model for the study area in Orange County, southern California. Orange County Central and Coastal Natural Communities Conservation Plan/Habitat Conservation Plan boundaries and major roads are shown at 28-m resolution. 


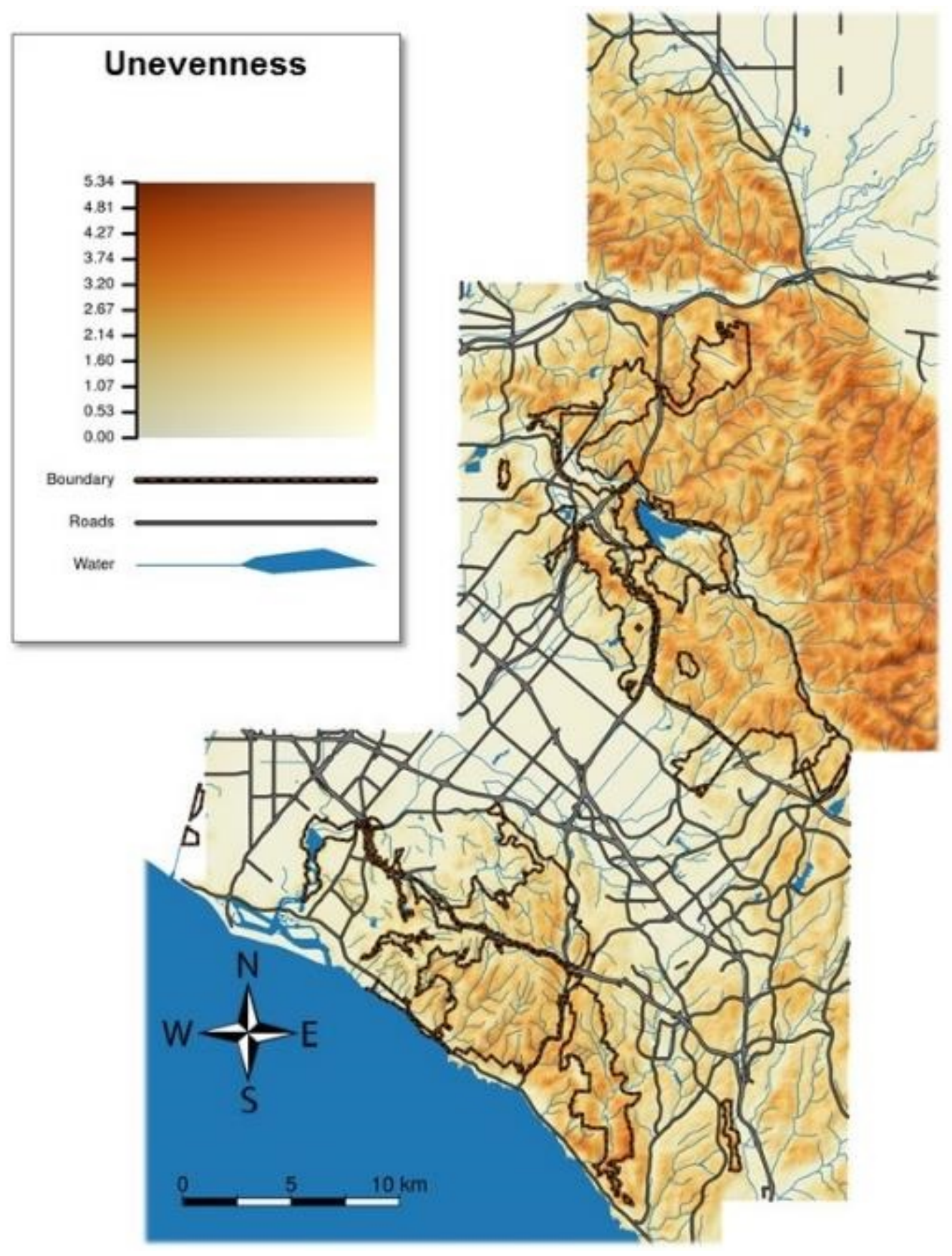

Figure 6. Image showing unevenness measure (Ironside, 2015), an index based on the standard deviation of terrain curvature, derived from Digital Elevation Model for the study area in Orange County, southern California. Orange County Central and Coastal Natural Communities Conservation Plan/Habitat Conservation Plan boundaries and major roads shown at 28-meter resolution. 

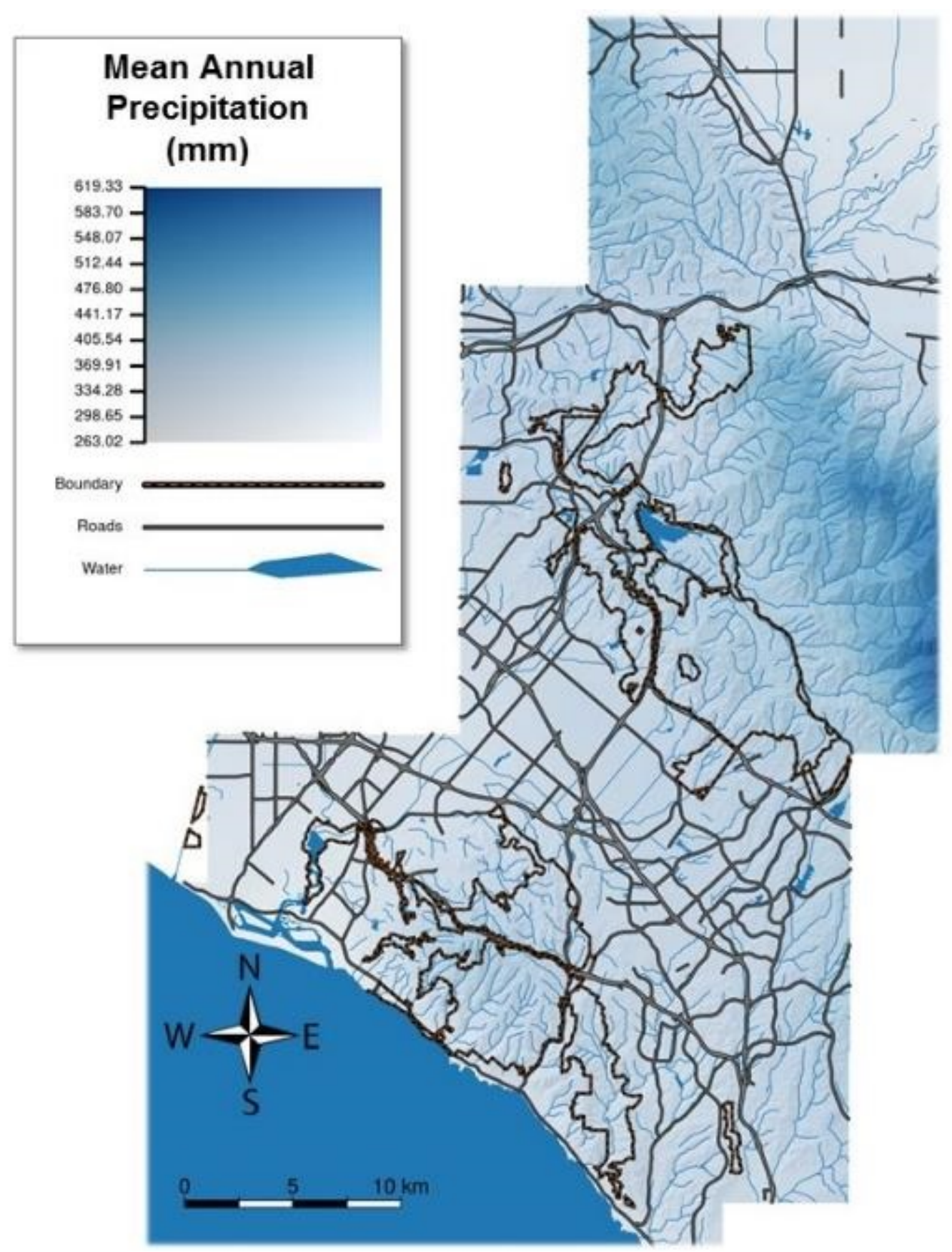

Figure 7. Image showing Mean Annual Precipitation of about 263- 619 millimeters (mm) (about 10-24 inches) for the study area in Orange County, southern California. Orange County Central and Coastal Natural Communities Conservation Plan/Habitat Conservation Plan boundaries and major roads shown at 28-meter resolution. 


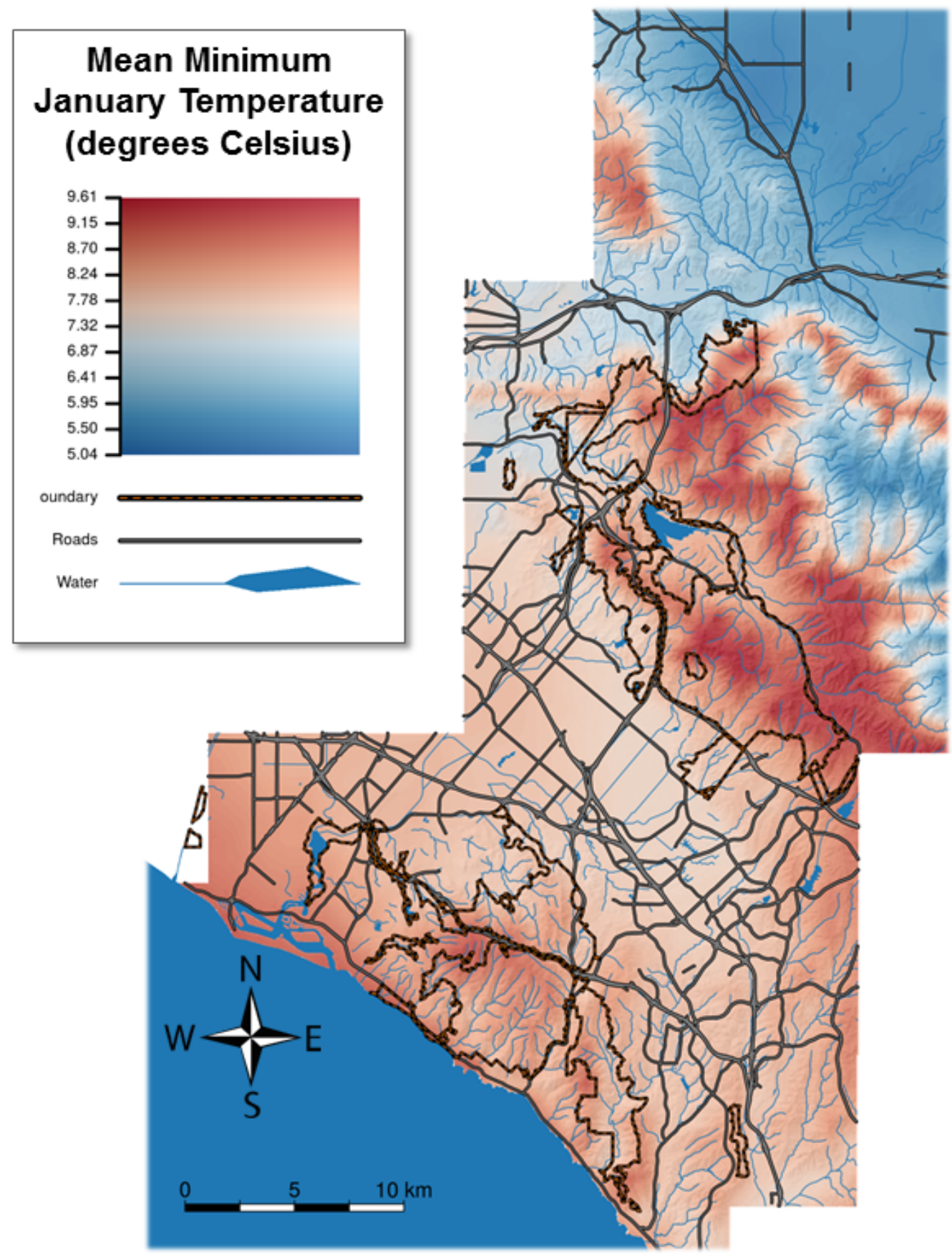

Figure 8. Image showing Mean Minimum Temperature in January for the study area in Orange County, southern California. Orange County Central and Coastal Natural Communities Conservation Plan/Habitat Conservation Plan boundaries and major roads are shown at 28-meter resolution. 


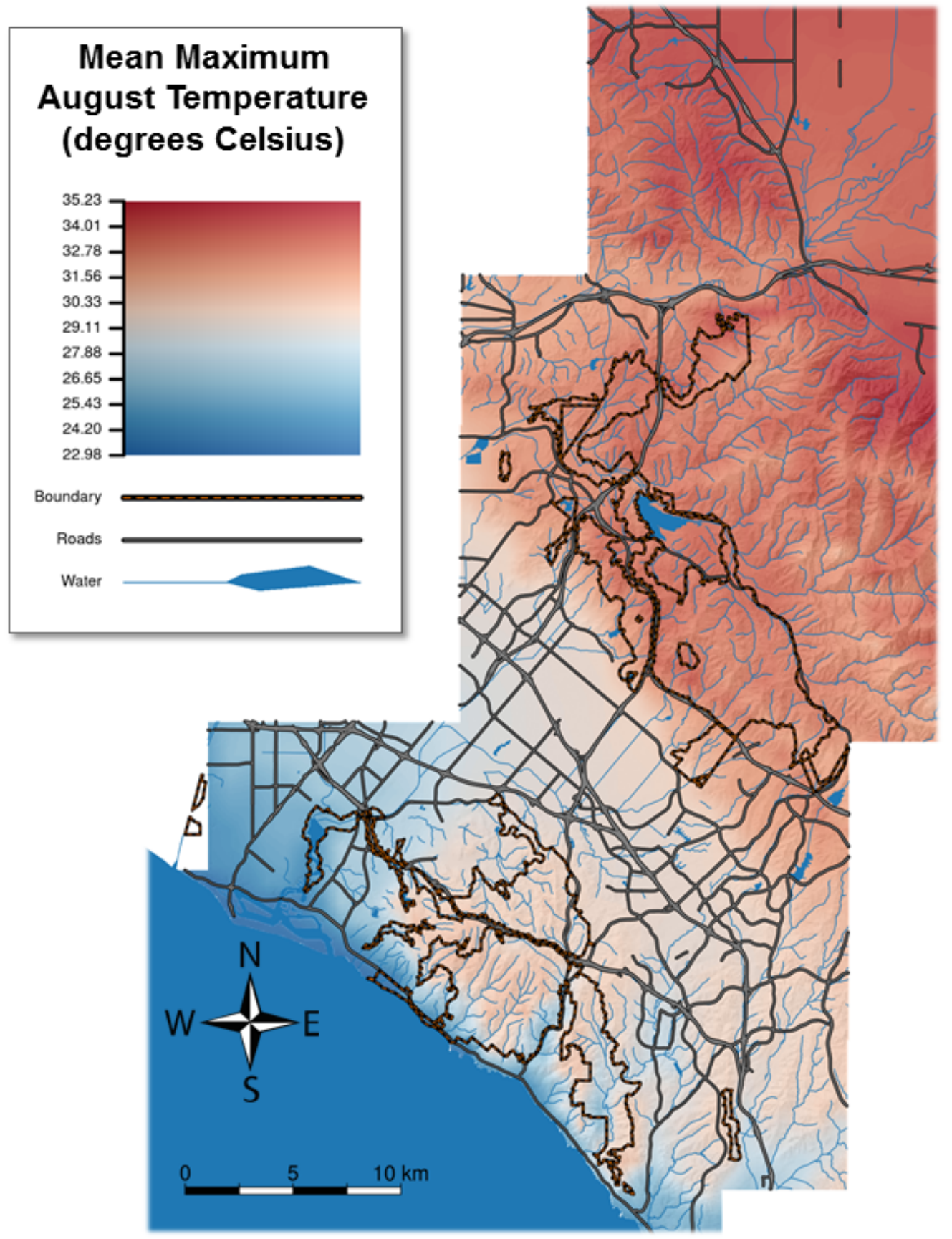

Figure 9. Image showing Mean Maximum Temperature in August for the study area in Orange County, southern California. Orange County Central and Coastal Natural Communities Conservation Plan/Habitat Conservation Plan boundaries and major roads are shown at 28-meter resolution. 

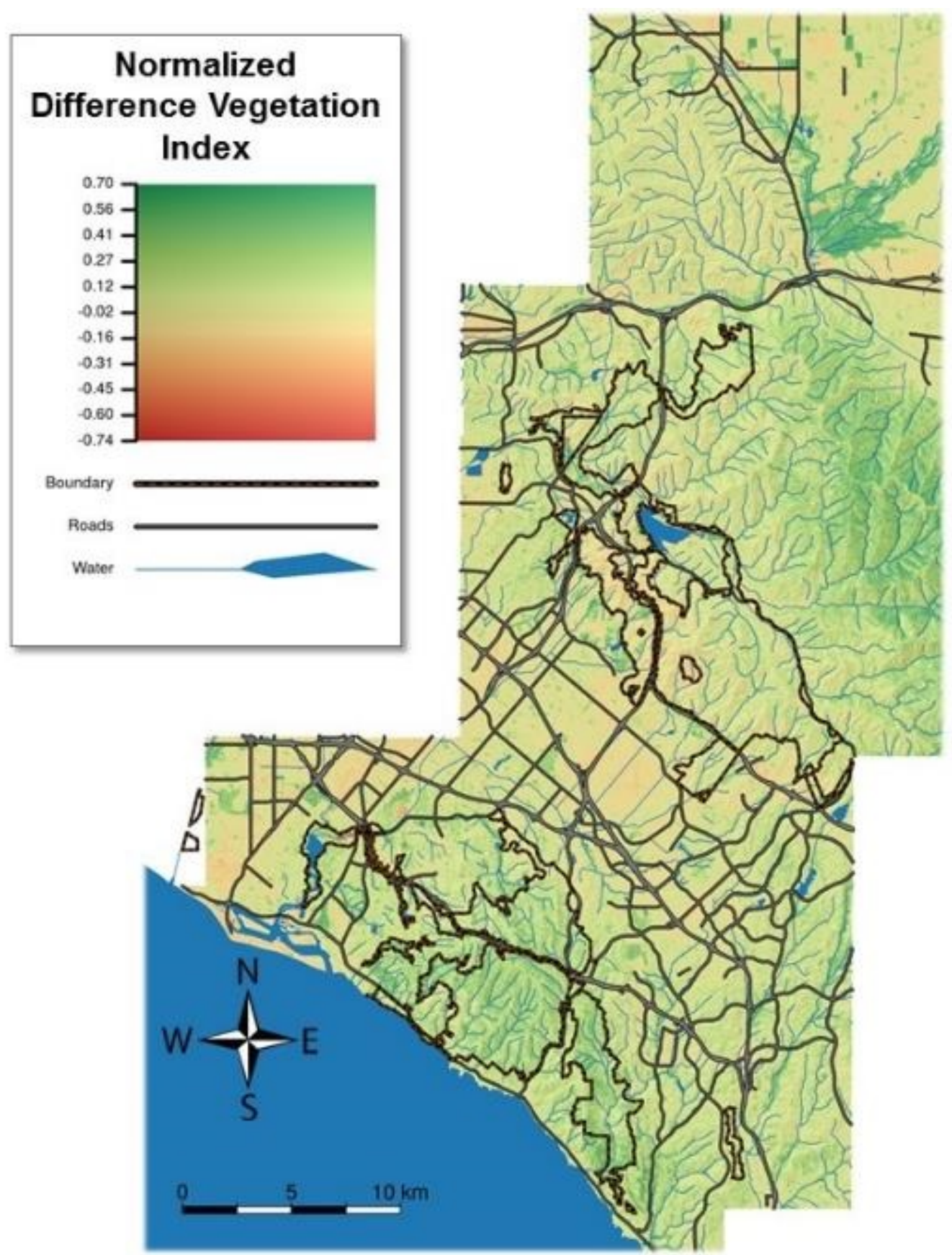

Figure 10. Image showing Normalized Difference Vegetation Index (NDVI) for the study area in Orange County, southern California. Orange County Central and Coastal Natural Communities Conservation Plan/Habitat Conservation Plan boundaries and major roads are shown at 28-meter resolution. 

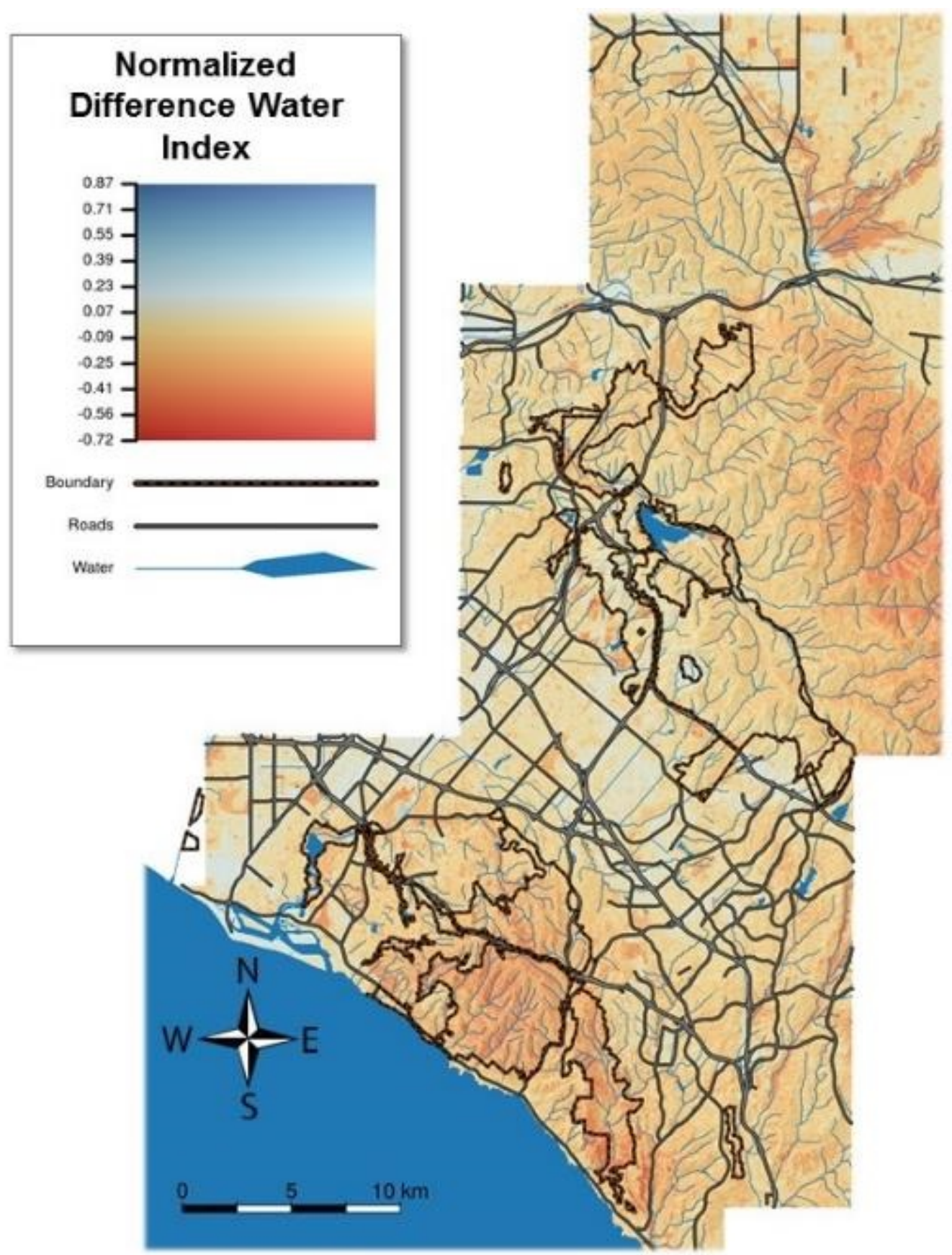

Figure 11. Image showing Normalized Difference Water Index (NDWI) for the study area in Orange County, southern California. Orange County Central and Coastal Natural Communities Conservation Plan/Habitat Conservation Plan boundaries and major roads are shown at 28-meter resolution. 


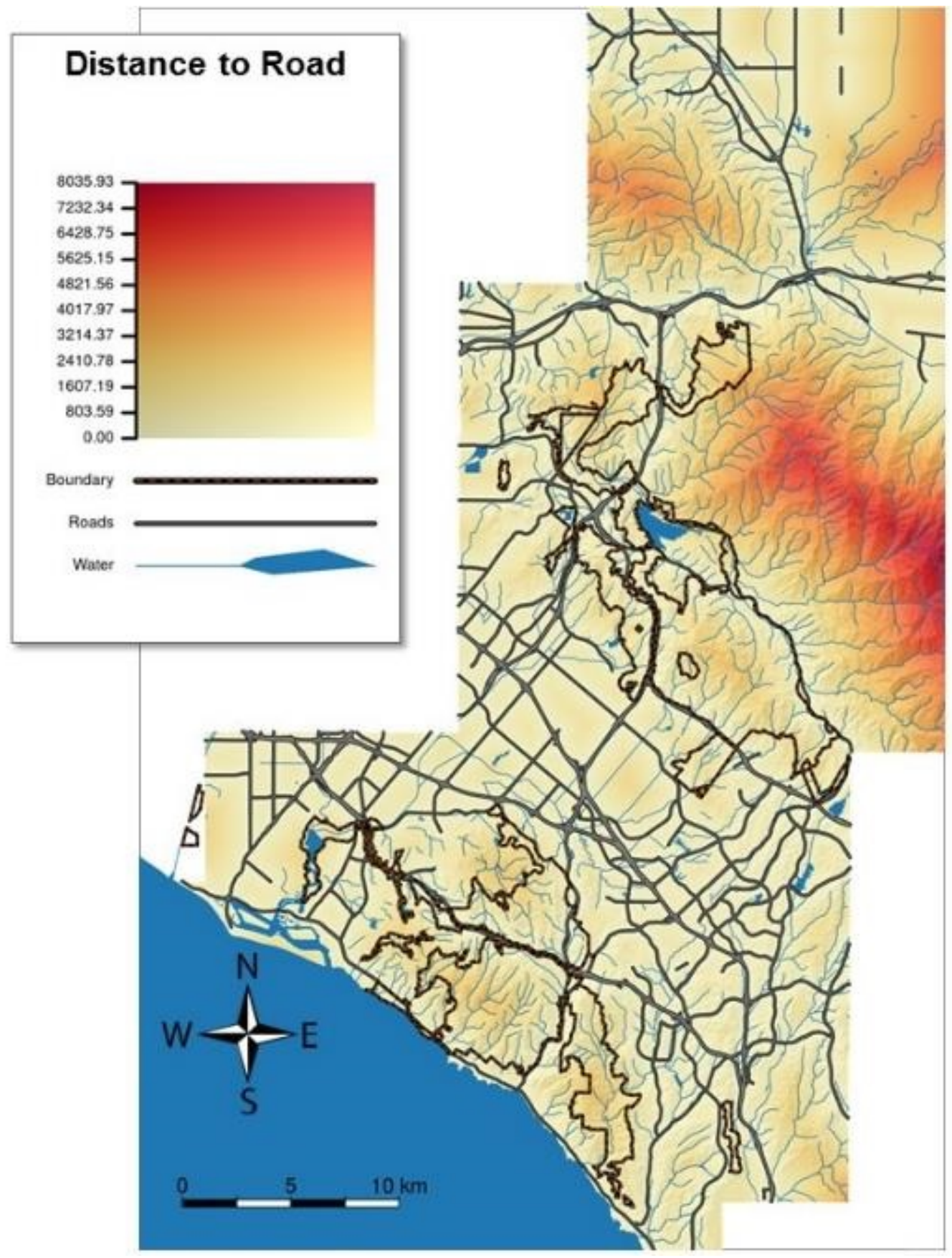

Figure 12. Image showing distance (in meters) to nearest road for the study area in Orange County, southern California. Orange County Central and Coastal Natural Communities Conservation Plan/Habitat Conservation Plan boundaries and major roads are shown at 28-meter resolution. 


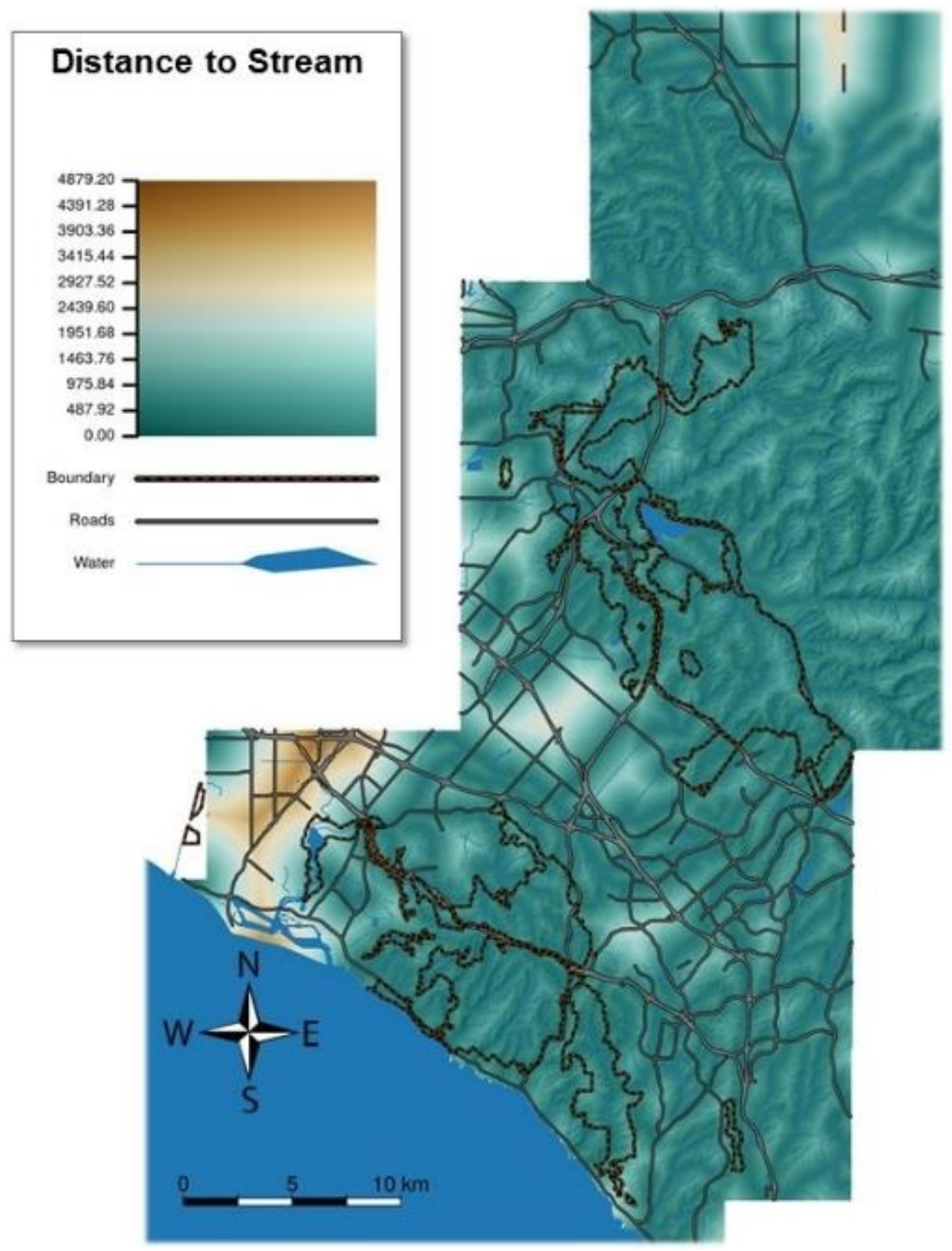

Figure 13. Image showing distance (in meters) to nearest stream, creek, or creek bed, for the study area in Orange County, southern California. Orange County Central and Coastal Natural Communities Conservation Plan/Habitat Conservation Plan boundaries and major roads are shown at 28-meter resolution. 


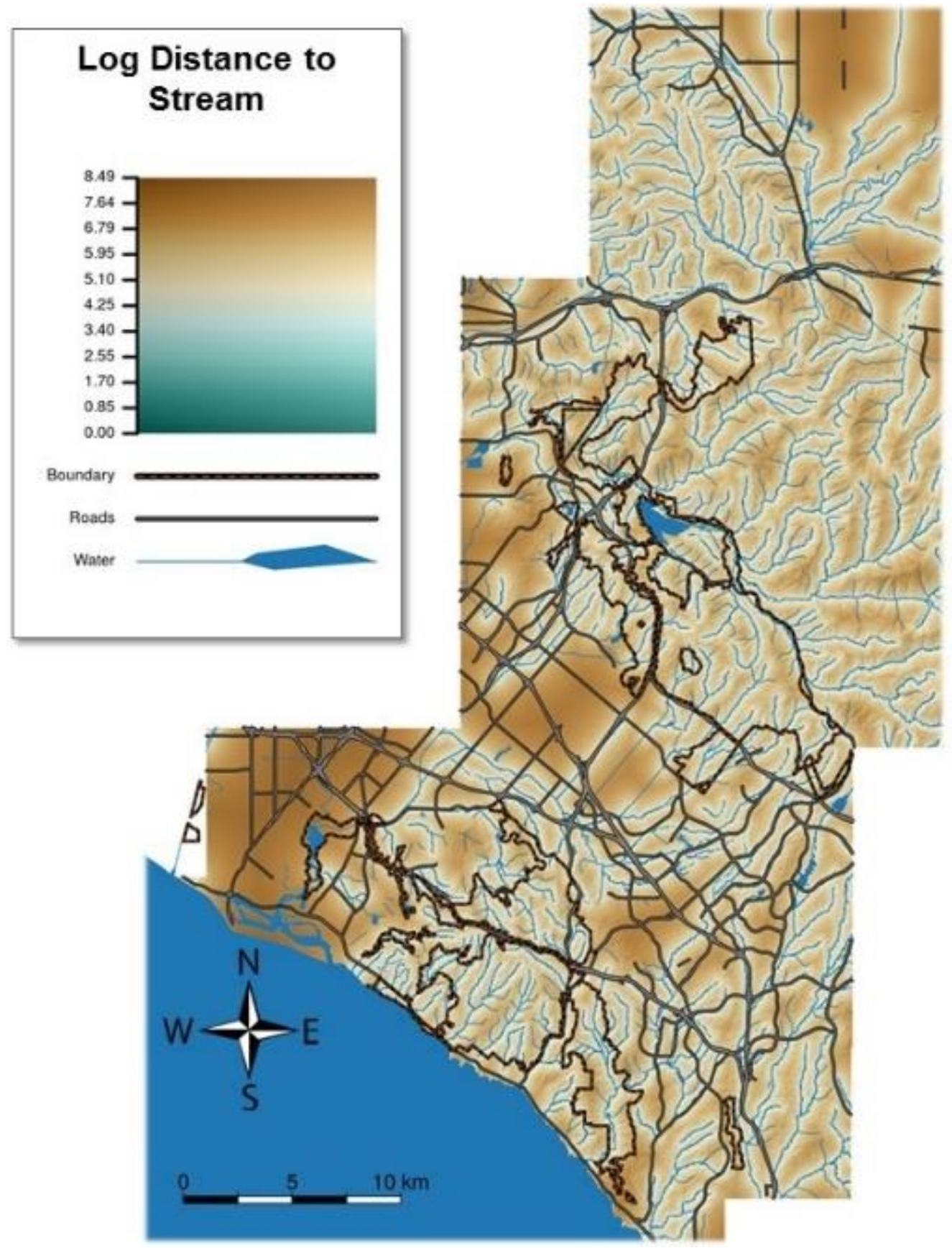

Figure 14. Image showing log of the distance (in log meters) to nearest stream for the study area in Orange County, southern California. Orange County Central and Coastal Natural Communities Conservation Plan/Habitat Conservation Plan boundaries and major roads are shown at 28-meter resolution. 


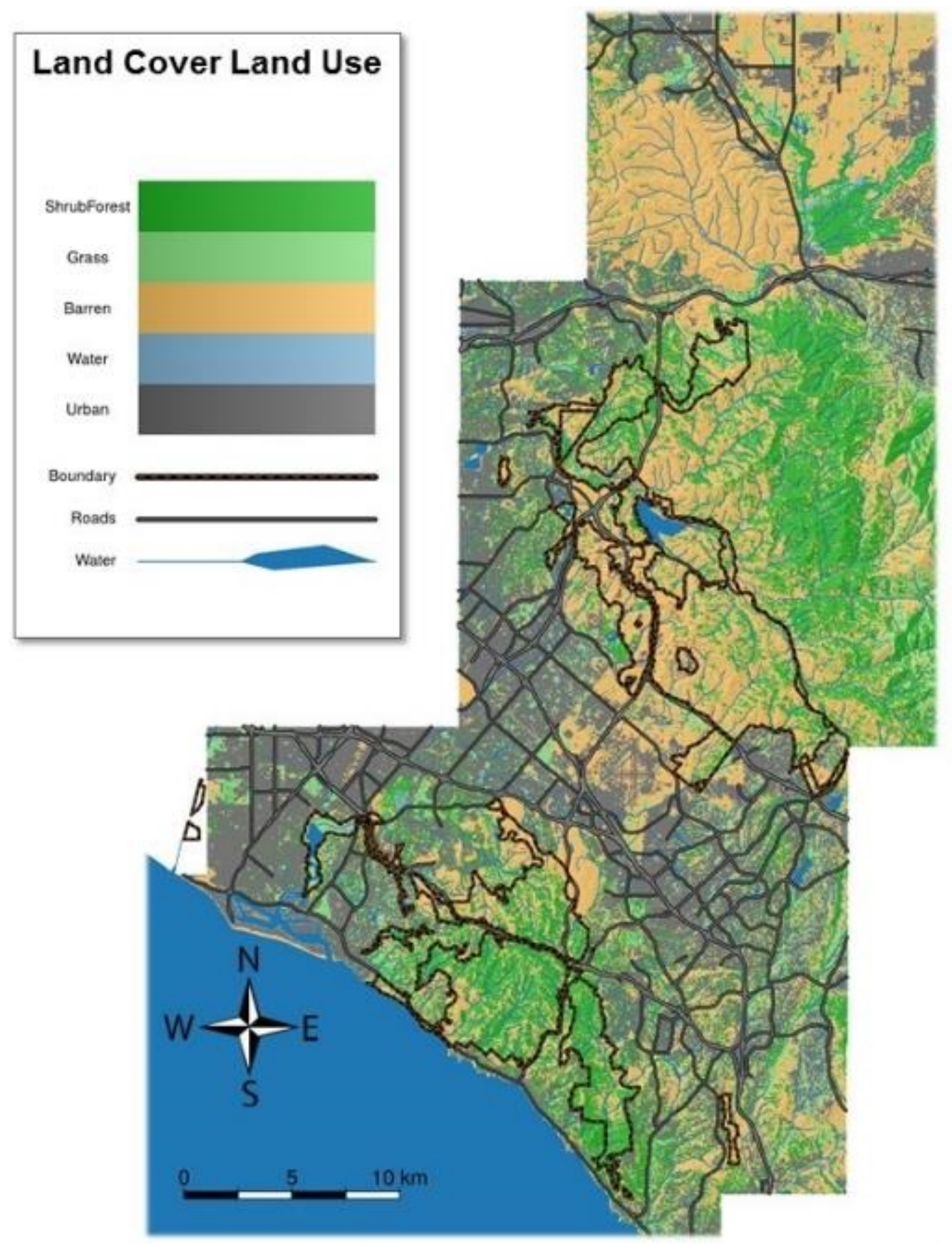

Figure 15. Image showing Land Cover Land Use classified from National Agriculture Imagery Program imagery for the study area in Orange County, southern California. Orange County Central and Coastal Natural Communities Conservation Plan/Habitat Conservation Plan boundaries and major roads shown at 28-m resolution. The category "Grass" is landscaped areas and some agriculture that were green (irrigated), whereas "Barren" includes grasslands that were not irrigated. 


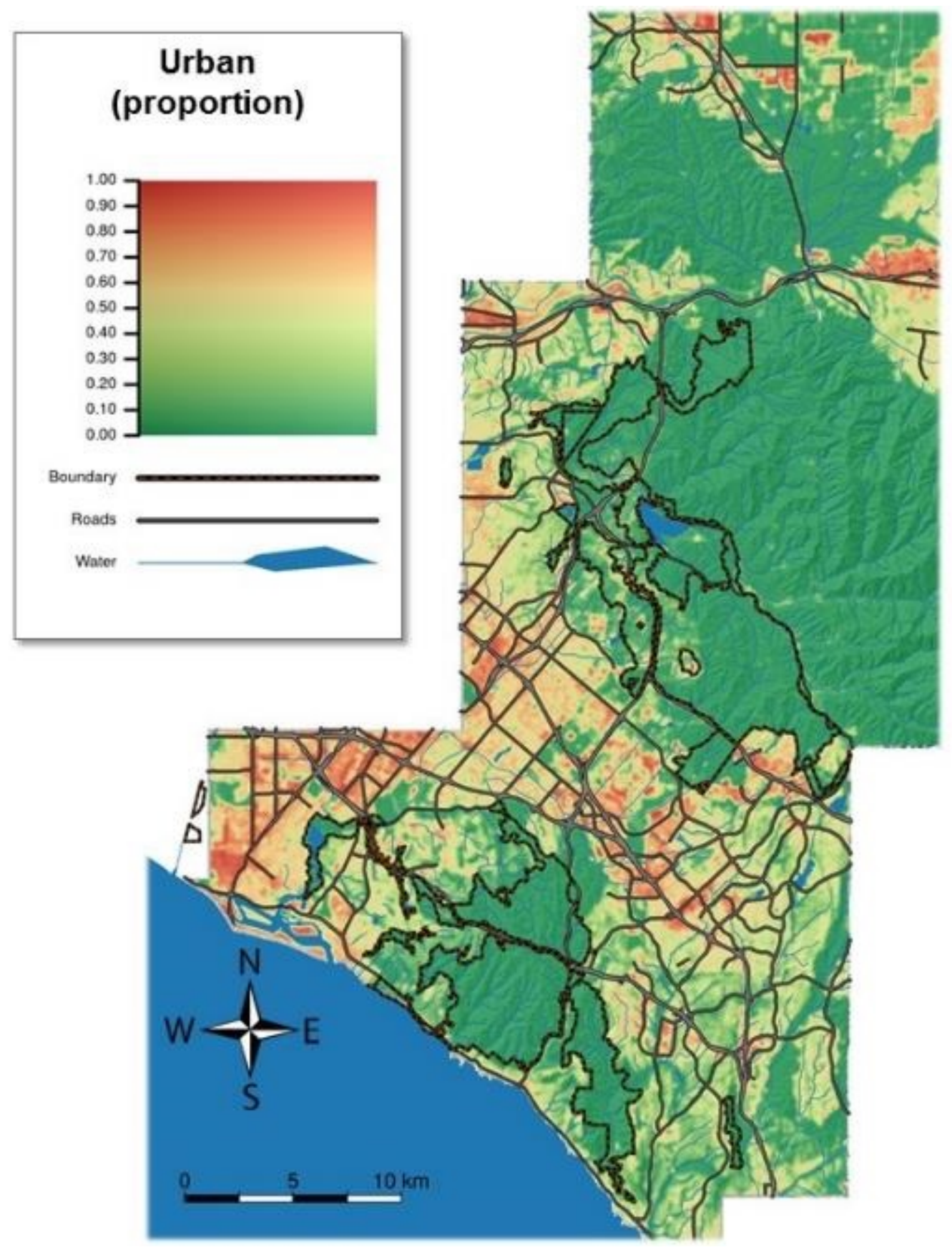

Figure 16. Image showing proportion urban within 125 meters of a pixel center, based on Land Cover Land Use, for the study area in Orange County, southern California. Orange County Central and Coastal Natural Communities Conservation Plan/Habitat Conservation Plan boundaries and major roads are shown at 28-meter resolution. Value of 1 indicates only urban land use; 0 means no urban land use. 


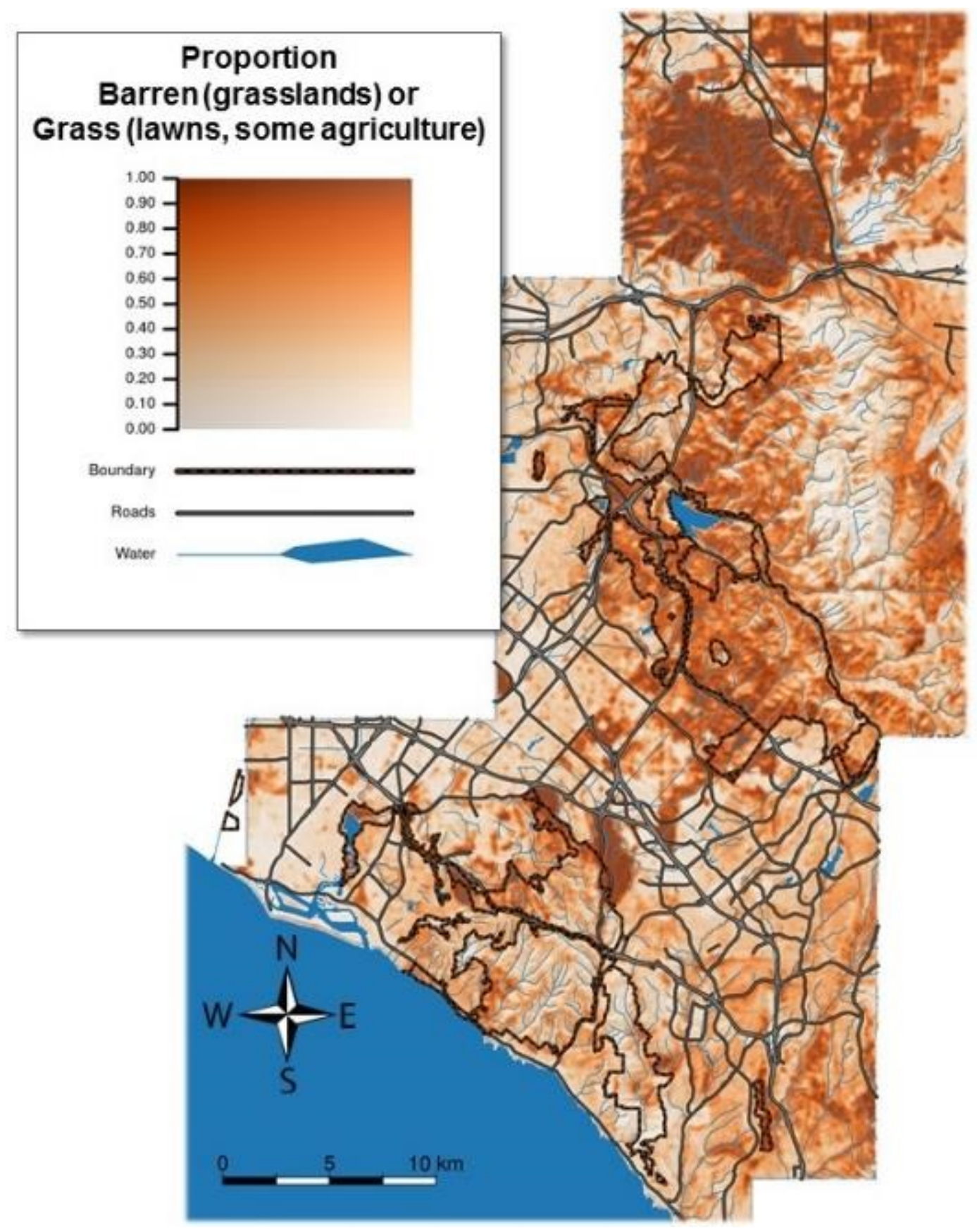

Figure 17. Image showing Land Use Land Cover categories of barren (mostly dry grasslands) and grass (lawns, playing fields, some agriculture) in Orange County, southern California. Orange County Central and Coastal Natural Communities Conservation Plan/Habitat Conservation Plan boundaries and major roads shown at 28meter resolution. Value of 1 indicates complete grassland or lawn/field coverage; 0 indicates no grassland/field coverage. 


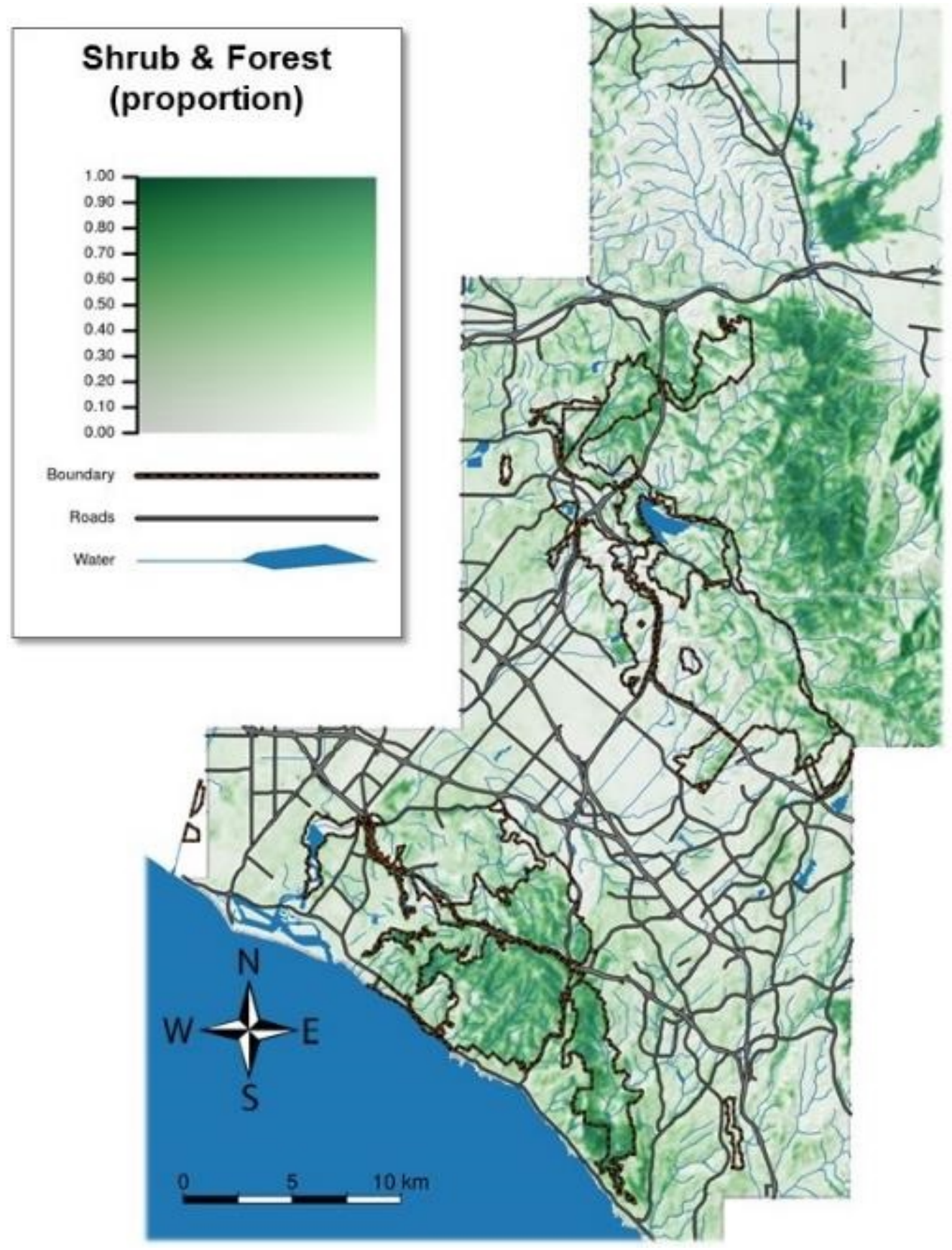

Figure 18. Image showing Land Use Land Cover categories of shrub (mostly California coast sage scrub) and forest, called "VegCover" in the models, depicted for the study area in Orange County, southern California. Orange County Central and Coastal Natural Communities Conservation Plan/Habitat Conservation Plan boundaries and major roads are shown at 28-meter resolution. Value of 1 indicates complete shrub/forest coverage; 0 indicates no shrub/forest coverage. 


\section{Vegetation Patches and Fragmentation}

We characterized contiguous patches of potential habitat from the LULC layer, creating a raster of potential habitat patches using the LULC raster that included roads, which was smoothed by applying a majority rule filter with 125 -m-radius moving window to eliminate many of the small patches. Any pixels that were not urban (or therefore, major roads) or water were included in the habitat patches. We used FRAGSTATS (McGarigal and others, 2002) and this raster to (1) assign unique ID numbers to each patch; and (2) compute several metrics to quantify landscape configuration and complexity, such as patch area, patch perimeter, perimeter-to-area ratio, shape index, and Euclidean nearest-neighbor distance to the nearest habitat patch (table 1). Perimeter-to-area ratio can indicate patch shape, but this metric varies with the size of the patch so cannot be used to compare reserves of different size. Patton (1975) proposed a diversity index based on shape for quantifying habitat edge for wildlife species and as a means for comparing alternative habitat improvement efforts (for example, wildlife clearings). This diversity shape index measures the complexity of patch shape compared to a standard shape (square) of the same size, and therefore alleviates the size dependency problem of the perimeter-area ratio. This shape index is widely applicable in landscape ecological research (Forman and Godron, 1986). Based on FRAGSTATS patches, we developed two raster layers as candidates for RSF models:

- Log Patch Area (fig. 19)—Derived from LULC layer, using FRAGSTATS (McGarigal and others, 2002), where a "patch" was composed of all vegetation classes and excluded urban and water classes.

- Log Distance to Patch (fig. 20)—Log of the distance to the nearest patch in meters (plus 1) for sites outside a patch; otherwise, 0 for sites within a patch.

Table 1. Descriptive statistics from FRAGSTATS output of about 771 vegetated patches identified for the study area in Orange County, southern California.

[Shape index of 1 is a circle and is the lowest value possible. See also figure 19]

\begin{tabular}{lcccc}
\hline \multicolumn{1}{c}{ Measurement } & Mean & Median & Minimum & Maximum \\
\hline Patch area (in hectares) & 95.29 & 1.11 & 0.08 & $21,601.37$ \\
Patch perimeter (in meters) & 2,838 & 506 & 113 & 134,910 \\
Perimeter-to-area ratio & 696 & 498 & 6 & 1,423 \\
$\begin{array}{l}\text { Shape index } \\
\begin{array}{l}\text { Euclidean nearest-neighbor distance (in } \\
\text { meters) to nearest habitat patch }\end{array}\end{array}$ & 1.31 & 1.17 & 1.00 & 4.20 \\
\hline
\end{tabular}




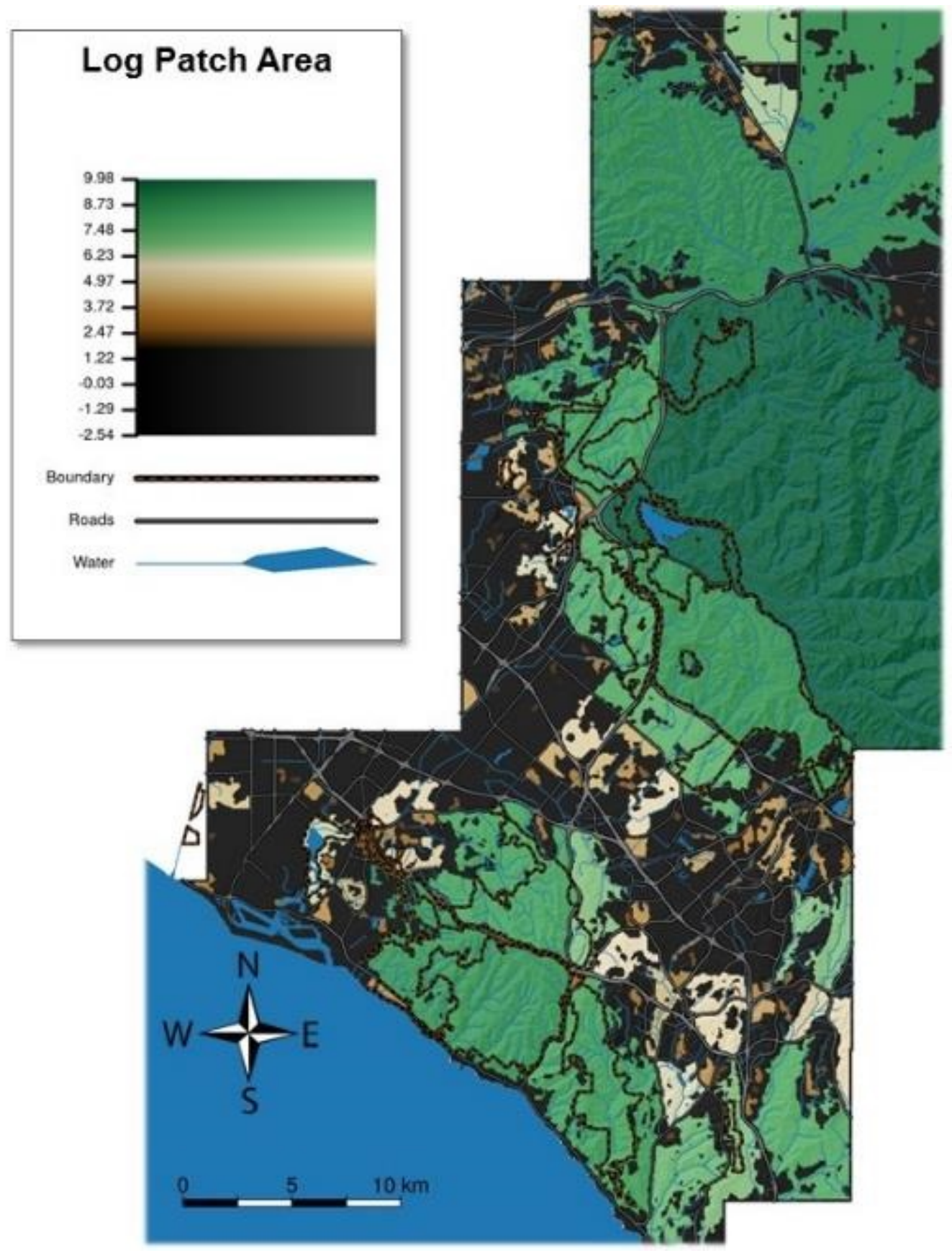

Figure 19. Image showing Log Patch Area (in log square kilometers) derived using FRAGSTATS applied to Land Use Land Cover, for the study area in Orange County, southern California. A "patch" was composed of all vegetation classes and excluded urban and water classes. Patches, at 28-meter resolution, are shaded according to size. 


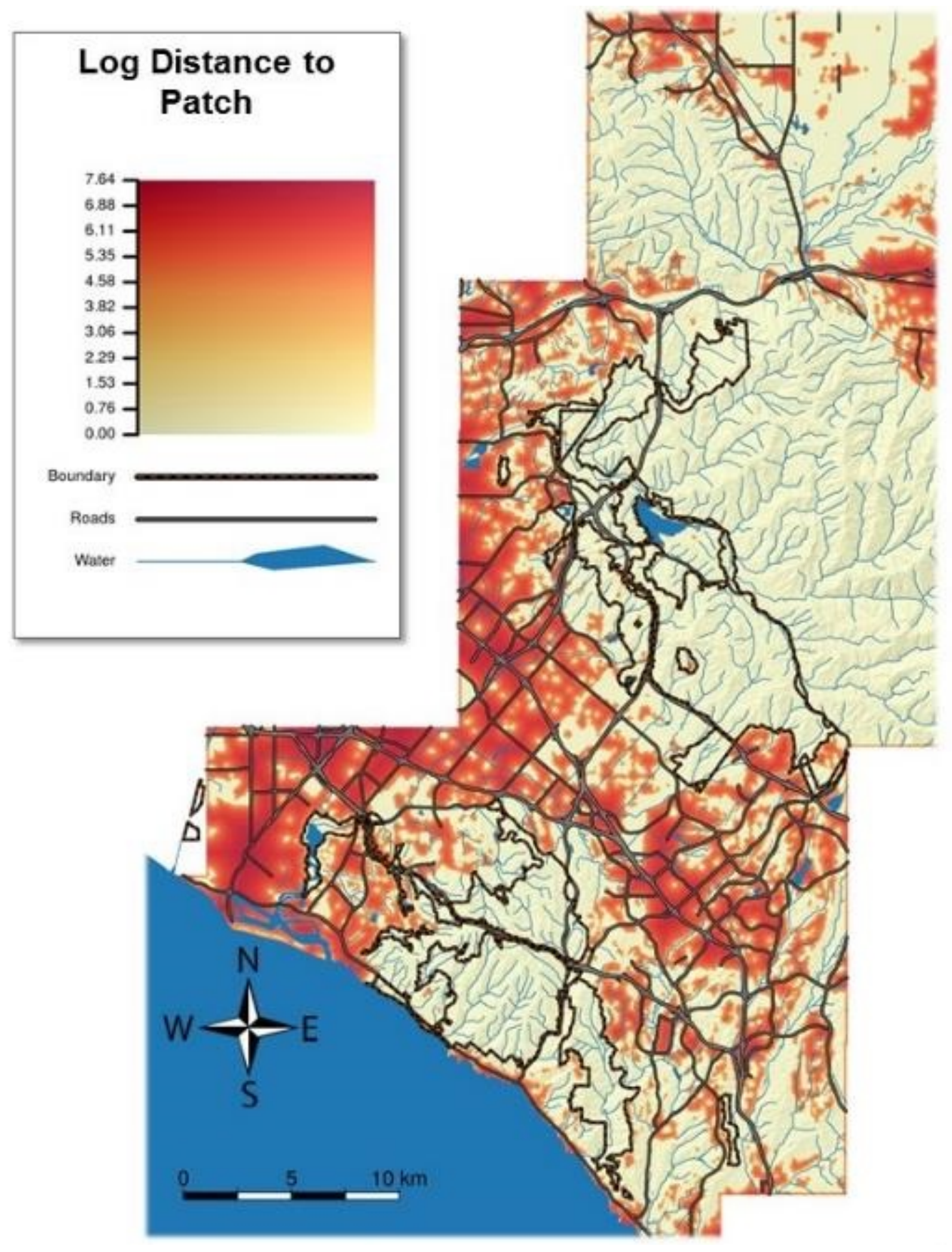

Figure 20. Image showing Log Distance to Patch (in log meters) indicates distance to the nearest patch (in meters [m]) for all areas outside a large patch, for the study area in Orange County, southern California. Orange County Central and Coastal Natural Communities Conservation Plan/Habitat Conservation Plan boundaries and major roads are shown at 28-m resolution. Pixels within large patches were assigned a value of 0 . 


\section{Resource Selection Functions}

In the RSF approach, regression models relate "used" RUs to attributes of the collection of all RUs for a particular spatial variable to determine if a resource is used more or less than in proportion to its availability. Field measurements on the species of interest served as the response variables in the regression function. We used GPS telemetry locations from bobcats collared in and near the $\mathrm{NCCP} / \mathrm{HCP}$ to indicate bobcat response; where a GPS point intersected a pixel, the location was considered used. The attributes of used (that is, selected) locations, such as elevation or proportion of vegetation cover, were compared to the background values of the attribute within a defined area of resource availability. To represent the spatial extent of resource availability to bobcats, we defined two different areas as the "background" from which the bobcat was sampling: (1) The extent of the study area; and (2) the extent of the home range of a bobcat, which was estimated from its GPS locations. Thus, bobcat home ranges indicated used RUs in some models and RU availability in others. The different combinations of how home ranges were incorporated, along with GPS points and the study area, led to the following three sets of comparisons of a sample of used RUs to a sample from the available background (fig. 21):

- Comparison A. GPS point locations are compared to availability of resources within home ranges. For this comparison, a sample of used RUs was compared to a background sample taken from within each home range, and is similar to third-order habitat selection (Johnson, 1980) and Design III in Manly and others (2002).

- Comparison B. Home ranges as indicators of use are compared to resource availability across the study area. For this comparison, a random sample of used RUs from within the home range is compared to a background sample from the larger study area, similar to second-order habitat selection (Johnson, 1980) and Design II in Manly and others (2002).

- Comparison C. GPS point locations are compared to resource availability across the study area. For this comparison, a sample of used RUs were compared to a background sample taken from the larger study area. This is somewhat similar to second-order selection (Johnson, 1980) and Design II in Manly and others (2002), but perhaps not explicitly defined by them because their work was prior to the development of GPS tracking technology that typically yields much more data than VHF collars.

In our three sets of comparisons, there were assumptions about the "background" from which we sampled the unused part of a resource. Because we compared use to a background (that is, available) sample, our RSF estimated the probability that a sample taken from a location was in the set of used samples (out of the used and background samples). Thus, we did not directly estimate probability of presence (Manly and others, 2002; Phillips and others, 2009). Although the mathematical relation between these two estimators is known, an unknown constant is involved (Manly and others, 2002; Phillips and others, 2009). However, estimating the probability of a sample being used is the best indicator of probability of presence given these data (Phillips and others, 2009). Furthermore, because not all individual bobcats were tracked (bobcats were collared only in part of the study area), and GPS data were collected at discrete time intervals (usually 15-min sampling) rather than continuous, we did not have true absence data for bobcats. These considerations are common in wildlife suitability modeling, but are not always explicitly mentioned. 


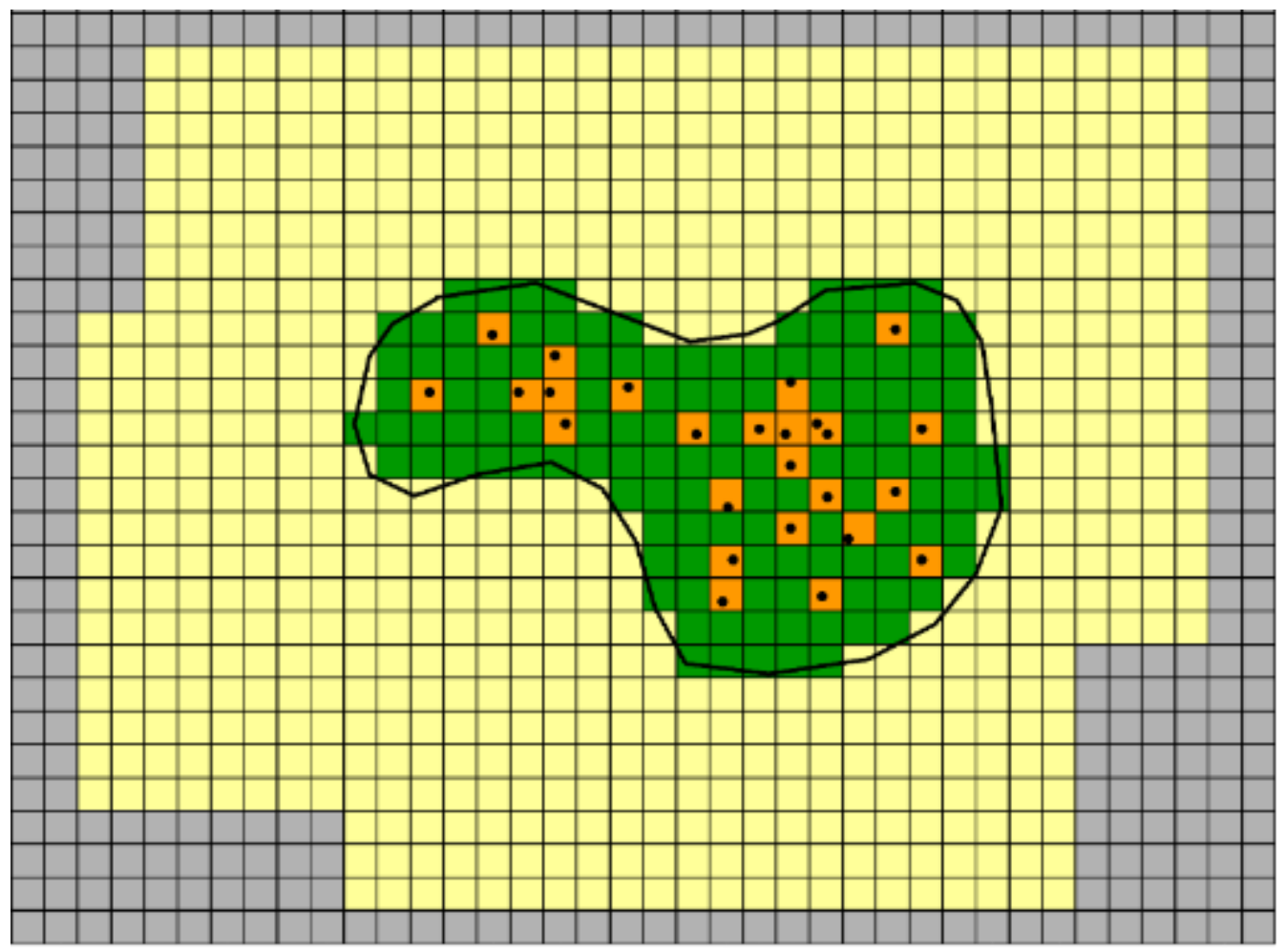

Figure 21. Schematic diagram showing levels of habitat selection. Black dots represent Global Positioning System (GPS) locations for one bobcat, and the black outline indicates the estimated home range (HR). The GPS points and HR outline are draped over a raster layer representing a resource, and each grid cell is a Resource Unit (RU). For Comparison A, orange cells (those cells each containing a black dot) represent used RUs, and green cells (those cells entirely or mostly within the black outline but without a black dot) represent additional available RUs within the HR. For Comparison B, all cells within the HR (green or orange cells) are considered used and are compared to the background of resource availability within a defined region (yellow cells). Comparison $\mathrm{C}$ makes no assumption about the estimated HR, and used RUs (orange cells) are compared to the entire region of defined resource availability (green or yellow cells).

We separated data for males and females for each of the three comparisons because males and females have differing roles and ecological requirements and, thus, may have very different responses and requirements from the landscape. In mammals, the distribution of females usually is closely related to food and shelter resources that are needed to sustain pregnancy, raising offspring, and survival. The distribution of males, however, generally depends on the distribution of potential mates and mate competition (Emlen and Oring, 1977; Clutton-Brock, 1989). Among most felid species, females occupy solitary home ranges or territories, whereas adult males, who do not contribute to parental care, have larger home ranges that may overlap home ranges of multiple females while attempting to avoid or exclude other males (Sandell, 1989; Sunquist and Sunquist, 1989). In the fragmented, developed southern California coastal landscape, we expected that RSF models based on data for female bobcats would indicate greater selectivity for natural areas and avoidance of anthropogenic activity than male RSFs. The models with a fit value above a certain level were considered viable representations of bobcat habitat selection, and these were mapped to show the predicted space use across the study area. 
For each bobcat, we identified the pixels in which its GPS locations occurred, which were the used RUs (for example, the orange cells in fig. 21) for comparisons A and C. We estimated the home range of each bobcat using a kernel density estimator (Worton, 1989) (using the kde2d() function from the R package MASS) of the dispersion of GPS locations. Smoothing parameters $\left(w_{x}, w_{y}\right)$, that determine how tightly or coarsely home range shape fits the GPS points were estimated separately in the $x$ and $y$ dimensions using the bandwidth.nrd() function in $\mathrm{R}$. We used the 99-percent kernel contour to define a general area of use by each bobcat, confirming by visual inspection that this contour yielded a good representation of home range for the GPS data (fig. 22). Pixels in kernel home ranges represented used RUs for comparison B. For each comparison, samples of used RUs were generated as input to RSF models indicating bobcat response to resource availability.

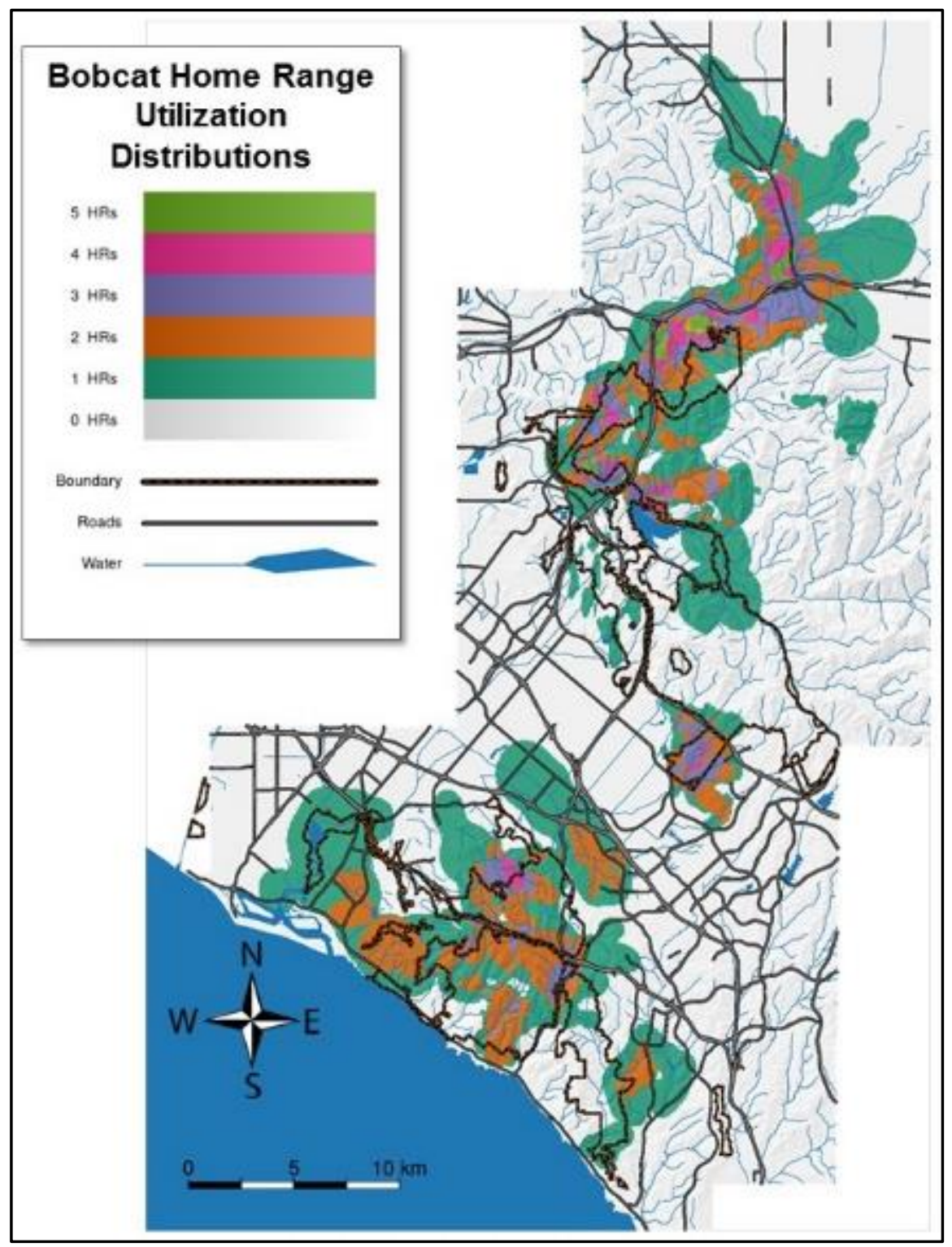

Figure 22. Image showing individual bobcat home range utilization distributions, estimated from Global Positioning System collar data for 51 bobcats tracked in Orange County, southern California, 2002-09. Home ranges (HRs) were overlaid and intersected to show the geographic dispersion in coastal and central Orange County. The color scale indicates how many HRs overlapped spatially (but not necessarily temporally), which was up to five individual HRs. 


\section{Generalized Additive Mixed-Effects Models}

We used Generalized Additive Mixed-effects Models (GAMMs) in our RSF modeling approach (Wood, 2006). GAMMs are related to Generalized Additive Models (GAMs) but allow for mixed modeling with both fixed and random effects as both are forms of General Linear Models. We used a mixed model because a GPS dataset is a type of repeated measures; in this case, successive observations of a bobcat. Because we had repeated observations of each bobcat and because natural variation among individual animals may be an important factor, we accounted for individual bobcats as a random effect; thus, a mixed-effects model was appropriate (that is, there was a different intercept term for each bobcat). We can think of GAMMs as having three main elements (Wood, 2006):

1. Smoothed functions of predictor variables. Predictors are passed through a smoothing function to produce the terms in the linear model. Let $i$ index individual RUs and the vector of predictors from the $i^{\text {th }} \mathrm{RU}$ for a particular model be xi. We divide these predictors into $\mathrm{G}$ groups, where each group is indexed by $g=1, \ldots, \mathrm{G}$. Thus, the vector of predictors for each group for the $i^{\text {th }} \mathrm{RU}$ is denoted as xi,g. A group may, for example, be predictors that are interrelated in some way. Some groups will contain only one predictor, whereas others may contain more than one. In our models, if a group g contains only one predictor, we use $\mathrm{s}(\mathrm{xi}, \mathrm{g})$, a univariate smoothing function of a single predictor with a cubic basis function. If a group g contains more than one predictor, we use te(xi,g), a multivariate tensor spline smoothing function with a cubic basis. For simplicity, we let yi,g $=f g(x i, g)$, where $f()$ is either the $\mathrm{s}()$ or te() smoothing function, depending on whether xi.g has one or more than one predictor.

2. A linear component. These terms are weighted by a regression coefficient and added, along with an intercept term, $\mathrm{zi}=\beta 0+\sum \beta \mathrm{g}$ yi,g. In the mixed-effect models (that is, GAMMs), a different intercept term is used for each individual bobcat, and these terms are normally distributed.

3. A nonlinear component. This sum is passed through a nonlinear link function. In our case, because our response variable is $\mathrm{s}=1$ if our observation is drawn from the set of RUs occupied by a telemetry location and $\mathrm{s}=0$ if it drawn from a background sample of RUs, we use a logistic link function, $\mathrm{p}(\mathrm{s}=1 \mid \mathrm{zi})=\exp (\mathrm{zi}) /(1+\exp (\mathrm{zi}))$.

\section{Implementation}

The non-linear component in our models was a logit link, $p\left(s \mid z_{i}\right)=\frac{e^{z_{i}}}{\left(1+e^{z_{i}}\right)}$, with:

- $s=1$ if an observation was drawn from a used RU;

- $s=0$ if it was drawn from a background RU; and

- $z_{i}=\beta_{0}+\sum \beta_{1} y_{i}$, the equation for a line given data $y_{i}$.

Separate GAMMs were run for separate subsets of predictors. We used R to fit (the gamm() function of the mgcv package) and evaluate (the prediction() and performance() functions of the ROCR package) models and to generate predictive raster images (the predict() function from the mgcv package and the raster package).

We used a two-stage modeling approach that consisted of (1) an exploratory phase during which we fit and evaluated a set of models to identify predictors that seemed most informative, and (2) an exploitation phase during which we fit a set of 128 alternative models based on the results of the exploratory phase.

The purpose of our first, exploratory stage of model fitting was to eliminate predictors that appeared to produce little change in area under the curve (AUC) from the final set of predictors used in the second stage. This often is necessary, as the number of combinations of predictors can be as large as $2^{\mathrm{k}}$, where $\mathrm{k}$ is the number of predictors (provided multiplicative interaction terms are not included). 
In the second stage of model fitting, we constructed our final set of models, based on our first stage of model fitting experiments. We combined smoothed functions of predictors to produce alternative models, and evaluated among these using the AUC metric $(\mathrm{AUC}=$ area under the curve, referring to the receiver operating characteristic, or ROC, curve) as a measure of model fit (Bradley, 1997). AUC ranges from 0.5 to 1.0, with a larger value indicating better predictive performance. An AUC value $>0.75$ usually is considered a minimum threshold for model performance, and we used that level here.

All analyses were performed using R statistical computing language (www.r-project.org). We fit all models using the gamm() function from the mgcv R package (cran.rproject.org/web/packages/mgcv/index.html) and evaluated models using the prediction() and performance() functions from the ROCR R package (cran.rproject.org/web/packages/ROCR/index.html). Finally, for the selected models, predictive raster images were made using the predict() function from the $\mathrm{mgcv}$ package and the raster package.

\section{Bobcat Models-Predictors, Output, and Interpretation}

As a result of our first stage of modeling, we selected eight predictors for use in the second stage of model fitting:

1. Urban $125 \mathrm{~m}$,

2. NoCover $125 \mathrm{~m}$,

3. VegCover $125 \mathrm{~m}$,

4. Unevenness,

5. VRM500m,

6. Slope,

7. PatchLogArea, and

8. StreamLogDist.

We combined smoothed functions of predictors (table 2) to produce alternative models that included:

1. Four different sets of land-cover terms,

2. Every combination of the four different sets of land-cover terms with seven different sets of topography terms,

3. Every combination of the four different sets of land-cover terms with three different sets of miscellaneous terms, and

4. Every combination of the four different sets of land-cover terms with seven different sets of topography terms and with three different sets of miscellaneous terms.

This resulted in 128 different model structures $([4+(4 \times 7)+(4 \times 3)+(4 \times 7 \times 3)]=128])$ that were fit to male and 128 that were fit to female bobcat data at the three different levels of comparison (A, B, and C).

These 128 models had 2-8 predictors each, and most models tested were successfully fit. We selected the model with the highest AUC within each combination of Comparison A, B, or C, male or female, and number of predictors. Our final prediction was based on the mean and standard deviation of the selected models for each group, excluding models with AUC less than $(<) 0.75$ (table 3; figs. 2330 ), with number of models serving as the sample size (table 3 ). In three cases where there were 8 predictors in each of 2 models tested, only 1 model converged to a solution; thus no standard deviation could be calculated and the result was not applicable. GIS layers of means show the predicted selection of the landscape by male or female bobcats, averaged across the best models for each comparison. Standard deviation layers for each mean showed where the best models for a particular comparison differed from each other. 
Table 2. Terms used in the linear component of the alternative models in the second stage of model fitting.

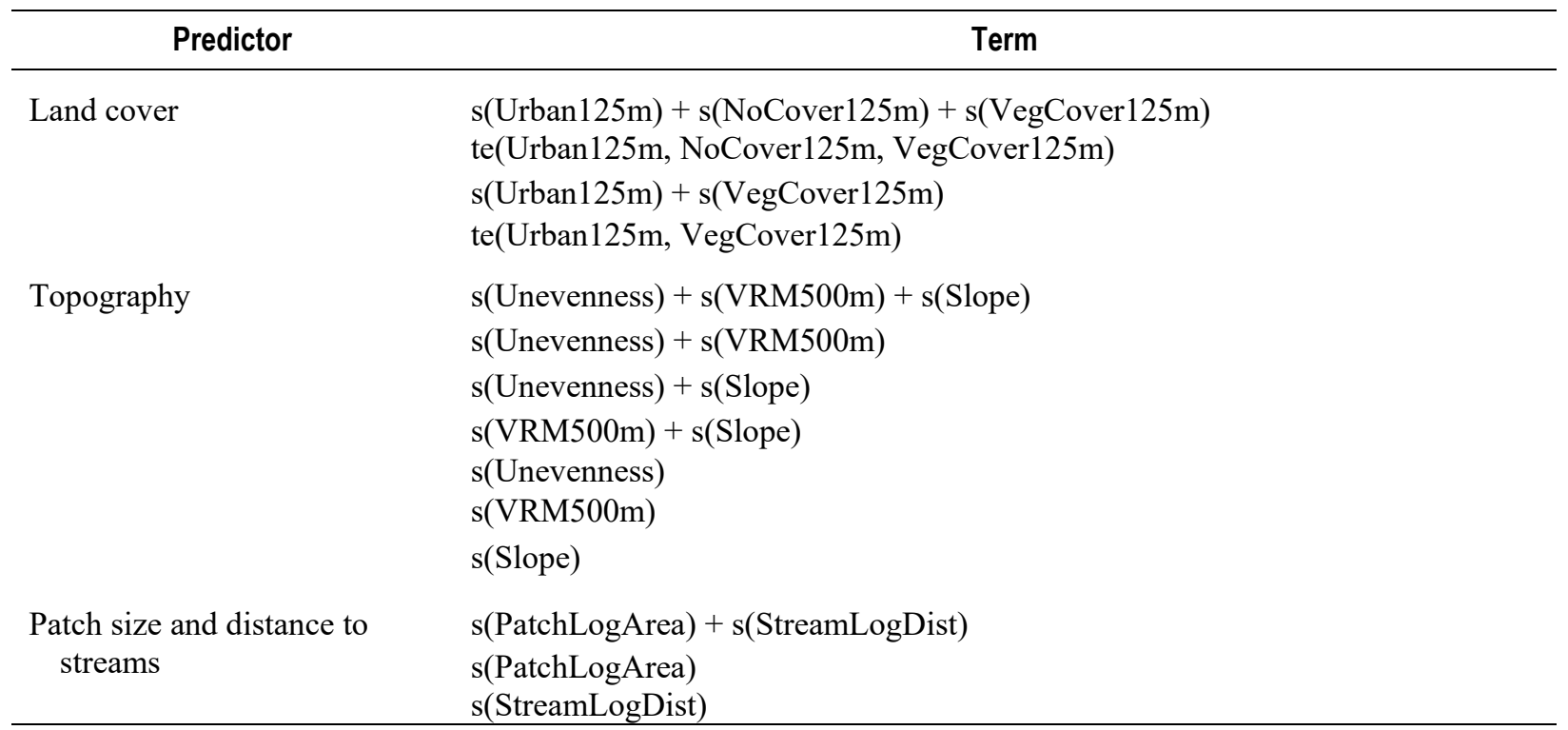

AUC values generally were distinctly clustered by comparison type and by sex (fig. 31). Comparison C (location compared to study area) performed the best of the three comparison groups, with AUC range per model of 0.785 to 0.864 for females and 0.760 to 0.839 for males (table 3 , fig. 31). Comparison B (home range compared to study area) followed, with most models for females above the minimum threshold of 0.75 AUC, ranging from 0.706 to 0.793 . Most AUC values for Comparison B applied to males were less than 0.75 , ranging from 0.658 to 0.755 (table 3 , fig. 31). AUC values were lowest for Comparison A (locations compared to home range), which performed poorly; all models tested and successfully fit had AUC values much less than 0.75 . AUC values for Comparison $\mathrm{A} / \mathrm{males}$ were $0.622-0.672$, and they were lower for Comparison $\mathrm{A} /$ females (0.584-0.652).

This same order of performance was true across comparisons when the number of predictors was held constant, with mean AUC decreasing in the following order: Comparison C/Females, Comparison C/Males, Comparison B/Females, Comparison B/Males, Comparison A/Males, Comparison A/Females (table 3, fig. 31). AUC values increased slightly with number of predictors included, which is expected with fitting models because of the tradeoff between adding more predictors and the power to explain areas beyond the input data. As AUC increases with added predictors, eventually a high number of predictors leads to "overfitting" and loss of the explanatory or predictive power of the model. 
Because models of bobcat resource selection within their individual home ranges (Comparison A) did not yield robust RSF results as indicated by low AUC values, we excluded Comparison A from further examination. The quantity of data yielded by GPS collars and the use of the kernel home range estimator may have led to greater similarity to use compared to available samples than seen in VHF and some GPS studies, and with convex polygon home range estimators. Here, results of RSF models for locations compared to the study area may offer the best combination of accuracy and precision, at an appropriate scale for resource management planning.

Mapped predictions of female and male RSFs were more similar to each other than expected. The areas predicted for bobcats generally were the same, but the strength of the prediction varied within them. Resource selection models highlighted the particular importance of the NCCP/HCP reserve habitat to them. Male bobcats appeared less specifically dependent on NCCP/HCP lands, as expected based on their wider movements in general, but they also were associated with undeveloped areas including the $\mathrm{NCCP} / \mathrm{HCP}$ reserve and adjacent lands. The NCCP/HCP Coastal Reserve appeared important to male and female bobcats as contiguous, high-quality open space but largely isolated by urbanization and the ocean, whereas the NCCP/HCP Central Reserve still neighbored other large undeveloped areas that may help support bobcat movements and home ranges spanning across management boundaries. Modeling efforts based on fine-scale selection from point locations highlighted small areas outside the NCCP/HCP Coastal Reserve that could provide additional suitable home range or movement areas for bobcats, potentially through restoration, connectivity, or reduced edge effects.

The mountainous region on the eastern edge of the study area showed mixed results across models but generally low RSF values. The high elevations of this region of the Santa Ana Mountains were not represented elsewhere in the study area. However, no bobcat tracking work was conducted here and no GPS data were obtained for these conditions, resulting in poor predictive ability of the models in this area. In the center of the study area, there were no GPS data for female bobcats immediately on the south side of State Route 241, but both male and female RSF results predicted bobcat occurrence here at the base of the Santa Ana Mountains. This was true for other parts of the study area with similar predictions for males and females despite the differences in spatial coverage in GPS data for them, providing confidence in the RSF results. 
Table 3. Mean area under the curve, standard deviation, minimum, and maximum, grouped by comparison category.

\begin{tabular}{|c|c|c|c|c|c|c|c|}
\hline & $\begin{array}{l}\text { Comparison } \\
\text { category }\end{array}$ & $\begin{array}{l}\text { Number of } \\
\text { predictors }\end{array}$ & $\begin{array}{l}\text { Number of } \\
\text { models }\end{array}$ & Mean & $\begin{array}{l}\text { Standard } \\
\text { deviation }\end{array}$ & Minimum & Maximum \\
\hline \multirow{21}{*}{ 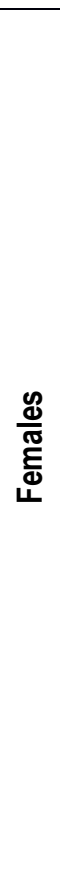 } & \multirow{7}{*}{$\begin{array}{l}\text { Comparison A: } \\
\text { Location and } \\
\text { home range }\end{array}$} & 2 & 2 & 0.602 & 0.007 & 0.597 & 0.607 \\
\hline & & 3 & 12 & 0.611 & 0.014 & 0.589 & 0.631 \\
\hline & & 4 & 30 & 0.617 & 0.017 & 0.584 & 0.642 \\
\hline & & 5 & 40 & 0.621 & 0.018 & 0.584 & 0.650 \\
\hline & & 6 & 30 & 0.622 & 0.016 & 0.587 & 0.652 \\
\hline & & 7 & 12 & 0.622 & 0.013 & 0.604 & 0.652 \\
\hline & & 8 & 2 & 0.620 & 0.007 & 0.615 & 0.625 \\
\hline & \multirow{7}{*}{$\begin{array}{l}\text { Comparison B: } \\
\text { Home range and } \\
\text { study area }\end{array}$} & 2 & 2 & 0.711 & 0.006 & 0.707 & 0.715 \\
\hline & & 3 & 12 & 0.736 & 0.021 & 0.706 & 0.765 \\
\hline & & 4 & 30 & 0.751 & 0.018 & 0.710 & 0.779 \\
\hline & & 5 & 40 & 0.767 & 0.013 & 0.735 & 0.787 \\
\hline & & 6 & 30 & 0.776 & 0.011 & 0.748 & 0.792 \\
\hline & & 7 & 12 & 0.784 & 0.008 & 0.770 & 0.793 \\
\hline & & 8 & 2 & 0.790 & NA & 0.790 & 0.790 \\
\hline & \multirow{7}{*}{$\begin{array}{l}\text { Comparison C: } \\
\text { Location and } \\
\text { study area }\end{array}$} & 2 & 2 & 0.787 & 0.002 & 0.785 & 0.788 \\
\hline & & 3 & 12 & 0.808 & 0.016 & 0.786 & 0.830 \\
\hline & & 4 & 30 & 0.823 & 0.014 & 0.791 & 0.843 \\
\hline & & 5 & 40 & 0.835 & 0.011 & 0.806 & 0.853 \\
\hline & & 6 & 30 & 0.843 & 0.008 & 0.819 & 0.858 \\
\hline & & 7 & 12 & 0.849 & 0.008 & 0.838 & 0.862 \\
\hline & & 8 & 2 & 0.858 & 0.008 & 0.852 & 0.864 \\
\hline \multirow{21}{*}{$\frac{\mathscr{\varpi}}{\sum^{\frac{\pi}{\Sigma}}}$} & \multirow{7}{*}{$\begin{array}{l}\text { Comparison A: } \\
\text { Location and } \\
\text { home range }\end{array}$} & 2 & 2 & 0.625 & 0.004 & 0.622 & 0.628 \\
\hline & & 3 & 12 & 0.635 & 0.007 & 0.622 & 0.646 \\
\hline & & 4 & 30 & 0.645 & 0.006 & 0.635 & 0.660 \\
\hline & & 5 & 40 & 0.653 & 0.007 & 0.642 & 0.668 \\
\hline & & 6 & 30 & 0.660 & 0.006 & 0.650 & 0.671 \\
\hline & & 7 & 12 & 0.666 & 0.005 & 0.660 & 0.672 \\
\hline & & 8 & 2 & 0.672 & 0.001 & 0.672 & 0.672 \\
\hline & \multirow{7}{*}{$\begin{array}{l}\text { Comparison B: } \\
\text { Home range and } \\
\text { study area }\end{array}$} & 2 & 2 & 0.658 & 0.001 & 0.658 & 0.659 \\
\hline & & 3 & 12 & 0.691 & 0.026 & 0.658 & 0.739 \\
\hline & & 4 & 30 & 0.712 & 0.023 & 0.678 & 0.746 \\
\hline & & 5 & 40 & 0.726 & 0.018 & 0.693 & 0.748 \\
\hline & & 6 & 30 & 0.738 & 0.014 & 0.704 & 0.754 \\
\hline & & 7 & 12 & 0.745 & 0.009 & 0.725 & 0.755 \\
\hline & & 8 & 2 & 0.749 & NA & 0.749 & 0.749 \\
\hline & \multirow{7}{*}{$\begin{array}{l}\text { Comparison C: } \\
\text { Location and } \\
\text { study area }\end{array}$} & 2 & 2 & 0.765 & 0.007 & 0.760 & 0.770 \\
\hline & & 3 & 12 & 0.791 & 0.019 & 0.772 & 0.821 \\
\hline & & 4 & 30 & 0.808 & 0.016 & 0.781 & 0.827 \\
\hline & & 5 & 40 & 0.822 & 0.010 & 0.795 & 0.833 \\
\hline & & 6 & 30 & 0.828 & 0.008 & 0.805 & 0.837 \\
\hline & & 7 & 12 & 0.834 & 0.004 & 0.826 & 0.839 \\
\hline & & 8 & 2 & 0.838 & NA & 0.838 & 0.838 \\
\hline
\end{tabular}




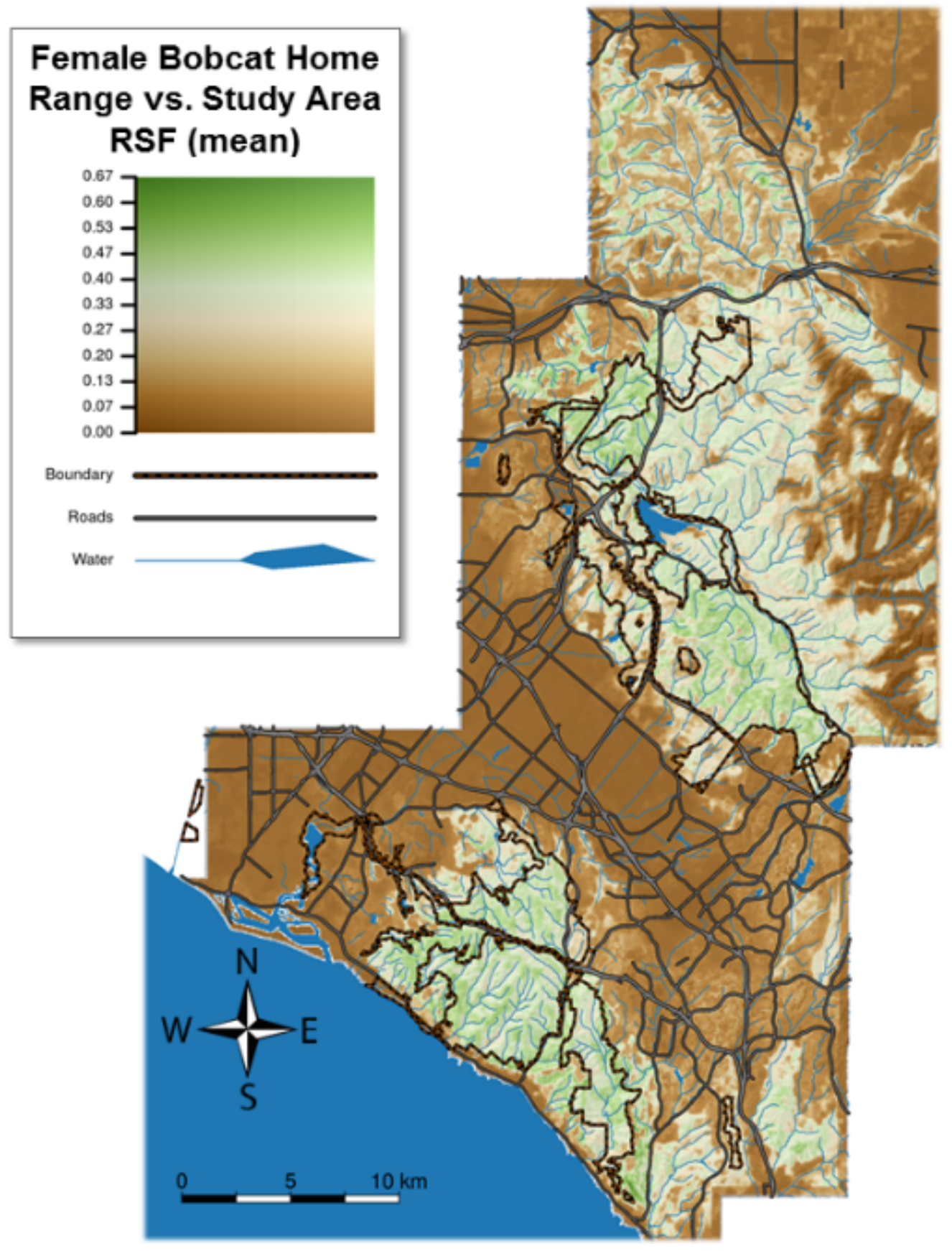

Figure 23. Image showing mean of the best Resource Selection Function (RSF) models for female bobcats based on home range compared to study area (Comparison B), in Orange County, southern California. Orange County Central and Coastal Natural Communities Conservation Plan/Habitat Conservation Plan boundaries and major roads are shown at 28-meter resolution. 


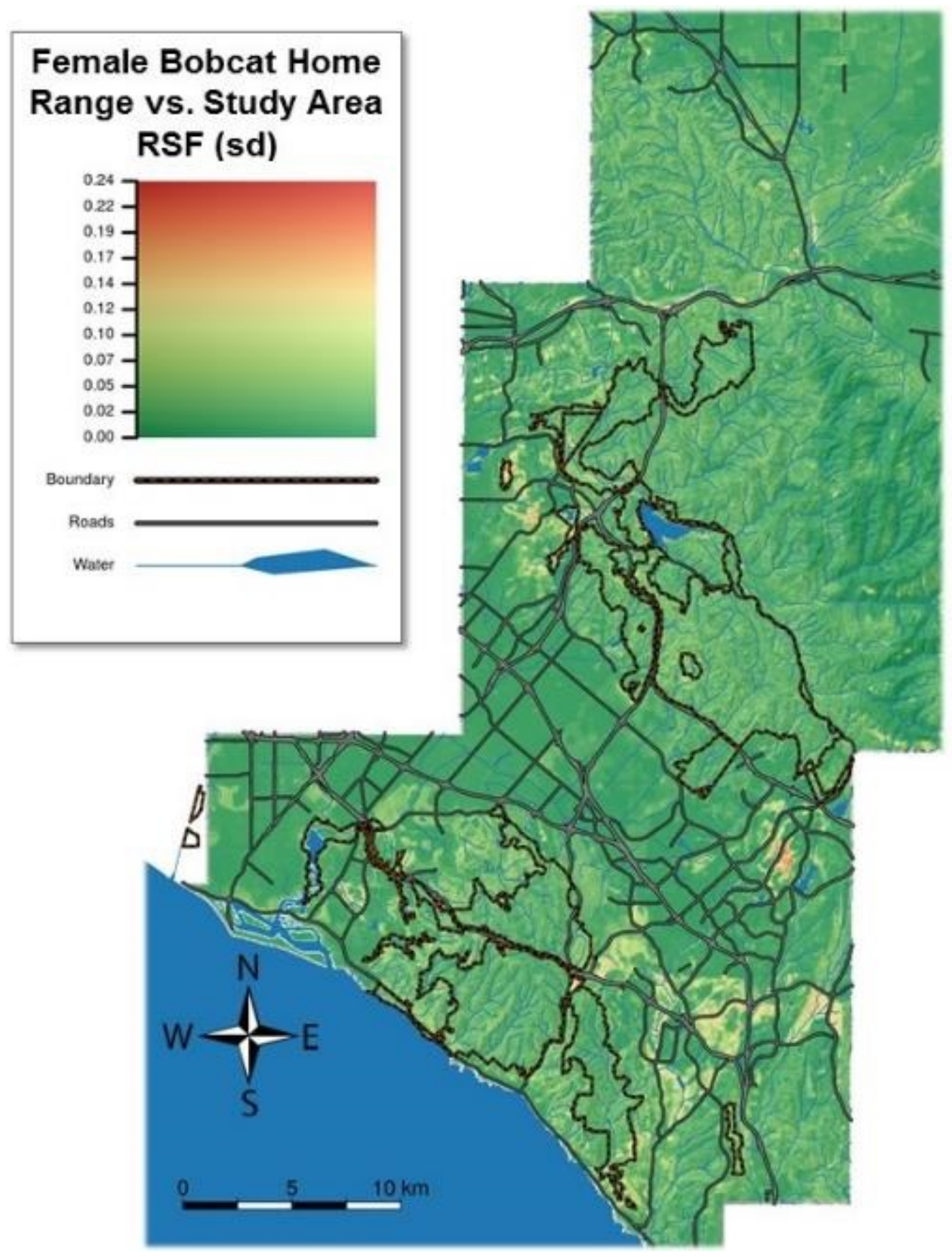

Figure 24. Image showing standard deviation (sd) of the mean for the best female bobcat Resource Selection Function (RSF) models based on home range compared to study area (Comparison B), in Orange County, southern California. Orange County Central and Coastal Natural Communities Conservation Plan/Habitat Conservation Plan boundaries and major roads are shown at 28-meter resolution. 


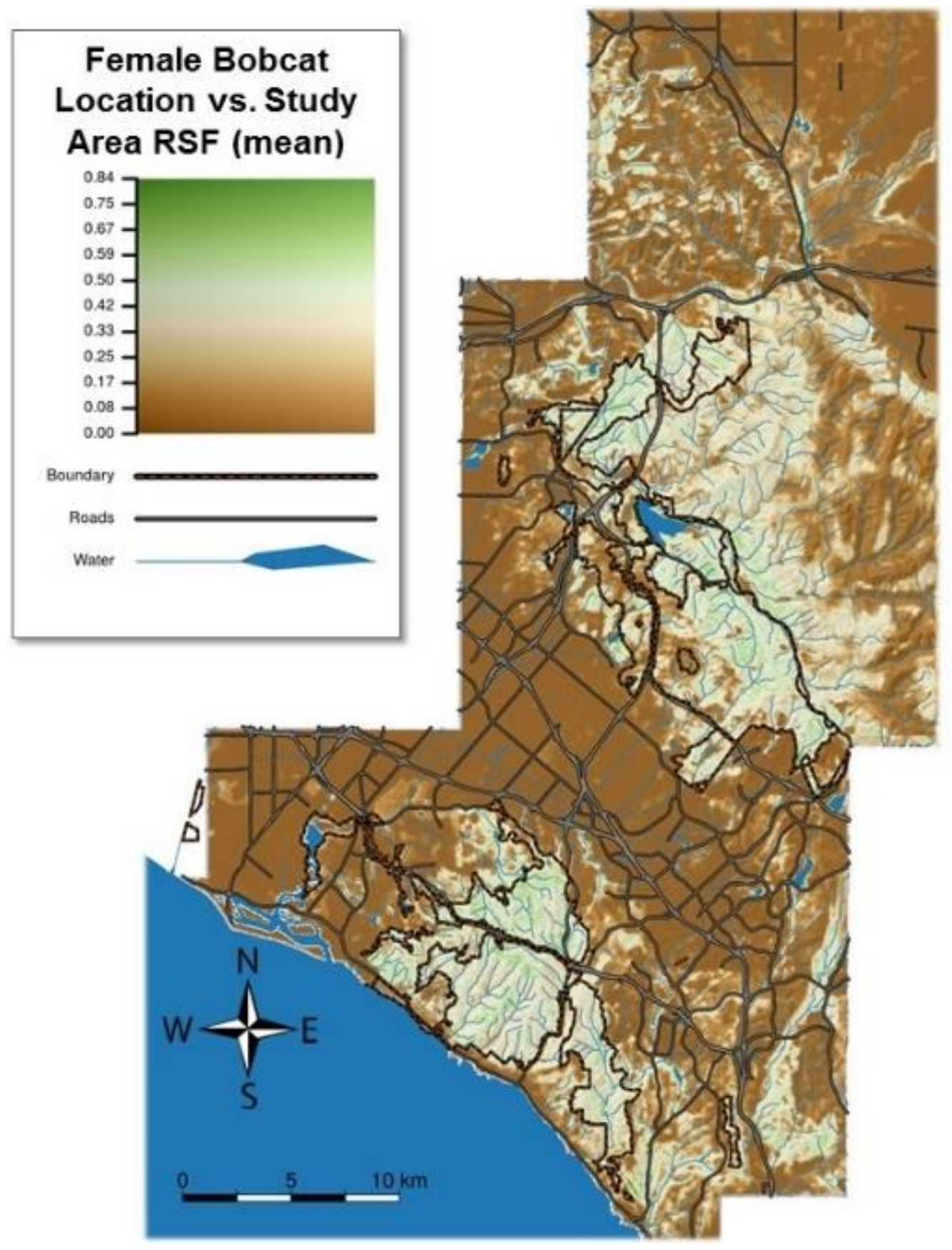

Figure 25. Image showing mean probability of use of the best Resource Selection Function (RSF) models for female bobcats based on Global Positioning System locations compared to study area (Comparison C), in Orange County, southern California. Orange County Central and Coastal Natural Communities Conservation Plan/Habitat Conservation Plan boundaries and major roads are shown at 28-meter resolution. 


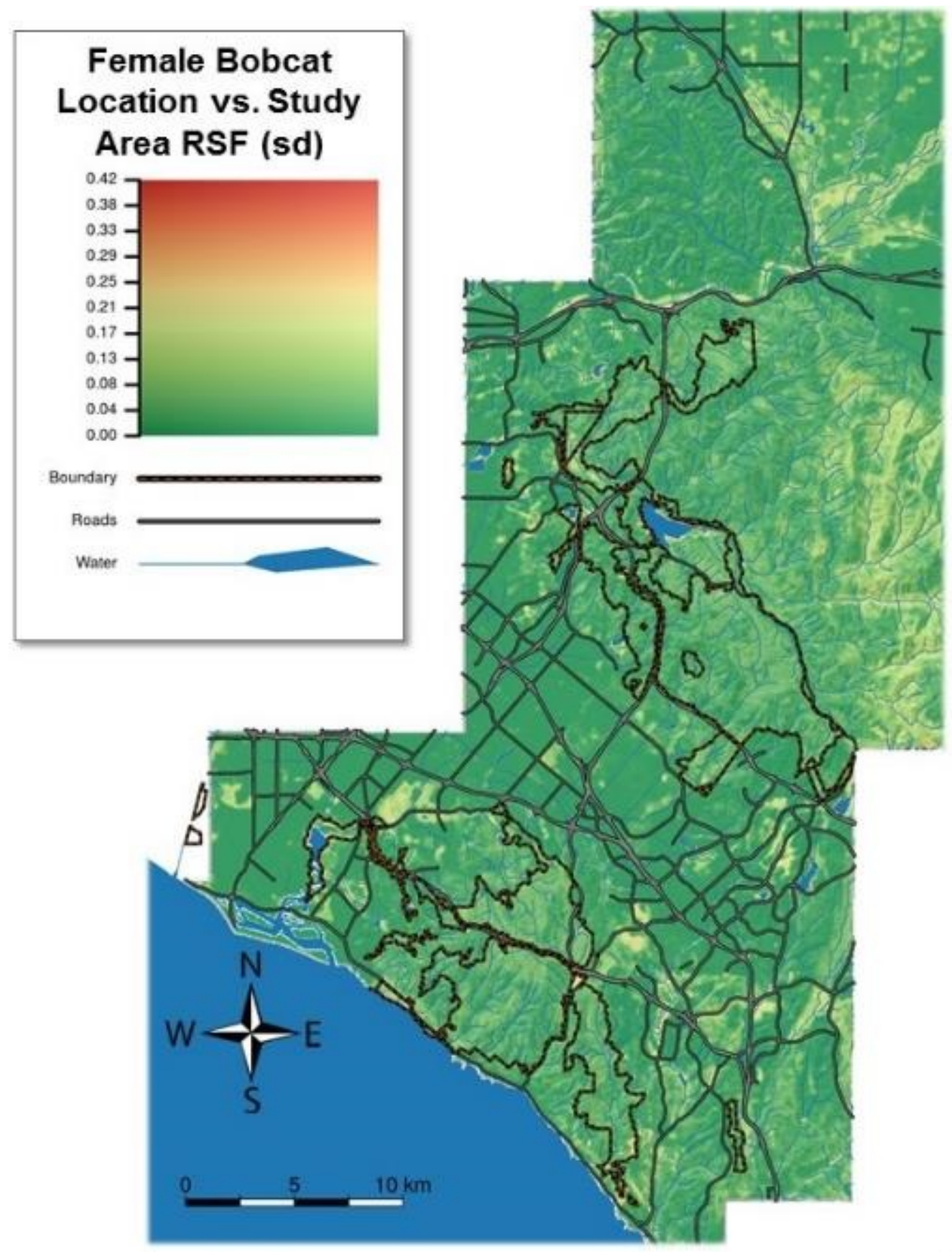

Figure 26. Image showing standard deviation (sd) of the mean probability of use of the best Resource Selection Function (RSF) models for female bobcats based on Global Positioning System locations compared to study area (Comparison C), in Orange County, southern California. Orange County Central and Coastal Natural Communities Conservation Plan/Habitat Conservation Plan boundaries and major roads are shown at 28-meter resolution. 


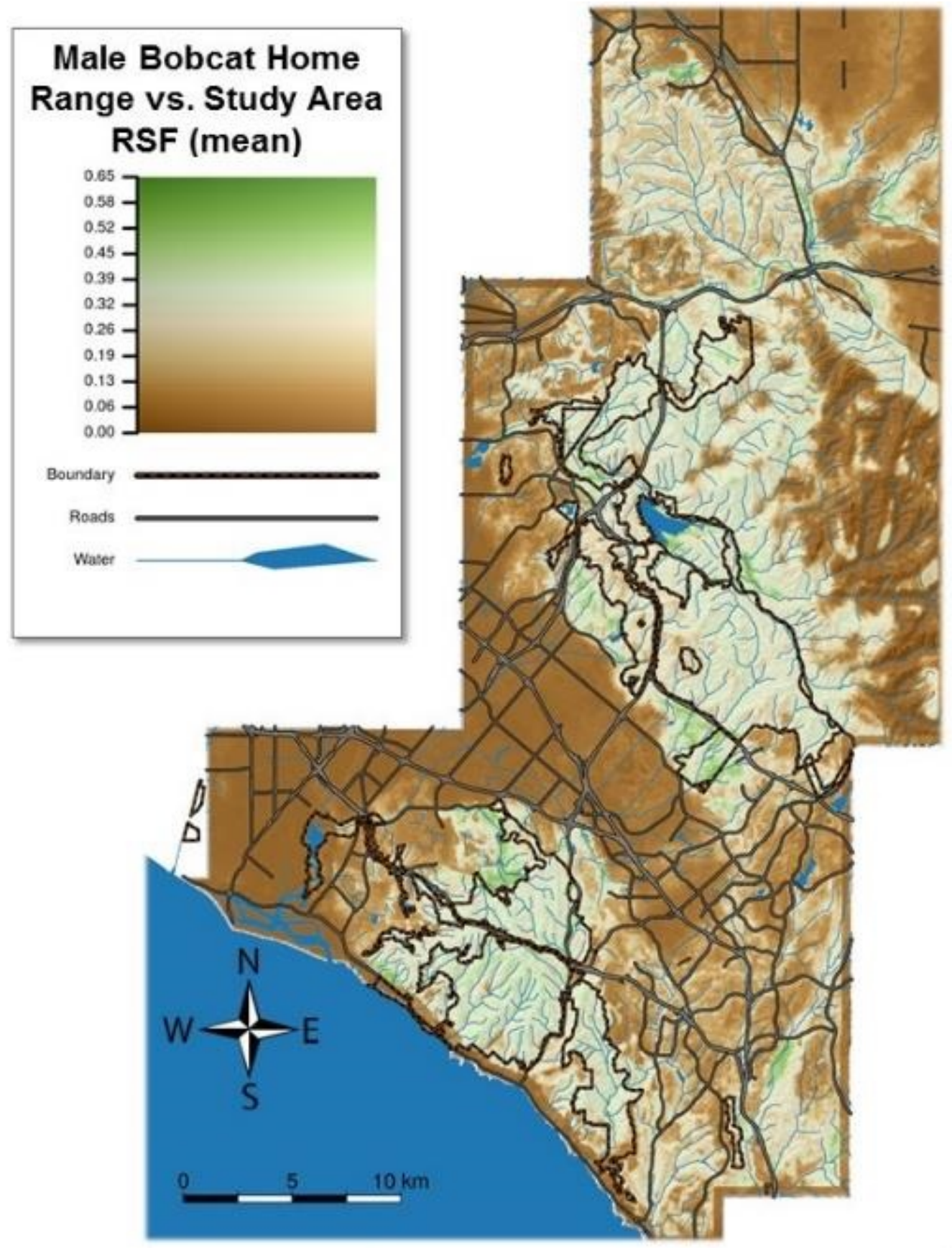

Figure 27. Image showing mean probability of use of the best Resource Selection Function (RSF) models for male bobcats based on home range compared to study area (Comparison B), in Orange County, southern California. Orange County Central and Coastal Natural Communities Conservation Plan/Habitat Conservation Plan boundaries and major roads are shown at 28-meter resolution. 


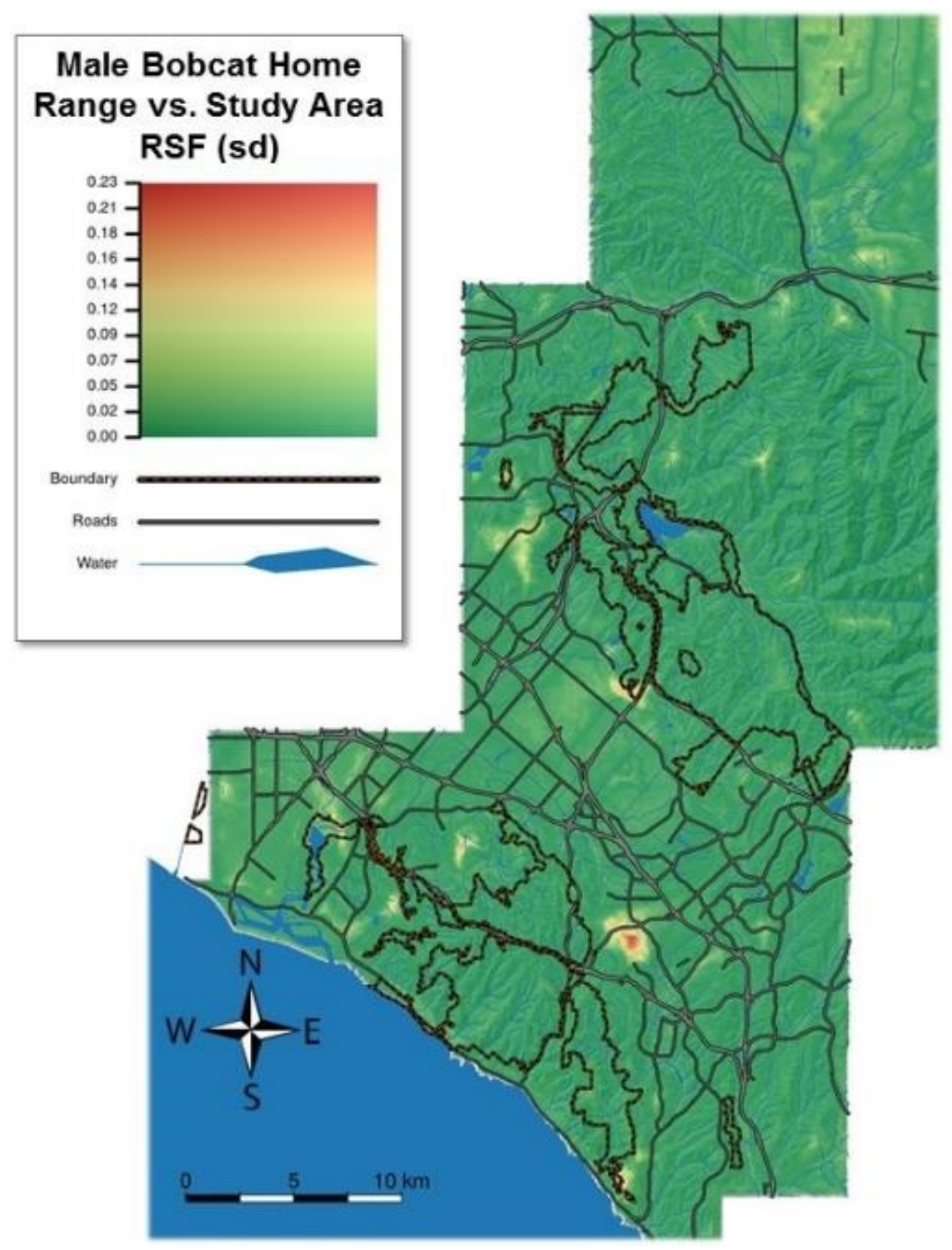

Figure 28. Image showing standard deviation (sd) of the mean probability of use for the best male bobcat Resource Selection Function (RSF) models based on home range compared to study area (Comparison B), in Orange County, southern California. Orange County Central and Coastal Natural Communities Conservation Plan/Habitat Conservation Plan boundaries and major roads are shown at 28-meter resolution. 


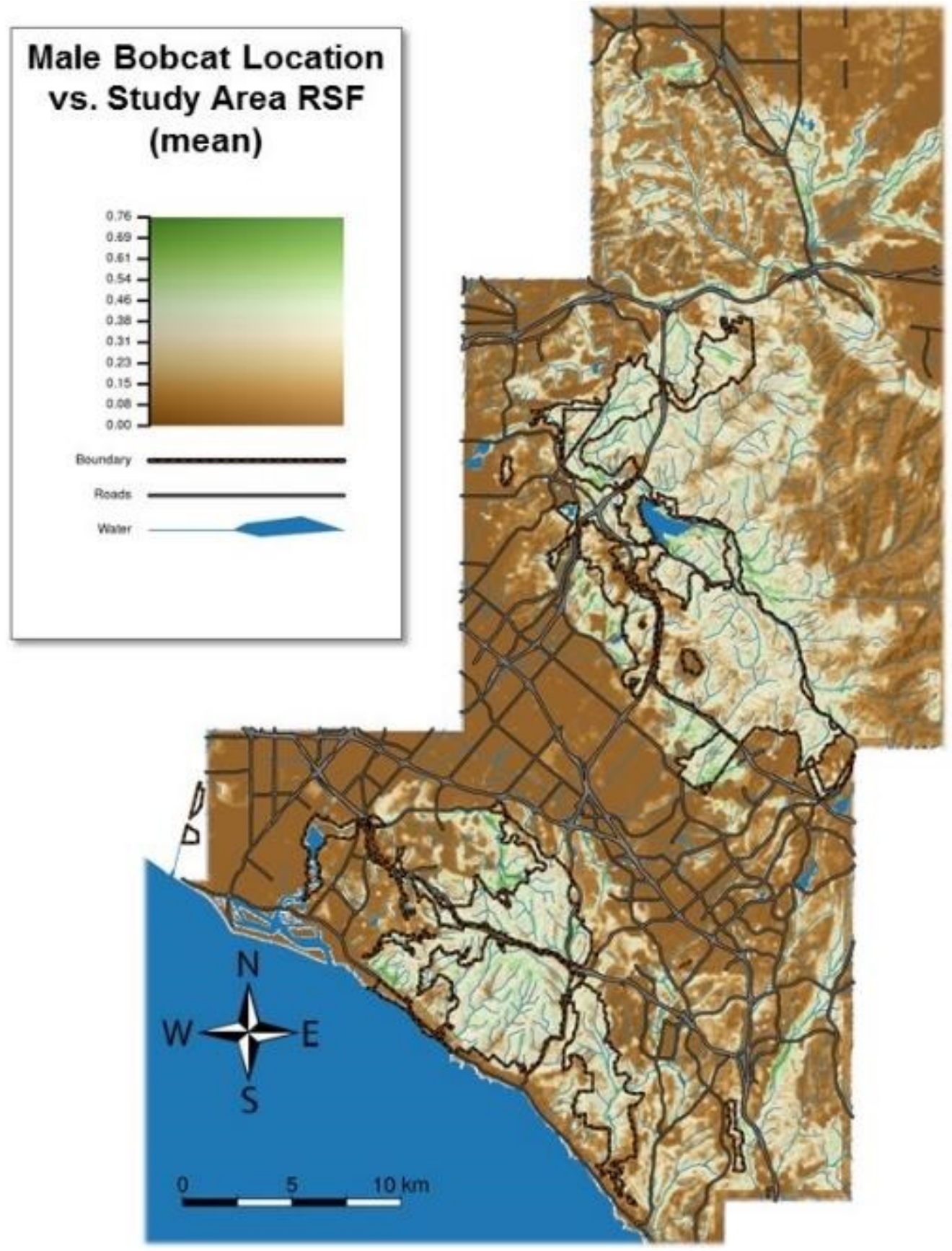

Figure 29. Image showing mean probability of use of the best Resource Selection Function (RSF) models for male bobcats based on Global Positioning System locations compared to study area (Comparison C), in Orange County, southern California. Orange County Central and Coastal Natural Communities Conservation Plan/Habitat Conservation Plan boundaries and major roads are shown at 28-meter resolution. 


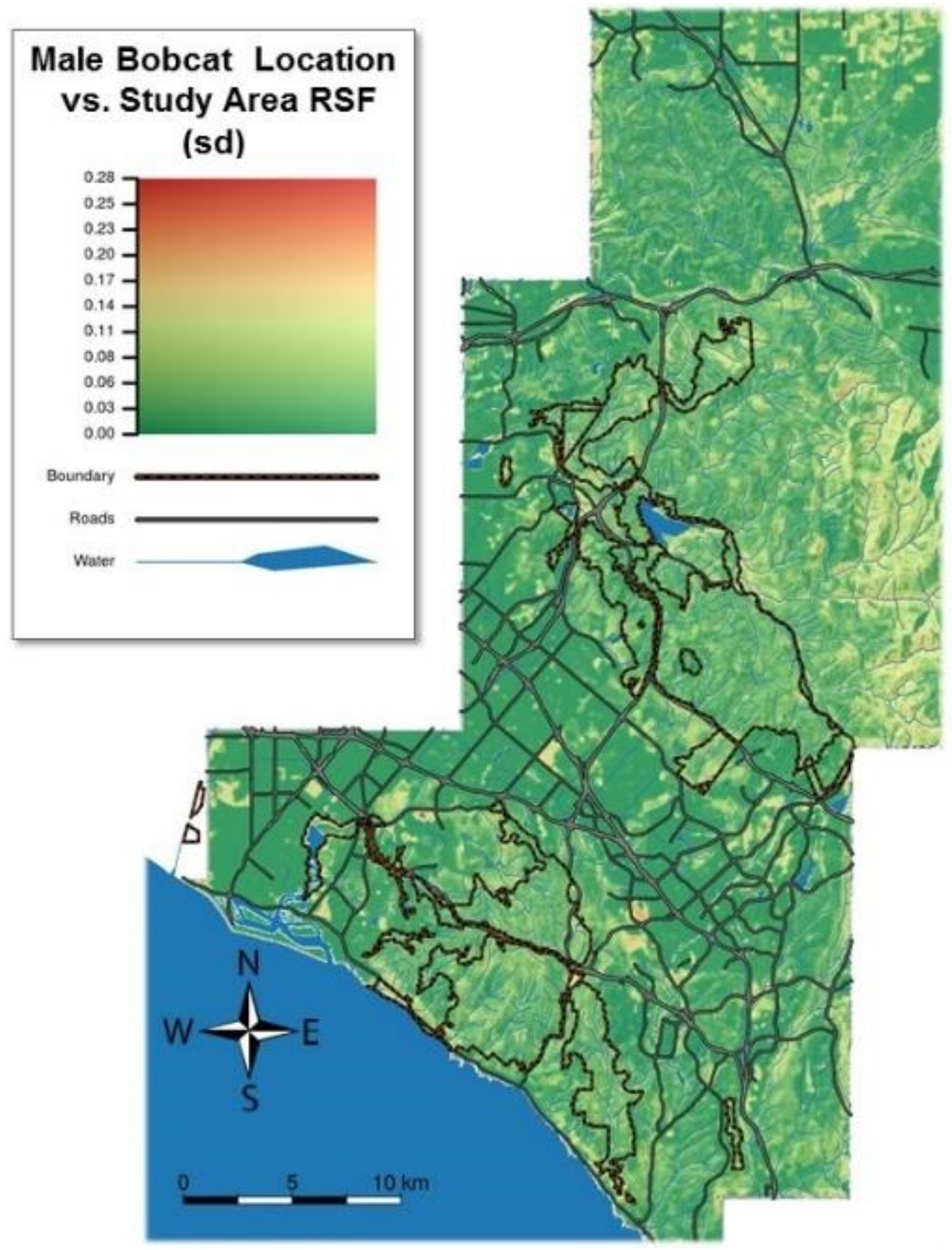

Figure 30. Image showing standard deviation (sd) of the mean probability of use of the best Resource Selection Function (RSF) models for male bobcats based on Global Positioning System locations compared to study area (Comparison C), in Orange County, southern California. Orange County Central and Coastal Natural Communities Conservation Plan/Habitat Conservation Plan boundaries and major roads are shown at 28-meter resolution. 


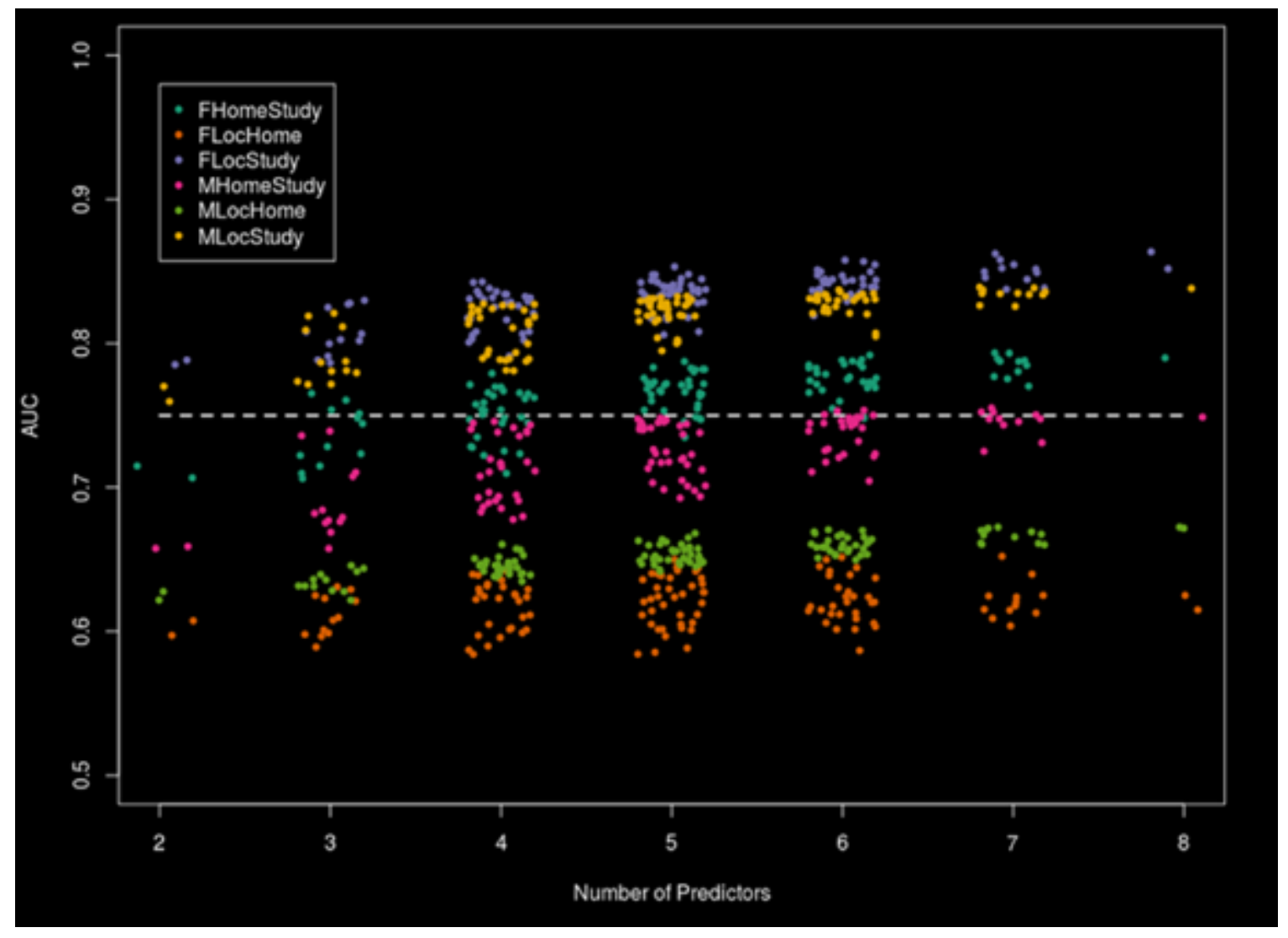

Figure 31. Scatterplot of area under the curve (AUC) values compared to the number of predictors for each of three model comparisons by sex. Results for models based on data for females are shown as (1) FHomeStudy, teal dots $=$ females, home range compared to study area $($ Comparison B); FLocHome, orange dots $=$ females, locations compared to home range (Comparison A); and FLocStudy, purple dots = females, locations compared to study area (Comparison $\mathrm{C}$ ). Results for models based on data for males are shown as MHomeStudy, pink dots = males, home range compared to study area (Comparison B); MLocHome, green dots = males, locations compared to home range (Comparison A); and MLocStudy, yellow dots = males, locations compared to study area (Comparison $\mathrm{C}$ ). Horizontal dashed line is at $\mathrm{AUC}=0.75$, the minimum acceptable threshold for model performance. 


\title{
Modeling for Reptile, Amphibian, and Bird Distributions
}

\author{
By Jeff A. Tracey, Kristine L. Preston, Carlton J. Rochester, Erin E. Boydston, and Robert N. Fisher
}

\section{Reptiles and Amphibians}

We used species distribution models (SDMs) conceived by Franklin (2010) and applied to 24 reptiles and five amphibians by Franklin and others (2009; table 4) that were relevant to the study area to indicate predicted occurrence and to estimate species richness for particular groups of species. Field data for the SDMs were collected between 1995 and 2008 by Fisher and others (2008) as part of ongoing herpetofauna pitfall surveys. Data from 591 pitfall arrays were used, and SDMs were developed for those species detected in $>5$ percent of the arrays.

For each amphibian or reptile species, a GAM (Wood, 2006) and a Random Forest (RF; Cutler and others, 2007) approach were used. Environmental covariates developed during previous research (Franklin and others, 2009; Syphard and Franklin, 2010) —including mean January minimum temperature, mean July maximum temperature, mean annual precipitation, mean summer solstice solar radiation, slope gradient, soil order, available water capacity, soil depth, soil pH (STATSGO), and vegetation (CalVeg) - were used in the GAMs and RF models. Model prediction performance was evaluated using the AUC for ROC plots (Hanley and McNeil, 1982). The model (GAM compared to $\mathrm{RF}$ ) with the highest AUC was used as the final model to predict the distribution of each species. The probability of presence for the 29 species was summed to yield predicted herpetofauna species richness.

\section{Chaparral and Coast Sage Scrub Birds}

We used SDMs based on presence-only data for six bird species in southern California that were associated with California coast sage scrub and chaparral habitats (Tracey and others, 2018; table 4). Locations for birds included records from U.S. Fish and Wildlife Service, California Natural Diversity Database, U.S. Geological Survey, San Diego County regional species database, Natural Community Conservation Plan surveys, and ORNIS online database (www.ornisnet.org), collected between about 1997 and 2011. An environmental variable grid of points spaced $150 \mathrm{~m}$ apart across southern California was constructed, and climatic, topographic, and land-cover variables were calculated at each grid point (Tracey and others, 2018). We removed spatially redundant bird location records and used a spatial balanced subsampling strategy (Knick and others, 2013), randomly subsampling 20-50 locations by subregion in each of 1,000 iterations and averaging model results.

We constructed alternative models with different combinations of environmental variables using the partitioned Mahalanobis D2 modeling approach (Rotenberry and others, 2006). We compared among habitat similarity index (HSI) median validation predictions (ranging from 0 [least suitable] to 1.0 [most suitable]) and AUC values to select the best-performing model for each species. We then summed HSI values across species to obtain a predictor of species richness at each grid point. 
Table 4. Species for which species distribution models were available; general taxonomic group; priority designation of target species, identified species, or species of interest in Orange County Central and Coastal Natural Communities Conservation Plan/Habitat Conservation Plan (NCCP/HCP); and common name for NCCP/HPC species, Orange County, southern California.

\begin{tabular}{|c|c|c|c|}
\hline Scientific name & Taxon & NCCP status & Common name \\
\hline Aspidoscelis hyperythra & Lizard & Target species & Orange-throated whiptail \\
\hline Aspidoscelis tigris & Lizard & None & Coast whiptail \\
\hline Batrachoseps major & Amphibian & None & Garden slender salamander \\
\hline Batrachoseps nigriventris & Amphibian & None & Black-bellied slender salamander \\
\hline Bufo boreas & Amphibian & None & California toad \\
\hline Coleonyx variegatus & Lizard & Species of interest & San Diego banded gecko \\
\hline Coluber mormon & Snake & None & Western yellow-bellied racer \\
\hline Crotalus oreganus & Snake & None & Southern Pacific rattlesnake \\
\hline Crotalus ruber & Snake & None & Red diamond rattlesnake \\
\hline Elgaria multicarinata & Lizard & None & Alligator lizard \\
\hline Plestiodon gilberti & Lizard & None & Red-tailed skink \\
\hline Plestiodon skiltonianus & Lizard & Identified species & Coronado skink \\
\hline Hypsiglena torquata & Snake & None & Nightsnake \\
\hline Lampropeltis getula & Snake & None & California kingsnake \\
\hline Leptotyphlops humilis & Snake & None & Threadsnake; blind snake \\
\hline Lichanura orcutti & Snake & None & Northern three-lined boa \\
\hline Masticophis flagellum & Snake & None & Red racer, coachwhip \\
\hline Masticophis lateralis & Snake & None & California striped racer \\
\hline Phrynosoma coronatum & Lizard & None & Horned lizard \\
\hline Pituophis catenifer & Snake & None & Gopher snake \\
\hline Pseudacris regilla & Amphibian & None & Pacific treefrog \\
\hline Rhinocheilus lecontei & Snake & None & Long-nosed snake \\
\hline Salvadora hexalepis & Snake & Species of interest & Coast patch-nosed snake \\
\hline Sceloporus occidentalis & Lizard & None & Fence lizard \\
\hline Sceloporus orcutti & Lizard & None & Granite spiny lizard \\
\hline Spea hammondii & Amphibian & None & Western spadefoot \\
\hline Tantilla planiceps & Snake & None & Western black-headed snake \\
\hline Thamnophis hammondii & Snake & Species of interest & Two-striped garter snake \\
\hline Uta stansburiana & Lizard & None & Side-blotched lizard \\
\hline Campylorhynchus brunneicapillus & Bird & Target species & Coastal cactus wren \\
\hline Polioptila californica & Bird & Target species & Coastal California gnatcatcher \\
\hline Toxostoma redivivum & Bird & None & California thrasher \\
\hline Calypte costae & Bird & None & Costa's hummingbird \\
\hline Amphispiza belli & Bird & Species of interest & Bell's sage sparrow \\
\hline Chamaea fasciata & Bird & None & Wrentit \\
\hline
\end{tabular}




\section{Implementation and Interpretation}

We cropped each species distribution raster and rescaled it using bilinear interpolation to match our RU raster (using functions from the R raster package). We then grouped species by general taxonomic categories or NCCP species status, and combined the rasters of the species to produce a single generalized distribution or prediction of species richness for that group. The species with SDM data available were grouped as follows: (1) taxonomically-amphibians (5 species), lizards (10 species), snakes (14 species), and birds (6 species); and (2) by NCCP management priority - target species ( 2 species), identified species (1 species), and species of interest (4 species).

The combined raster for five species of amphibians for which SDMs were available indicated that within the NCCP, the highest biodiversity appeared to be across the Coastal Subregion, although away from the coastline (fig. 32). The Central Subregion appeared to have captured some areas of high value for amphibians relative to the surrounding landscape. Within the study area, the Prado Basin riparian habitat had high amphibian species richness. Snake diversity appeared higher outside the NCCP than within it (fig. 33).

Prado Basin showed the highest snake species richness within the study area. Other low-lying, relatively flat areas had intermediate values for diversity. Lizard species richness was relatively low in the Coastal Subregion but inland NCCP lands and mountainous terrain showed higher modeled species richness from the combined SDMs (fig. 34). In contrast to the varied images for herptofauna (all of which contrasted with bobcat models), the species richness raster image for six bird species more closely matched bobcat model predictions and NCCP/HCP design (fig. 35).

A combined raster for the three target species for which SDMs were available (orange-throated whiptail lizard, Aspidoscelis hyperythra; coastal cactus wren, Campylorhynchus brunneicapillus; and coastal California gnatcatcher, Polioptila californica californica) suggested that areas adjacent to the NCCP/HCP might have better potential habitat for these three species as a group (fig. 36). An SDM for the Coronado skink (Plestiodon skiltonianus), the one identified species for which these data were available, showed that much of the study area was potential habitat, with the Coastal Subregion having some of the highest-value area (fig. 37). There were SDMs for four NCCP species of interest (San Diego banded gecko [Coleonyx variegatus], Coast patch-nosed snake [Salvadora hexalepis], Twostriped garter snake [Thamnophis hammondii], and Bell's sage sparrow [Amphispiza belli belli]). Little of the study area appeared suited for all four species, but SDM raster values within the NCCP/HCP were higher than for the rest of the study area (fig. 38). 


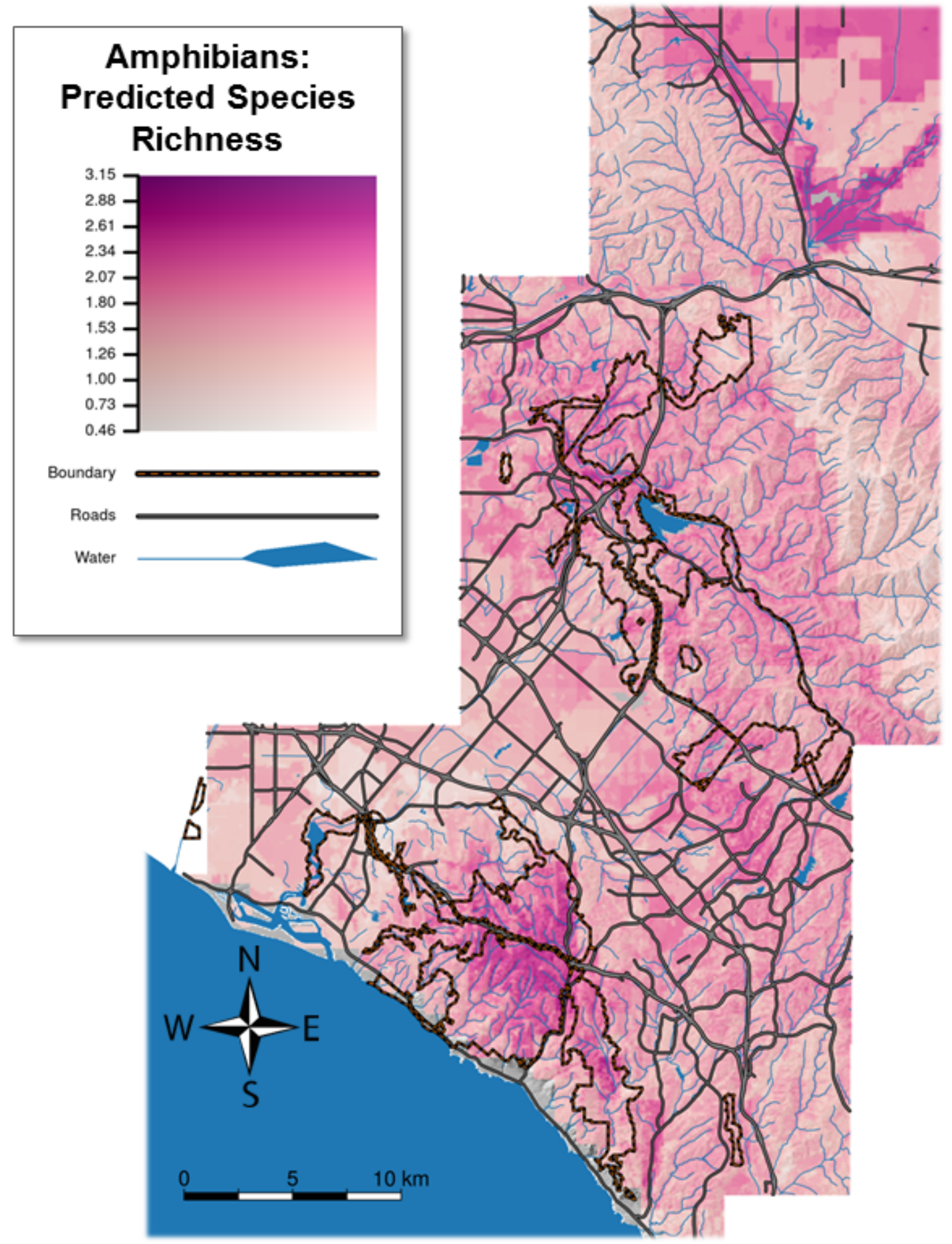

Figure 32. Image showing average predicted species richness for five amphibian species, indicating that a maximum of 3-4 of these species were likely to co-occur in a few concentrated areas, Orange County, southern California. Orange County Central and Coastal Natural Communities Conservation Plan/Habitat Conservation Plan boundaries and major roads are shown at 28-meter resolution. 


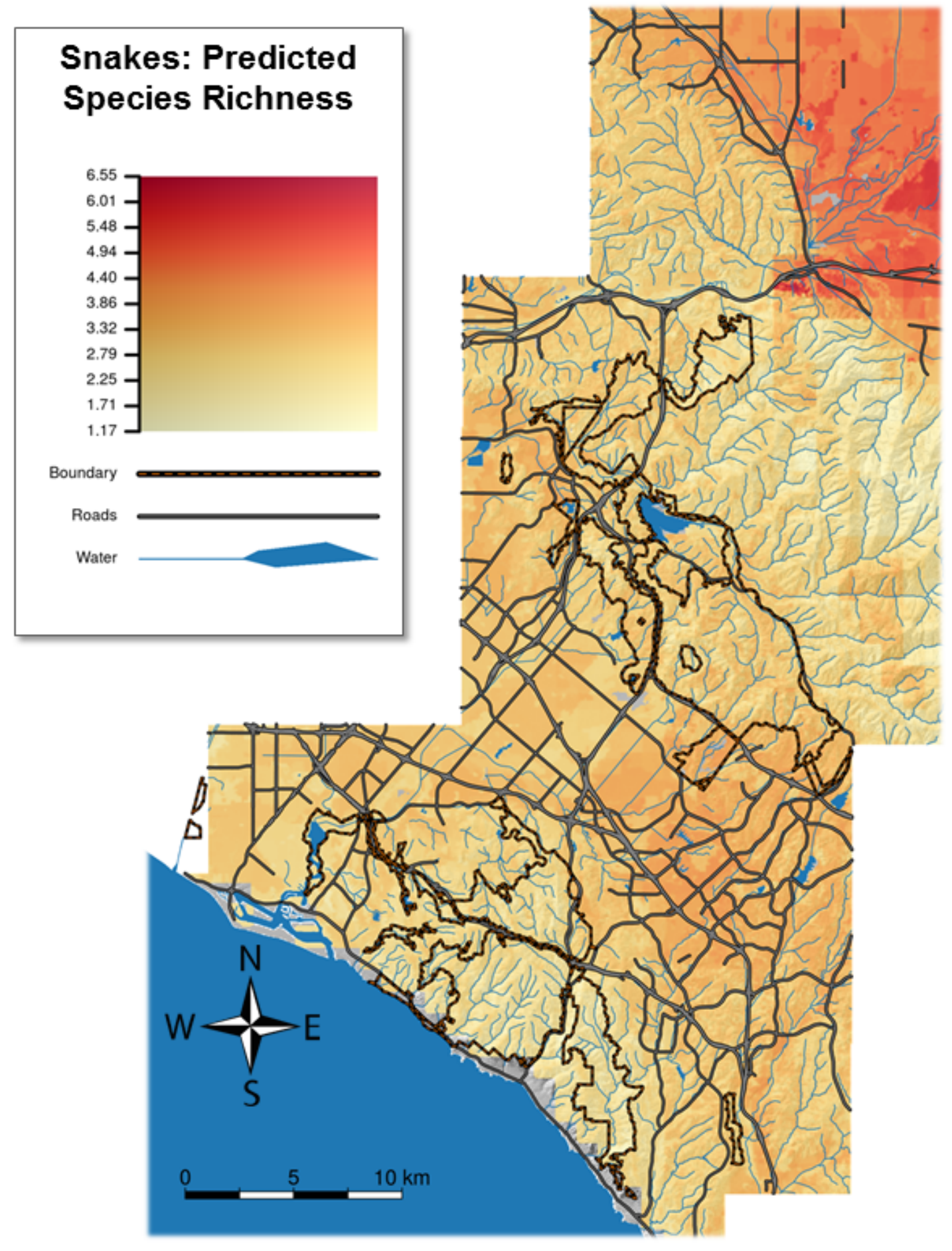

Figure 33. Image showing average predicted species richness for 14 snake species, in Orange County, southern California. A maximum of 6-7 species were likely to co-occur, and at least 1 snake was predicted for most of the study area. Orange County Central and Coastal Natural Communities Conservation Plan/Habitat Conservation Plan boundaries and major roads are shown at 28-meter resolution. 


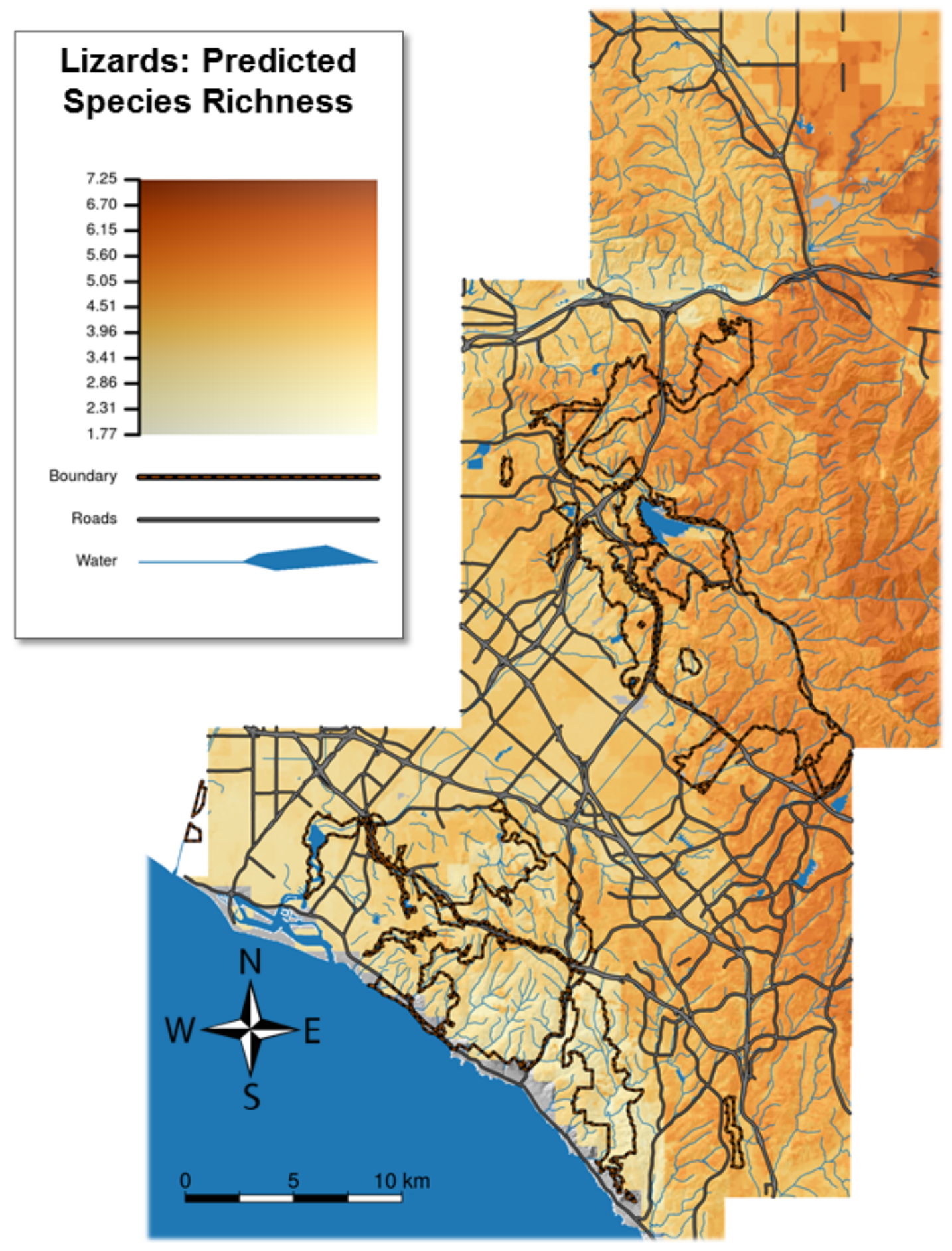

Figure 34. Image showing average predicted species richness for 10 lizard species, in Orange County, southern California. Most areas were predicted to have at least 2 species, with as many as 7-8 species likely to co-occur. Orange County Central and Coastal Natural Communities Conservation Plan/Habitat Conservation Plan boundaries and major roads are shown at 28-meter resolution. 


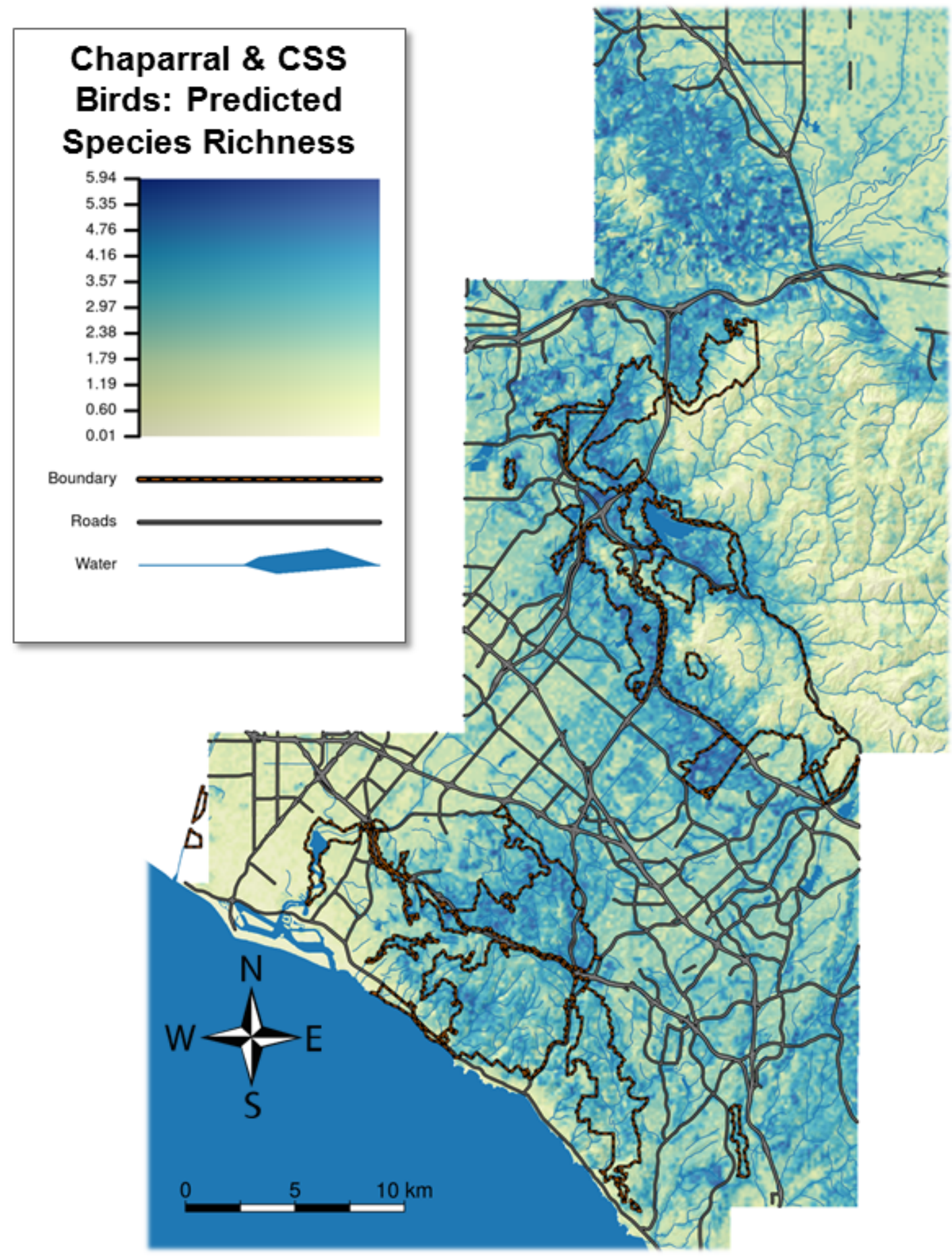

Figure 35. Image showing average predicted species richness for six bird species in chaparral and California coast sage scrub (CSS) habitats, indicating that there were areas where all six species were likely to co-occur, Orange County, southern California. Orange County Central and Coastal Natural Communities Conservation Plan/Habitat Conservation Plan boundaries and major roads are shown at 28-meter resolution. 


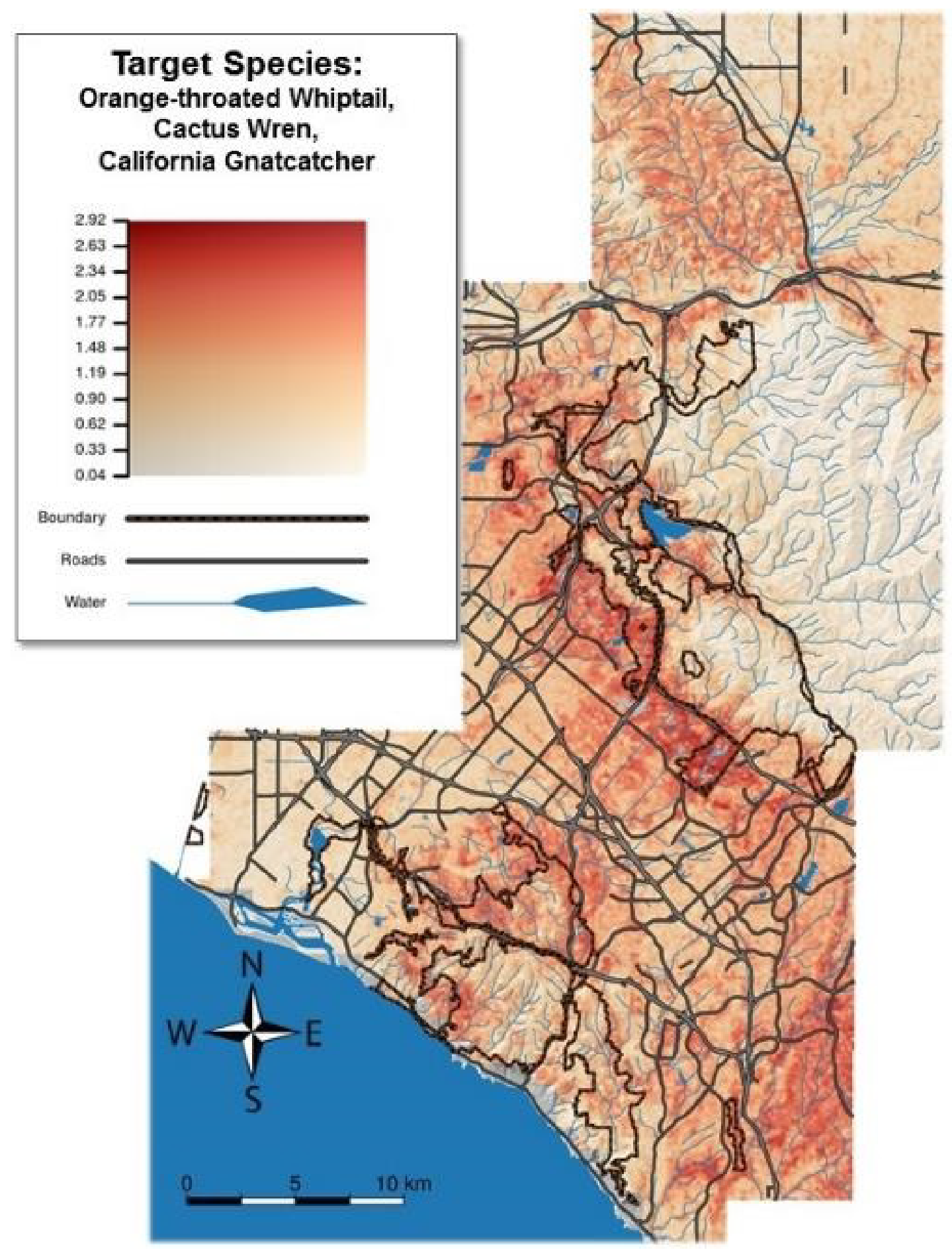

Figure 36. Image showing Combined Species Distribution Model for three target species in the Orange County Central and Coastal Natural Communities Conservation Plan/Habitat Conservation Plan (NCCP/HCP) (orangethroated whiptail lizard [Aspidoscelis hyperythra], cactus wren [Campylorhynchus brunneicapillus], and California gnatcatcher [Polioptila californica californica]), Orange County, southern California. NCCP/HCP boundaries and major roads are shown at 28-meter resolution. 


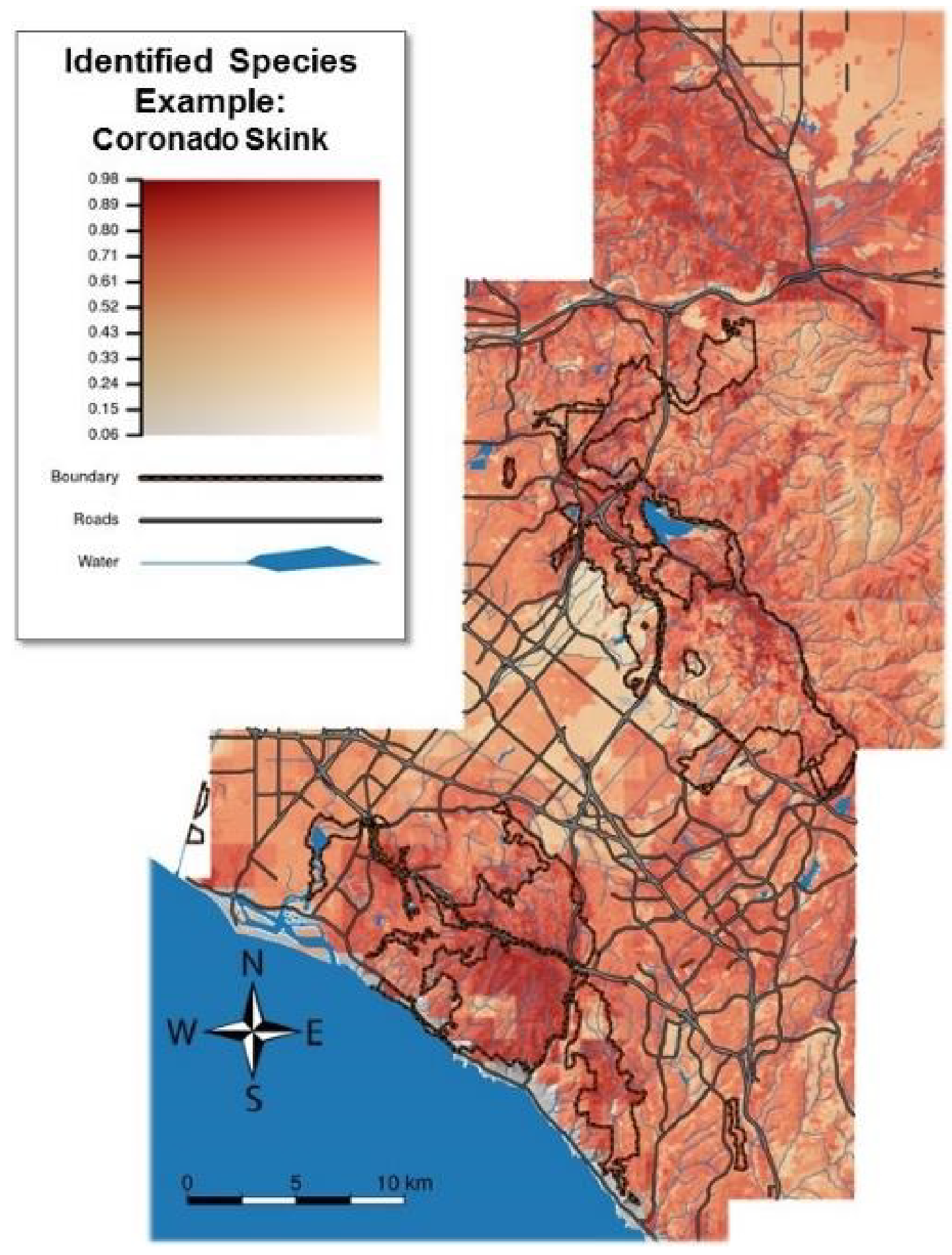

Figure 37. Image showing Species Distribution Model for one identified species in the Orange County Central and Coastal Natural Communities Conservation Plan/Habitat Conservation Plan (NCCP/HCP) (Coronado skink [Plestiodon skiltonianus]), Orange County, southern California. NCCP/HCP boundaries and major roads are shown at 28-meter resolution. 


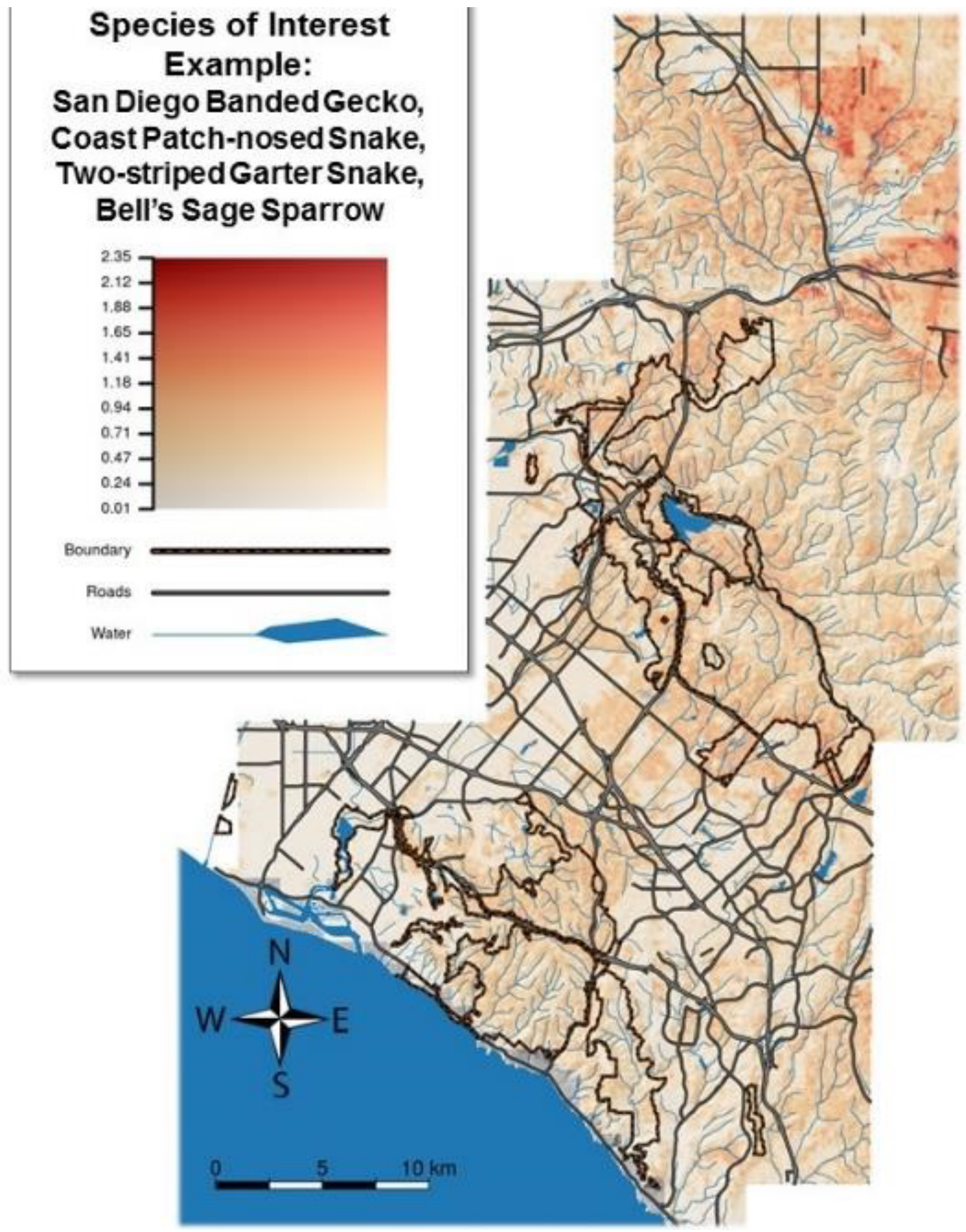

Figure 38. Image showing Combined Species Distribution Model for four species of interest in the Orange County Central and Coastal Natural Communities Conservation Plan/Habitat Conservation Plan (NCCP/HCP) (San Diego banded gecko [Coleonyx variegatus], coast patch-nosed snake [Salvadora hexalepis], two-striped garter snake [Thamnophis hammondii], and Bell's sage sparrow [Amphispiza belli belli]), Orange County, southern California. $\mathrm{NCCP} / \mathrm{HCP}$ boundaries and major roads are shown at 28-meter resolution. 


\section{A Spatially Explicit Filter for Identifying High-Value Areas}

To identify potential High-Value Areas (HVAs) for a particular species or for multiple species, we developed a method for making alternative decision-rule-trees to identify such areas through a stepwise filtering process of spatial data layers (fig. 39). Alternative decision models for HVAs can be proposed to capture a range of management considerations and test different assumptions. Spatial layers input into this filter process could be the raster layers acquired and generated here, such as environmental layers, bobcat RSF models, or SDMs for other vertebrates. Furthermore, HVAs may be based on landscape attributes and model outputs beyond those in this report.

We first proposed alternative models based on spatial attributes that might contribute to an HVA, with the attributes selected based on perceived importance for a particular species, component of biodiversity, or resource management target. We then represented alternative models as a set of rules that sequentially filtered out grid cells in a raster for inclusion in the HVA. For example, a set of rules could be used to (1) first identify raster cells more than $200 \mathrm{~m}$ from urban land use; (2) then among those cells, select cells with hilly terrain based on the unevenness values; (3) then select those cells that are within $500 \mathrm{~m}$ of a stream; and (4) finally select those cells with positive NDVI values. As general computer code, this set of rules could be written as a sequence of binary filtering steps:

1: IF (distance to urban $<200 \mathrm{~m}$ ) THEN return 0 ELSE goto 2

2: IF (unevenness $<1.1$ ) THEN return 1 ELSE goto 3

3: IF (distance to stream $>500 \mathrm{~m}$ ) THEN return 2 ELSE goto 4

4: IF (NDVI $<0)$ THEN return 3 ELSE return

We converted such general filtering sequences to $\mathrm{R}$ statistical computing language for processing in $\mathrm{R}$. After processing, the filter rules yielded spatial representations of proposed HVAs_— that is, raster images of high-value habitat areas as identified by alternative models for the HVA components. As a similar example, we filtered in this order:

1. Proportion to urban (undeveloped land),

2. Distance from a road,

3. If terrain was rolling and uneven,

4. If terrain was near a creek bed, and

5. Positive primary productivity (positive NDVI) (fig. 39).

The final raster output (fig. 40) identified areas that were relatively free of urban effects, hilly, near water courses, and had green vegetation. This final output layer can then be compared to steps along the tree, with each step indicating what areas were additionally removed by the filtering process.

Other applications of the filter from spatial layers in this report could include:

1. Examination of abiotic factors (fig. 41) to understand environmental variation in the absence of development or identify areas of extremes or greatest variation that might support particular elements of biodiversity or offer climate change refugia;

2. Identification of possible core areas for bobcats based on RSF results as areas that might be important for other species (fig. 42); and

3. Intersection of select vertebrate biodiversity based on species distribution models and RSFs (fig. 43), which could be used as hypotheses about biodiversity of unrepresented taxa.

To facilitate alternative rule sets, we provide here an example of R code (figs. 44 and 45) that can be adjusted depending on the spatial data layers and decision rules needed to address particular information and management questions. 
Output layers can be used further to assist with recreation management and identify potential areas for restoration. Recreation trails or other indicators of human activity can be intersected with filter results to identify areas where human activity approaches or overlaps HVAs. Areas considered for restoration could be based on proximity to HVAs and identified through the filter output, along with the step or steps that may be lacking to meet HVA criteria. Furthermore, the areas identified as containing high-value habitat can be compared to the boundaries of the NCCP/HCP to show the distribution of HVAs relative to protected lands to help determine management options based on the geography, connectivity, or other aspects of the HVAs. As landscape and management challenges change, these spatial layers and decision rules can be adjusted based on new information. Our approach thus establishes a general framework for identifying high-value habitat that can be used for current management decisions and refined in the future, depending on management interests and goals and the availability of suitable quality data or adequate surrogate information.
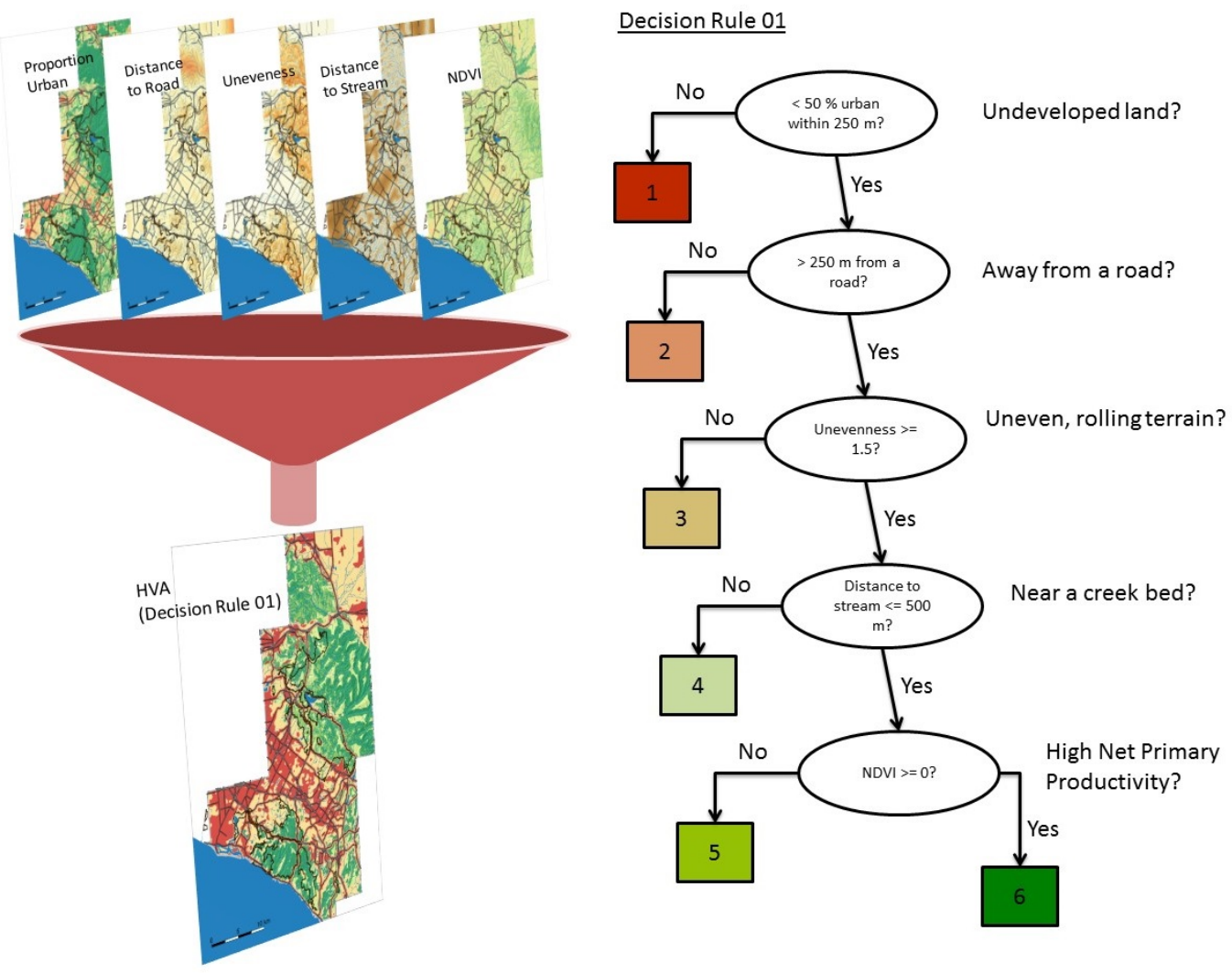

Figure 39. Diagram showing example of High-Value Area step-wise decision rule, with geographic information system layers for selected environmental variables passing through a virtual filter (left side) to yield an output layer (fig. 40) indicating which areas met the step-wise criteria used for filtering (right side). HVA, High-Value Area; NDVI, Normalized Difference Vegetation Index; $m$, meter; < less than; <=, less than or equal to; >, greater than; >=, greater than or equal to; \%, percent. 


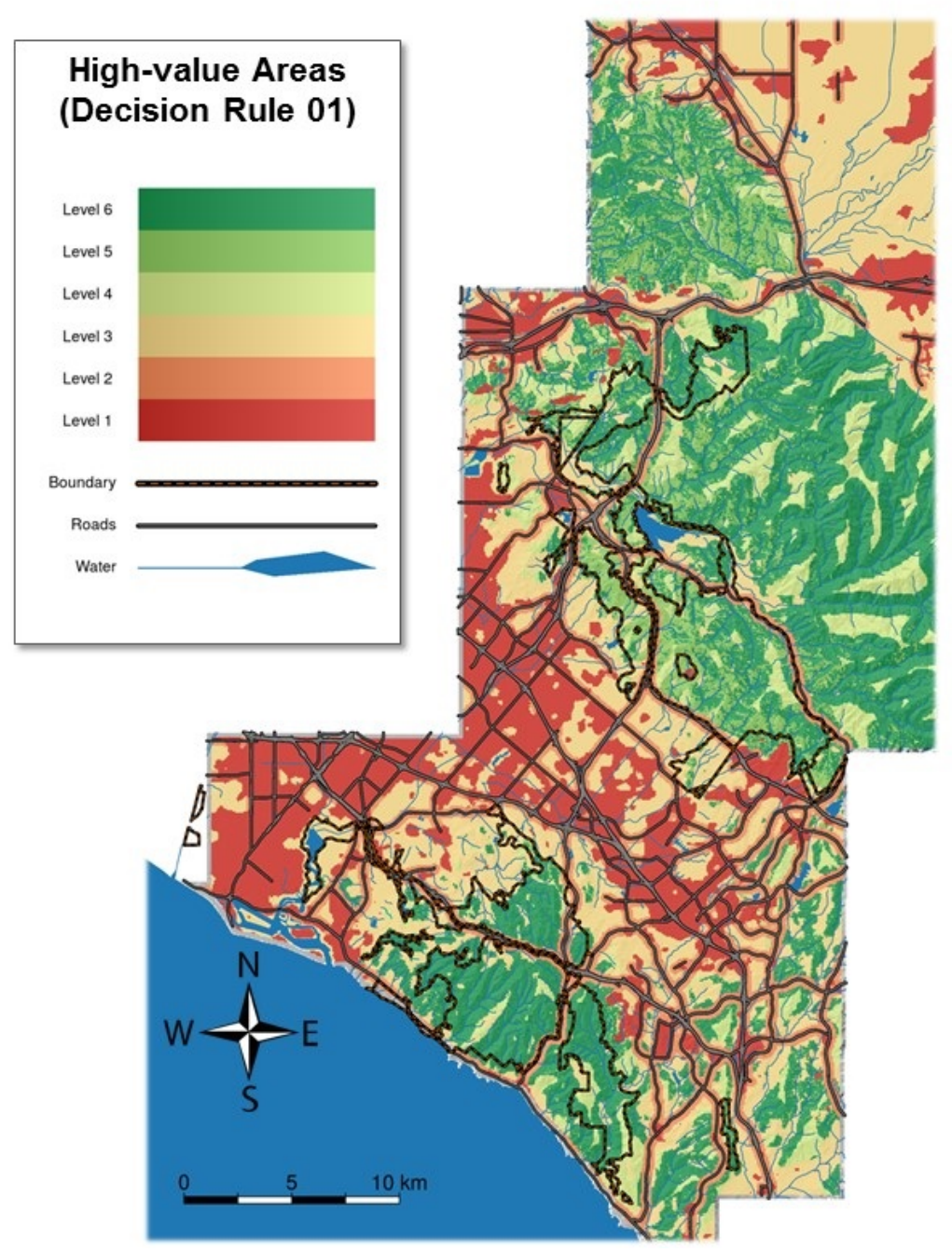

Figure 40. Image showing example output results of applying a step-wise decision rule (Decision Rule 01) to filter five input layers to depict a possible scenario for determining High-Value Areas in Orange County, southern California. Levels indicate input layers and filter rules as follows: Level 1, more than 50-percent urban per pixel; Level 2, undeveloped (less than 50-percent urban) but near a road; Level 3, flat, undeveloped land, away from a road; Level 4, undeveloped, uneven terrain away from a road, not near a creek bed; Level 5, undeveloped, uneven terrain away from a road, near a creek bed; and Level 6, undeveloped, uneven terrain away from a road, near a creek, with Normalized Difference Vegetation Index greater than 0 . Orange County Central and Coastal Natural Communities Conservation Plan/Habitat Conservation Plan boundaries and major roads are shown at 28meter resolution. 


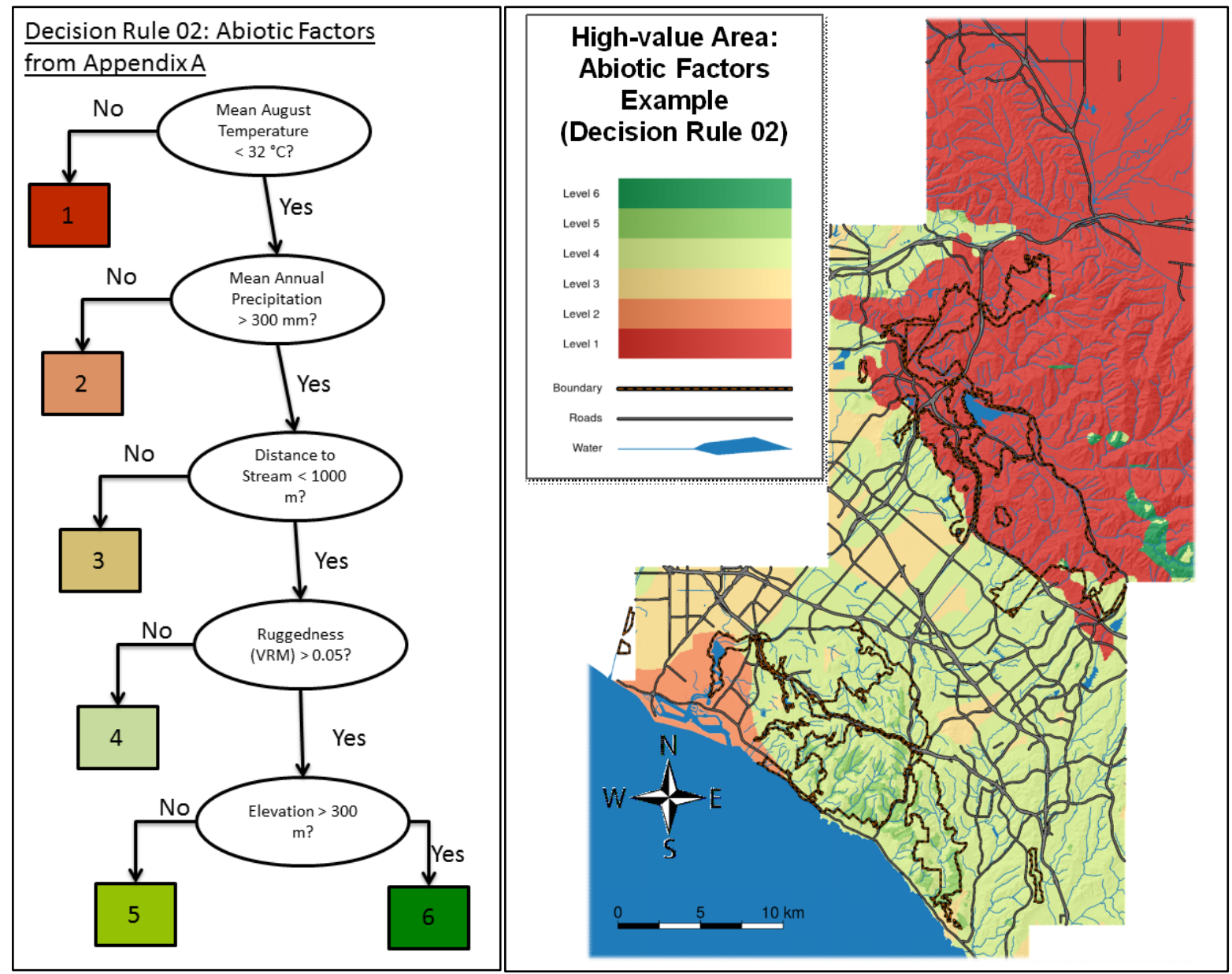

Figure 41. Image showing Decision Rule 02 as a step-wise filter using abiotic factors. Level 1 indicates areas with relatively high summer temperatures; Level 2 indicates areas with moderate summer temperatures but less than 300 millimeters $(\mathrm{mm})$ of annual precipitation; Level 3 indicates areas with relatively moderate summer temperatures with greater than (>) $300 \mathrm{~mm}$ of annual precipitation but not near streams; Level 4 indicates areas with relatively moderate summer temperatures with $>300 \mathrm{~mm}$ of annual precipitation, near streams, and with gentle topography; Level 5 indicates areas with relatively rugged topography, near streams, and with moderate climate; Level 6 indicates areas with relatively rugged topography, near streams, with moderate climate, and at elevations $>300$ meters (m). Orange County Central and Coastal Natural Communities Conservation Plan/Habitat Conservation Plan boundaries and major roads are shown. VRM, Vector Ruggedness Measure; ${ }^{\circ} \mathrm{C}$, degrees Celsius; <, less than. 


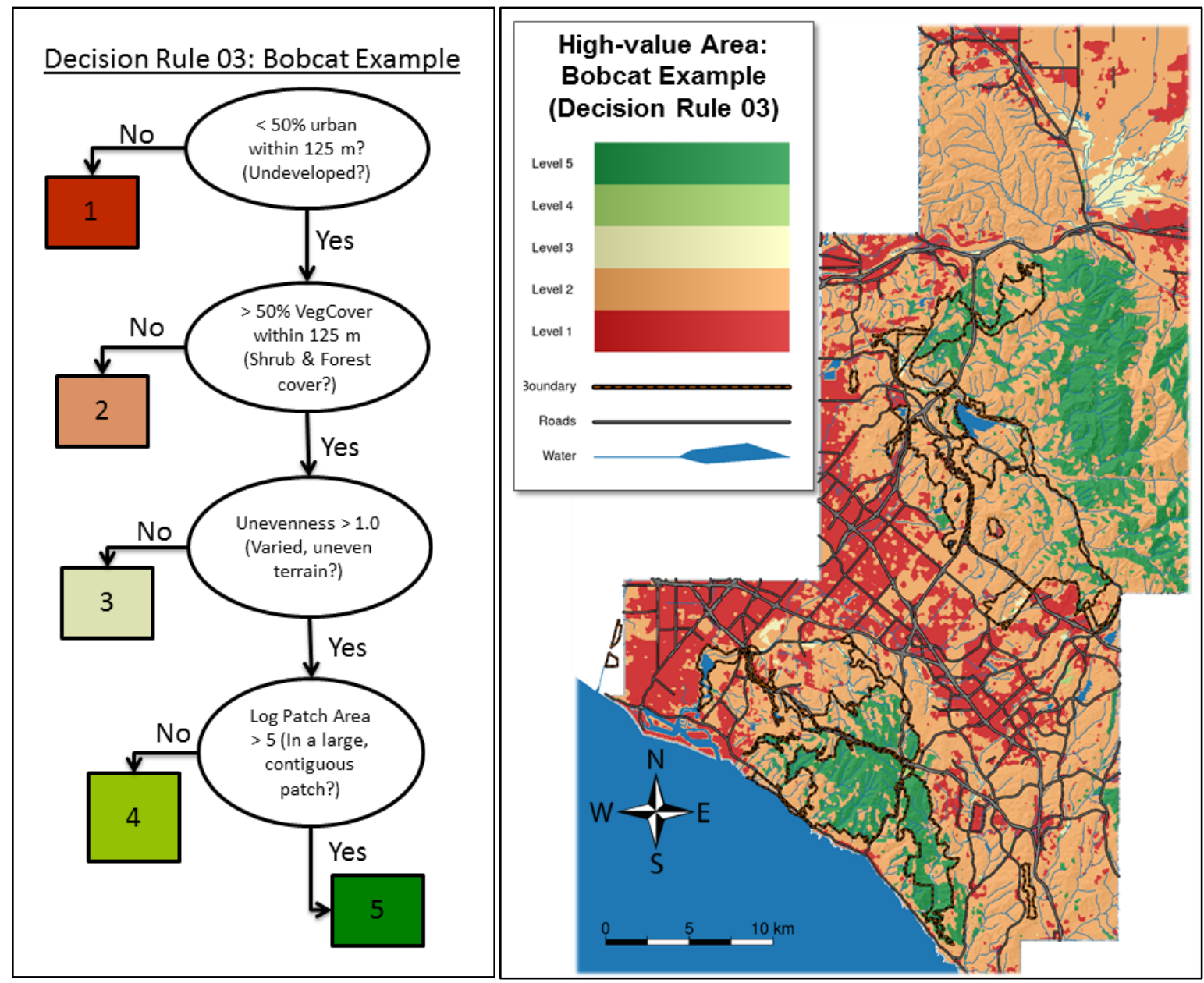

Figure 42. Image showing Decision Rule 03 as one way of depicting threshold values for environmental characteristics relevant to bobcats, in Orange County, southern California. Areas in Level 2 extend beyond what was predicted in Resource Selection Function models for bobcats, but if some of these areas were converted to shrublands from grasslands, bobcats also might use them. The final filtered results (Level 5) show where conditions favorable to bobcats existed within relatively large, contiguous habitat patches. Conditions specified by Level 3 (undeveloped areas with more than 50-percent shrub cover, in somewhat flat or relatively gentle terrain) and Level 4 (undeveloped areas with more than 50-percent shrub cover, with uneven terrain, and outside large patches) were small and few within the study area. Orange County Central and Coastal Natural Communities Conservation Plan/Habitat Conservation Plan boundaries and major roads are shown. 

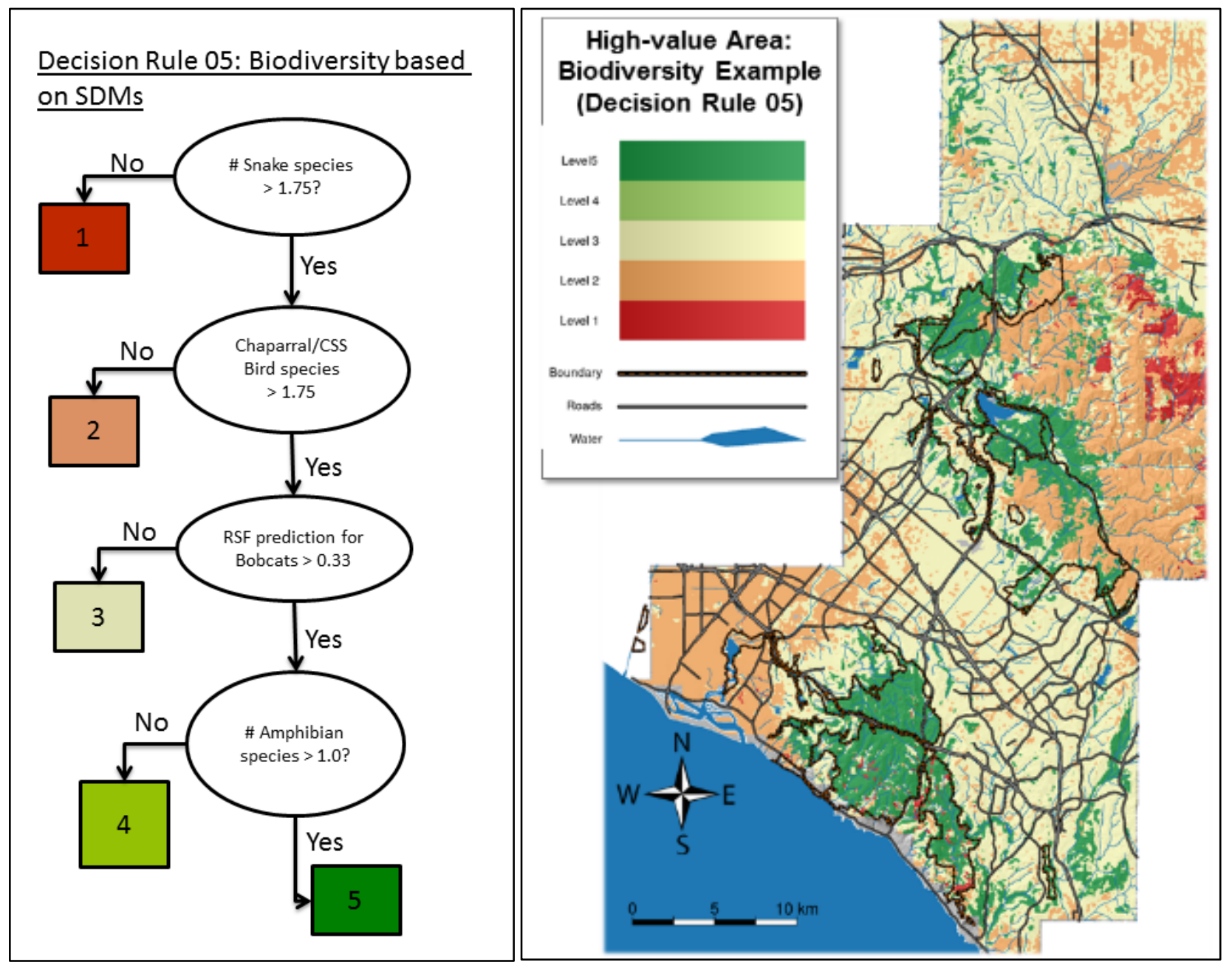

Figure 43. Image showing Decision Rule 05 as a step-wise filter using species distribution models as an example method for prioritizing levels of biodiversity, in Orange County, southern California. Orange County Central and Coastal Natural Communities Conservation Plan/Habitat Conservation Plan boundaries and major roads are shown. CSS, California coast sage scrub; RSF, Resource Selection Function; SDMs, Species Distribution Models; >, greater than. 


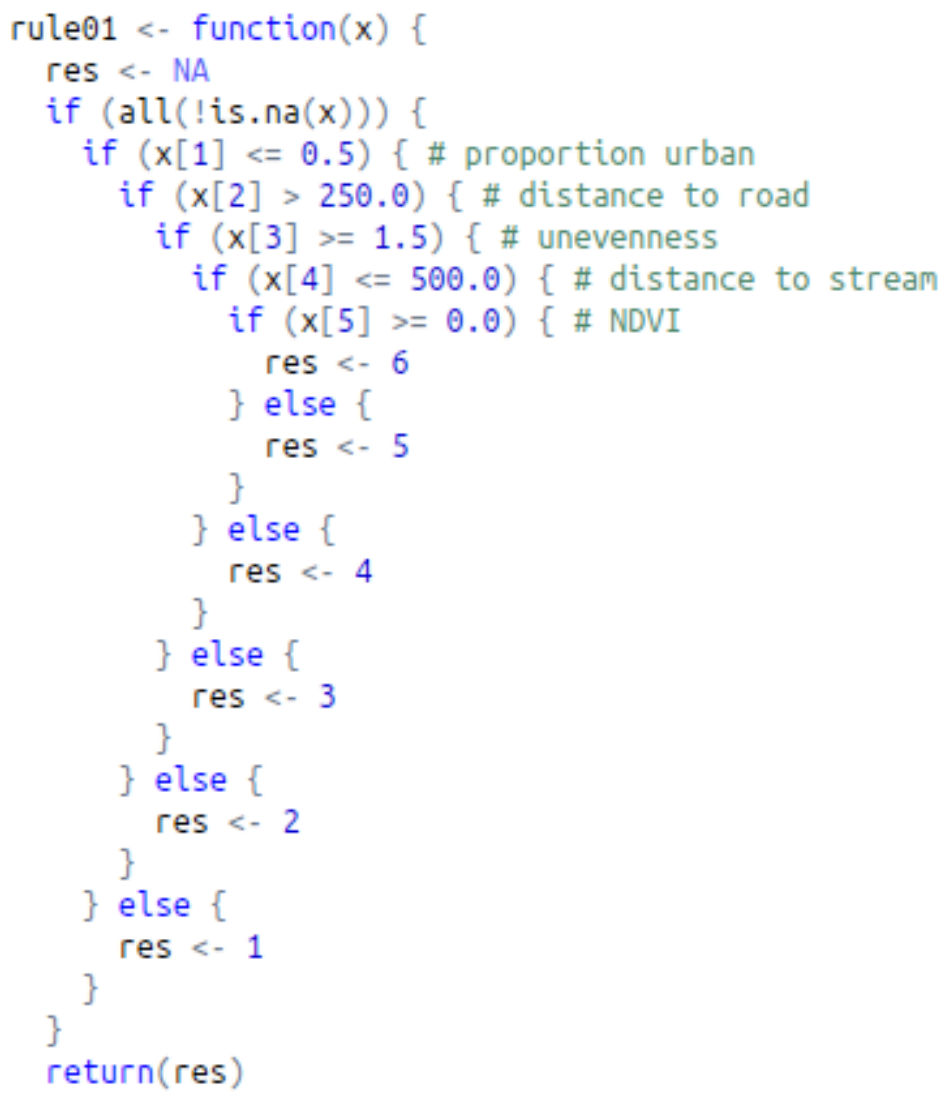

Figure 44. R code example for the function to assign High-Value Area levels, with raster inputs from the filter example (figs. 39 and 40). This function takes a vector $(\mathrm{x})$ with values corresponding to (1) proportion urban within 250 meters, (2) distance to road in meters, (3) terrain unevenness, (4) distance to stream in meters, and (5) Normalized Difference Vegetation Index for a raster cell, and assigns an integer code indicating how many levels the raster cell passed in the filter. Therefore, a higher value in the decision rule path indicates a higher-value area. 


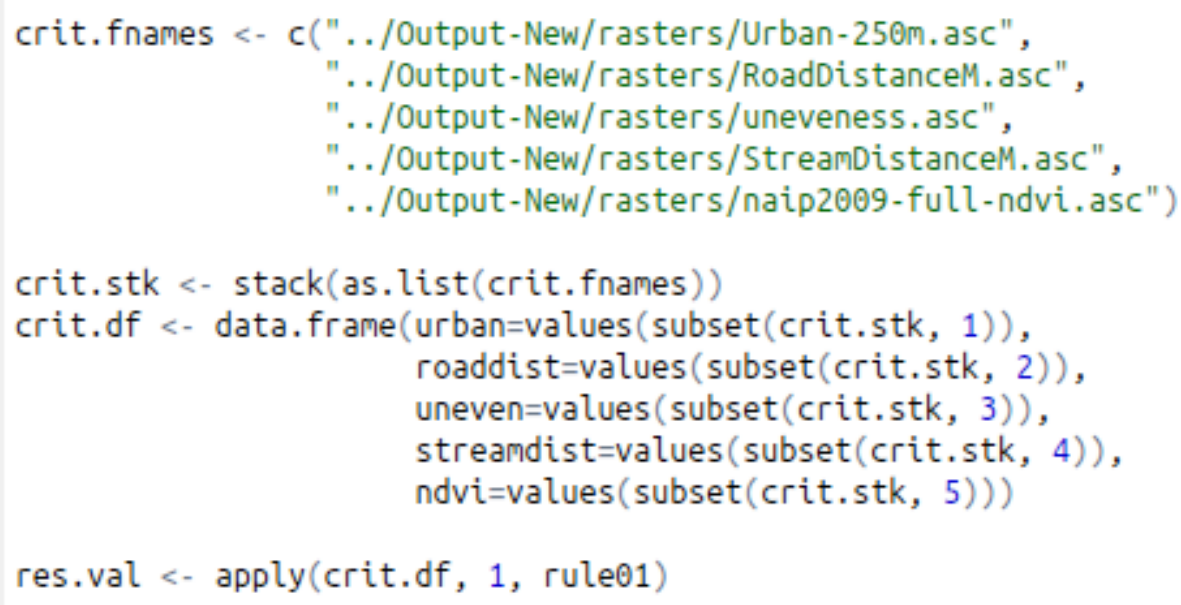

Figure 45. R code example for the function to get a vector of High-Value Area (HVA) levels for each step in the filter process, with raster inputs from the detailed example (figs. 39 and 40). This code creates a raster stack from the input layers, converts the raster stack to a data frame, and then applies the filter function to the data frame to get a vector of HVA levels for each step in the filter process. 


\section{References Cited}

Bradley, A.P., 1997, The use of the area under the ROC curve in the evaluation of machine learning algorithms: Pattern Recognition, v. 30, p. 1,145-1,159.

Carroll, C., Zielinski, W.J., and Noss, R.F., 1999, Using presence-absence data to build and test spatially-explicit habitat models for the fisher in the Klamath Region, U.S.A.: Conservation Biology, v. 13, p. 1,344-1,359.

Clutton-Brock, T.H., 1989, Mammalian mating systems: Proceedings of the Royal Society of London B: v. 236, p. 339-372.

Cohen, D.T., 2015, Population trends in incorporated places - 2000 to 2013 population estimates and Projections - Current population reports: U.S. Census Bureau, 19 p., accessed April 16, 2017, at https://www.census.gov/content/dam/Census/library/publications/2015/demo/p25-1142.pdf.

Crooks, K.R., 2000, Mammalian carnivores as target species for conservation in southern California, in Keeley, J.D., Baer-Keeley, M., and Fotheringham, C.J., eds., Second interface between ecology and land development in California: U. S. Geological Survey. Open-File Report 00-62, p. 105-112. Crooks, K.R., 2002, Relative sensitivities of mammalian carnivores to habitat fragmentation: Conservation Biology, v. 16, p. 488-502.

Cutler, D.R., Edwards, T.C., Beard, K.H., Cutler, A., Hess, K.T., Gibson, J., and Lawler, J.J., 2007, Random forests for classification in ecology: Ecology, v. 88, p. 2,783-2,792.

Emlen, S.T., and Oring, L.W., 1977, Ecology, sexual selection, and the evolution of mating systems: Science, v. 197, p. 215-223.

Fisher, R.N., Stokes, D., Rochester, C.J., Brehme, C.S., Hathaway, S.A., and Case, T.J. 2008, Herpetological monitoring using a pitfall trapping design in southern California: U.S. Geological Survey Techniques and Methods, book 2, chap. A5, 44 p.

Forman, R.T.T., and Godron, M., 1986, Landscape ecology: New York, Wiley.

Fountain-Jones, N.M., Craft, M.E., Funk, W.C., Kozakiewicz, C., Trumbo, D.R., Boydston, E.E., Lyren, L.M., Crooks, K., Lee, J.S., VandeWoude, S., and Carver, S., 2017, Urban landscapes can change virus gene flow and evolution in a fragmentation-sensitive carnivore: Molecular Ecology, $\mathrm{v}$. 26, p. 6487-6498.

Franklin, J., 2010, Mapping species distributions-Spatial inference and prediction: New York, Cambridge University Press, $340 \mathrm{p}$.

Franklin, J., Wejnert, K.E., Hathaway, S.A., Rochester, C.J., and Fisher, R.N., 2009, Effect of species rarity on the accuracy of species distribution models for reptiles and amphibians in southern California: Diversity and Distributions, v. 15, p. 167-177.

Hanley, J.A., and McNeil, B.J., 1982, The meaning and use of the area under a receiver operating characteristics curve: Radiology, v. 143, p. 29-36.

Hunter, R.D., Fisher, R.N., and Crooks, K.R., 2003, Landscape-level connectivity in coastal southern California, USA, as assessed through carnivore habitat suitability: Natural Areas Journal, v. 23, p. 302-314.

Ironside, K.E., 2015, Inferring behavior from GPS data-Challenges and successes modeling behavior of a large solitary carnivore: Flagstaff, Northern Arizona University, Ph.D. dissertation.

Johnson, D.H., 1980, The comparison of usage and availability measurements for evaluating resource preference: Ecology, v. 61, p. 65-71.

Knick, S.T., Hanser, S.E., and Preston, K.L., 2013, Modeling ecological minimum requirements for distribution of greater sage-grouse leks-Implications for population connectivity across their western range, USA: Ecology and Evolution, v. 3, p. 1,539-1,551.

Lambeck, R.J., 1997, Focal species - A multi-species umbrella for nature conservation: Conservation Biology, v. 11, p. 849-856. 
Manly, B.F.J., McDonald, L.L., Thomas, D.L., McDonald, T.L., and Erickson, W.P., 2002, Resource selection by animals - Statistical analysis and design for field studies: Dordrecht, The Netherlands, Kluwer, $222 \mathrm{p}$.

McGarigal, K., Cushman, S.A., Neel, M.C., and Ene, E., 2002, FRAGSTATS v3 - Spatial pattern analysis program for categorical maps: Computer software program produced by the authors at the University of Massachusetts, Amherst, accessed March 1, 2016, at

http://www.umass.edu/landeco/research/fragstats/fragstats.html.

Miller, B., Reading, R., Strittholt, J., Carroll, C., Noss, R., Soulé, M., Sanchez, O., Terborgh, J., Brightsmith, D., Cheeseman, T., and Foreman, D., 1998, Using focal species in the design of nature reserve networks: Wild Earth, v. 8, p. 81-92.

Nogeire, T.M., Davis, F.W., Crooks, K.R., McRae, B.H., Lyren, L.M., and Boydston, E.E., 2015, Can orchards help connect Mediterranean ecosystems?-Animal movement data alter conservation priorities: The American Midland Naturalist, v. 174, p. 105-116.

Ordeñana, M.A., Crooks, K.R., Boydston, E.E., Fisher, R.N., Lyren, L.M., Siudyla, S., Haas, C.D., Harris, S., Hathaway, S.A., Turschak, G.M., Miles, A.K., and Van Vuren, D.H., 2010, Effects of urbanization on carnivore species distribution and richness: Journal of Mammalogy, v. 91, p. 1,3221,331 .

Patton, D.R., 1975, A diversity index for quantifying habitat" edge": Wildlife Society Bulletin, v. 3, p. 171-173.

Phillips, S.J., Dudík, M., Elith, J., Graham, C.H., Lehmann, A., Leathwick, J., and Ferrier, S., 2009, Sample selection bias and presence-only distribution models-Implications for background and pseudo-absence data: Ecological Applications, v. 19, p. 181-197.

Poessel, S.A., Breck, S.W., Teel, T.L., Shwiff, S., Crooks, K.R., and Angeloni, L., 2013, Patterns of human-coyote conflicts in the Denver metropolitan area: The Journal of Wildlife Management, $v$. 77, p. 297-305.

Poessel, S.A., Burdett, C.L., Boydston, E.E., Lyren, L.M., Alonso, R.S., Fisher, R.N., and Crooks, K.R., 2014, Roads influence movement and home ranges of a fragmentation-sensitive carnivore, the bobcat, in an urban landscape: Biological Conservation, v. 180, p. 224-232.

PRISM Climate Group, 2016, PRISM climate data: Corvallis, Oregon State University PRISM Climate Group database, accessed November 1, 2016, at http://prism.oregonstate.edu.

Riley, S.P.D., Boydston, E.E., Lyren, L.M., and Crooks, K.R., 2010, Bobcats, in Gehrt, S.D., Riley, S.P.D., and Cypher, B.L., eds., Urban carnivores-Ecology, conflict, and conservation: Baltimore, Johns Hopkins University Press, p. 121-138.

Riley, S.P.D., Sauvajot, R.M., Fuller, T.K., York, E.C., Kamradt, D.A., Bromley, C., and Wayne, R.K., 2003, Effects of urbanization and habitat fragmentation on bobcats and coyotes in southern California: Conservation Biology, v. 17, p. 566-576.

Rotenberry, J.T., Preston, K.L., and Knick, S.T., 2006, GIS-based niche modeling for mapping species' habitat: Ecology, v. 87, p. 1,458-1,464.

Sandell, M., 1989, The mating tactics and spacing of solitary carnivores, in Gittleman, J.L., ed., Carnivore behavior, ecology, and evolution: Ithaca, New York, Cornell University Press, p. 164182.

Sappington, J.M., Longshore, K.M., and Thompson, D.B., 2007, Quantifying landscape ruggedness for animal habitat analysis-A case study using desert bighorn sheep in the Mojave Desert: Journal of Wildlife Management, v. 71, p. 1,419-1,426.

Sunquist, M.E., and Sunquist, F.C., 1989, Ecological constraints on predation by large felids, in Gittleman, J.L., ed., Carnivore behavior, ecology, and evolution: Ithaca, New York, Cornell University Press, p. 283-301. 
Syphard, A.D., and Franklin, J., 2010, Species traits affect the performance of species distribution models for plants in southern California: Journal of Vegetation Science, v. 2, p. 177-189, doi:10.1111/j.1654-1103.2009.01133.x.

Tigas, L.A., Van Vuren, D.H., and Sauvajot, R.M., 2002, Behavioral responses of bobcats and coyotes to habitat fragmentation and corridors in an urban environment: Biological Conservation, v. 108, p. 299-306.

Tracey, J.A., Rochester, C.J., Hathaway, S.A. Preston, K.L., Syphard, A.D., Vandergast, A.G., Diffendorfer, J.E., Franklin, J., MacKenzie, J.B., Oberbauer, T.A., Tremor, S., Winchell, C.S., and Fisher, R.N., 2018, Prioritizing conserved areas threatened by wildfire for monitoring and management, PLOS ONE. V. 13, no. 9, https://doi.org/10.1371/journal.pone.0200203.

Tracey, J.A., Zhu, J., Boydston, E.E., Lyren, L.M., Fisher, R.N., and Crooks, K.R., 2013, Mapping behavioral landscapes for animal movement-A finite mixture modeling approach: Ecological Applications, v. 23, p. 654-669.

Wood, S., 2006, Generalized additive models_-An introduction with R: Boca Raton, Florida, CRC Press, $410 \mathrm{p}$.

Woodroffe, R., and Ginsberg, J.R., 1998, Edge effects and the extinction of populations inside protected areas: Science, v. 280, p. 2,126-2,128.

Worton, B.J., 1989, Kernel methods for estimating the utilization distribution in home-range studies: Ecology, v. 70, p. 164-168. 

Publishing support provided by the U.S. Geological Survey

Science Publishing Network, Tacoma Publishing Service Center

For more information concerning the research in this report, contact the Director, Western Ecological Research Center

U.S. Geological Survey

3020 State University Drive East

Sacramento, California 95819

https://www.werc.usgs.gov/ 
